March 2005 - NREL/SR-560-37572

\title{
Distributed and Electric Power System Aggregation Model and Field Configuration Equivalency Validation Testing
}

\section{Supplemental Report on Penetration Software Algorithms}

M. Davis

DTE Energy Technologies

Farmington Hills, Michigan

D. Costyk

DTE Energy

Detroit, Michigan

A. Narang

Kinectrics

Toronto, Ontario
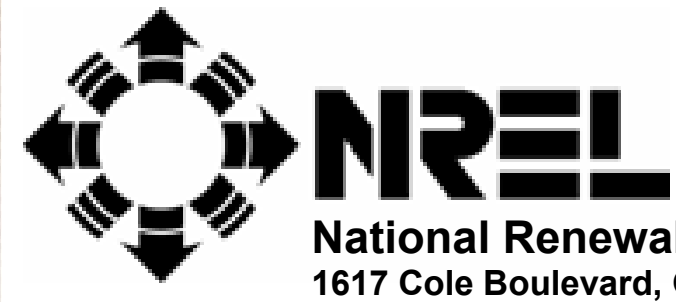

National Renewable Energy Laboratory

1617 Cole Boulevard, Golden, Colorado 80401-3393

303-275-3000 • www.nrel.gov

Operated for the U.S. Department of Energy

Office of Energy Efficiency and Renewable Energy

by Midwest Research Institute - Battelle

Contract No. DE-AC36-99-G010337 
March 2005 - NREL/SR-560-37572

\section{Distributed and Electric Power System Aggregation Model and Field Configuration Equivalency Validation Testing}

\section{Supplemental Report on Penetration Software Algorithms}

M. Davis

DTE Energy Technologies

Farmington Hills, Michigan

D. Costyk

DTE Energy

Detroit, Michigan
A. Narang
Kinectrics
Toronto, Ontario

NREL Technical Monitor: Thomas Basso

Prepared under Subcontract No. AAD-0-30605-09

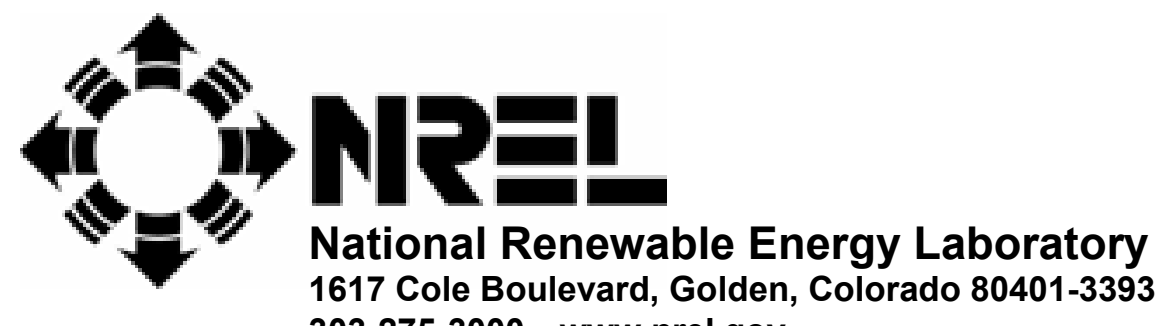

303-275-3000 • www.nrel.gov

Operated for the U.S. Department of Energy

Office of Energy Efficiency and Renewable Energy

by Midwest Research Institute $\bullet$ Battelle

Contract No. DE-AC36-99-G010337 


\section{NOTICE}

This report was prepared as an account of work sponsored by an agency of the United States government. Neither the United States government nor any agency thereof, nor any of their employees, makes any warranty, express or implied, or assumes any legal liability or responsibility for the accuracy, completeness, or usefulness of any information, apparatus, product, or process disclosed, or represents that its use would not infringe privately owned rights. Reference herein to any specific commercial product, process, or service by trade name, trademark, manufacturer, or otherwise does not necessarily constitute or imply its endorsement, recommendation, or favoring by the United States government or any agency thereof. The views and opinions of authors expressed herein do not necessarily state or reflect those of the United States government or any agency thereof.

Available electronically at http://www.osti.gov/bridge

Available for a processing fee to U.S. Department of Energy and its contractors, in paper, from:

U.S. Department of Energy

Office of Scientific and Technical Information

P.O. Box 62

Oak Ridge, TN 37831-0062

phone: 865.576.8401

fax: 865.576 .5728

email: mailto:reports@adonis.osti.gov

Available for sale to the public, in paper, from:

U.S. Department of Commerce

National Technical Information Service

5285 Port Royal Road

Springfield, VA 22161

phone: 800.553 .6847

fax: 703.605.6900

email: orders@ntis.fedworld.gov

online ordering: http://www.ntis.gov/ordering.htm 


\section{Foreword}

This report supplements the July 2003 report "Distributed and Electric Power System Aggregation Model and Field Configuration Equivalency Validation Testing" (NREL/SR560-33909), the base report of Subcontract No. AAD-0-30605-09. This report expands on the algorithms used to evaluate system protection issues and voltage and stability issues. The original report can be found at http://www.nrel.gov/docs/fy03osti/33909.pdf. In addition, Appendix $G$ contains a fact sheet that summarizes this subcontract work and the importance of devising algorithms to determine the maximum size of distributed resources that can be applied to a distribution circuit.

DTE Energy, which includes the regulated electric utility Detroit Edison and the unregulated subsidiary DTE Energy Technologies, recognized a need to encourage the use of distributed resources to mitigate future generation capacity shortages, improve reliability, and provide a lower-cost energy delivery system. DTE Energy Technologies is the prime contractor of this study.

Kinectrics is a recognized authority in determining whether harmonics exceed Institute of Electrical and Electronics Engineers Standard 519 and evaluating the steady-state and transient stability of distributed resources connected with distribution circuits. Kinectrics was also a major contributor to the Edison Electric Institute Planning, Operations, and Interconnection Distributed Resources Task Force's 29-issue report issued in September 1999. Kinectrics was selected as a subcontractor for DTE Energy.

The study team consisted of:

DTE Energy

- Murray Davis, vice president and chief technology officer

- David M. Costyk, principal engineer, Relay Engineering

Kinectrics

- Arun Narang, principal engineer, Transmission and Distribution Technologies. 


\section{List of Abbreviations and Acronyms}

$\begin{array}{ll}\text { CB } & \text { circuit breaker } \\ \text { DC } & \text { distribution circuit } \\ \text { DG } & \text { distributed generation } \\ \text { DR } & \text { distributed resource } \\ \text { EMTP } & \text { electromagnetic transients program } \\ \text { EPS } & \text { electric power system } \\ \text { P } & \text { real power } \\ \text { PCC } & \text { point of common coupling } \\ \text { PSLF } & \text { positive load flow program } \\ \text { pu } & \text { per unit } \\ \text { Q } & \text { reactive power } \\ \text { rms } & \text { root mean square } \\ \text { TCC } & \text { time-current characteristic }\end{array}$




\section{Table of Contents}

Table of Figures

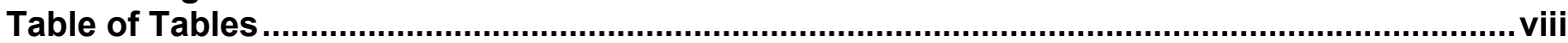

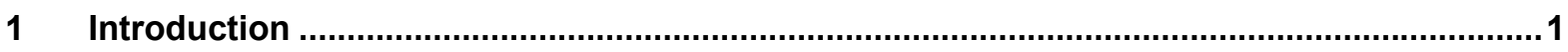

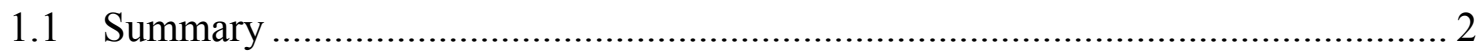

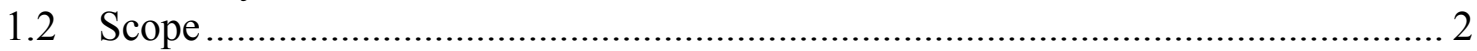

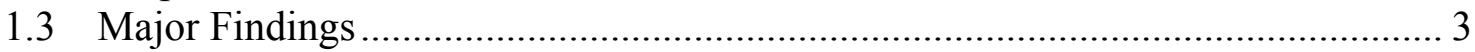

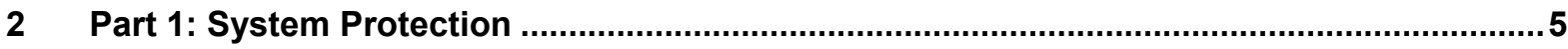

2.1 Issue 1: Improper Coordination - Protective Device Operates for Fault on

Adjacent Circuit (Selectivity) ................................................................................ 5

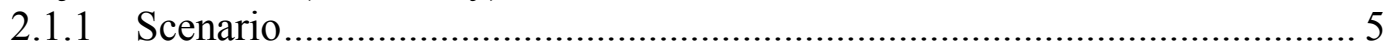

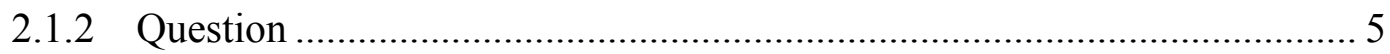

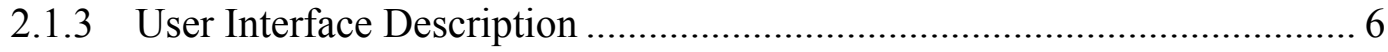

2.1.4 Associated Algorithm ...................................................................... 6

2.2 Issue 1: Improper Coordination - Reduced Fault Detection (Sensitivity) ............ 10

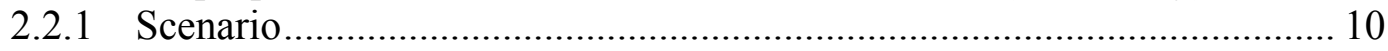

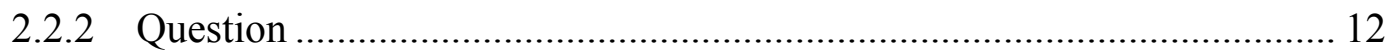

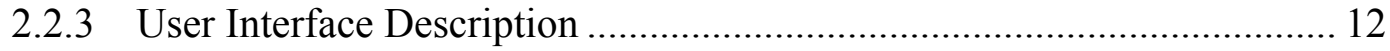

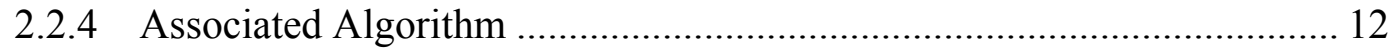

2.3 Issue 2: Nuisance Fuse-Blowing Because of DR Fault Current .......................... 12

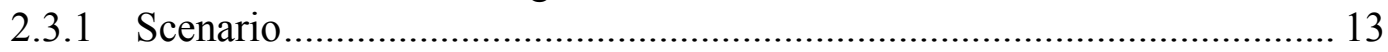

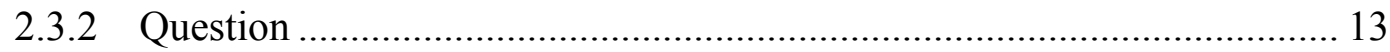

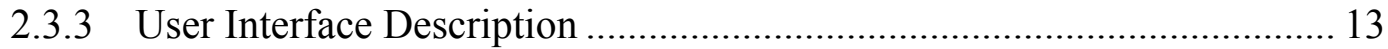

2.3.4 Associated Algorithm ........................................................................ 14

2.4 Issue 15: Faults Within the Distributed Resource Zone .......................................... 16

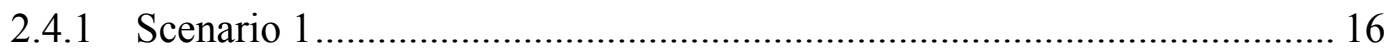

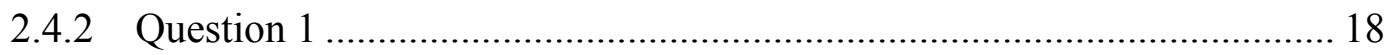

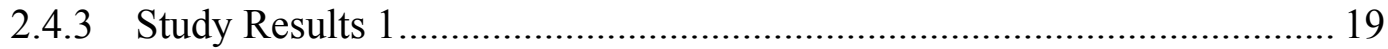

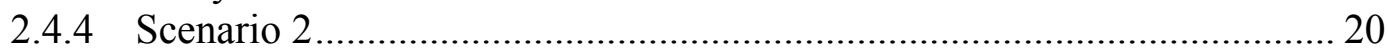

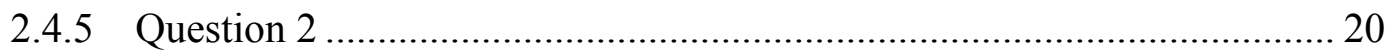

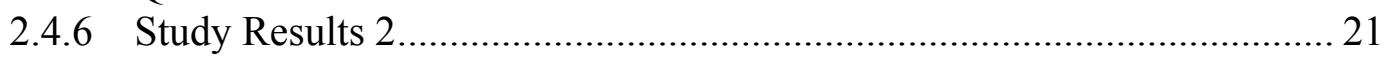

2.4.7 User Interface Description ................................................................ 23

2.4.8 Associated Algorithm …………………………................................. 23

2.5 Issue 16: Isolate Distributed Resource for Upstream Fault ................................. 24

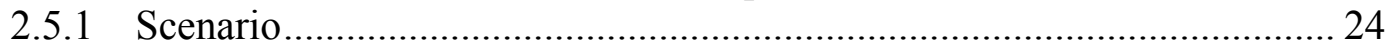

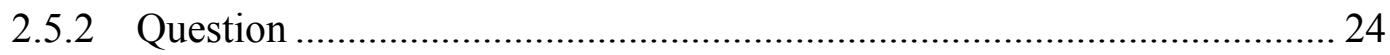

2.5.3 User Interface Description ............................................................. 25

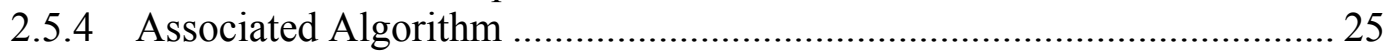

2.6 Issue 27: Upstream Single-Phase Fault Causes Fuse-Blowing ............................. 28

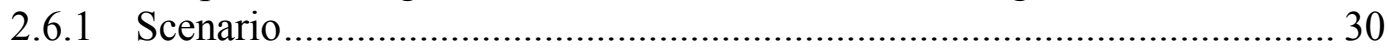

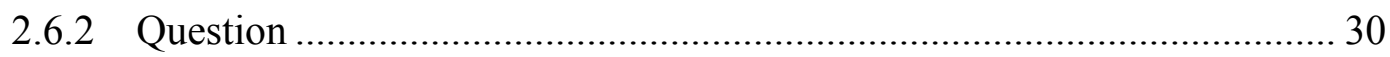

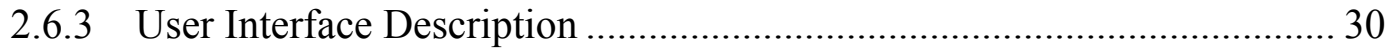

2.6.4 Associated Algorithm ………………………........................................ 30 
3 Part 2: Methodology for Assessing Voltage and Stability Effects of Distributed

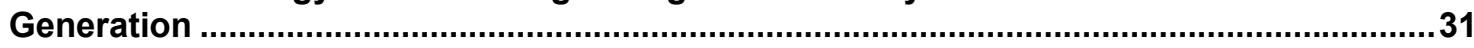

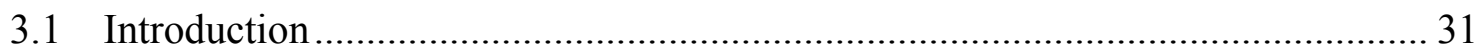

3.2 Modeling Techniques................................................................................. 31

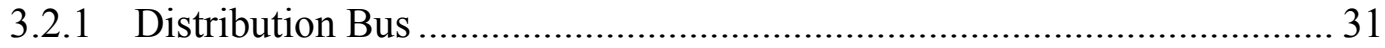

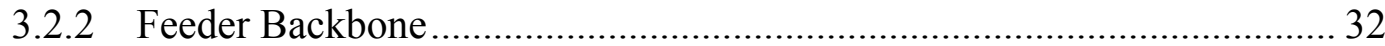

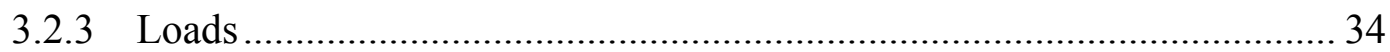

3.2.4 Capacitor Banks and Cables ............................................................. 34

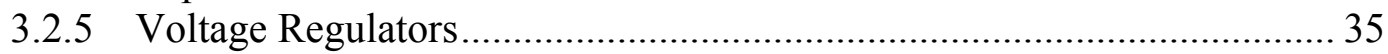

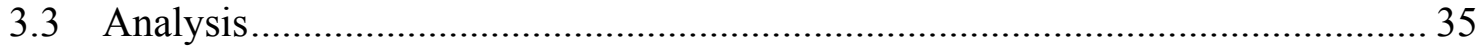

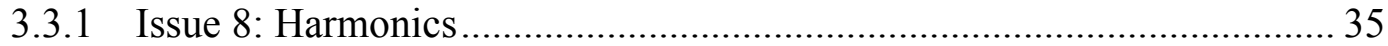

3.3.2 Issue 11: Voltage Regulation Malfunctions ....................................... 37

3.3.3 Issue 21: Dynamic Stability During Fault Conditions ............................. 38

3.3.4 Issue 22: Loss of Excitation Causes Low Voltage ................................... 40

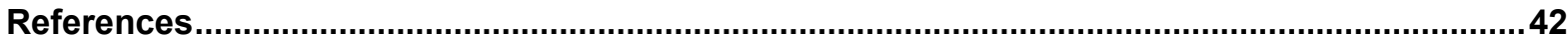

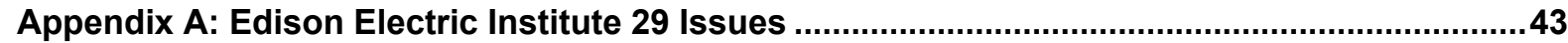

Appendix B: Time-Versus-Current Characteristics Database...................................................44

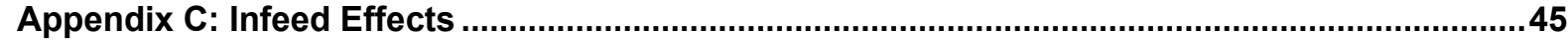

Appendix D: Issue 15: Faults Within the Distributed Resource Zone .......................................50

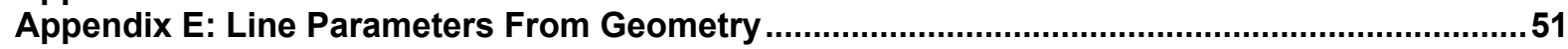

Appendix F: Rudimentary Network Solution Algorithm .....................................................54

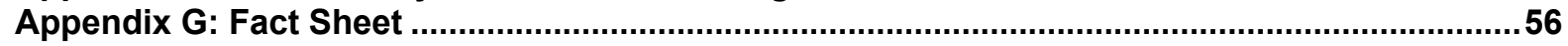




\section{Table of Figures}

Figure 1. 13.2-kV radial distribution system - improper device coordination fault

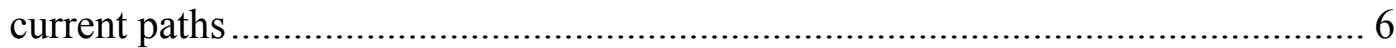

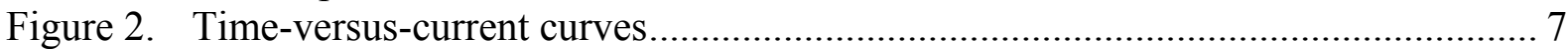

Figure 3. Plot of maximum DR fault current versus breaker fault current........................... 8

Figure 4. Plot showing system current as the difference between breaker current and

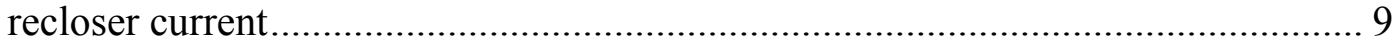

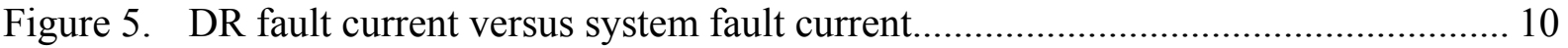

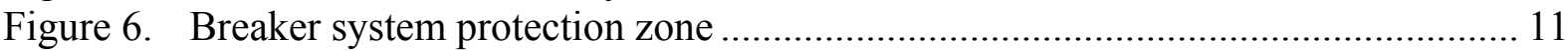

Figure 7. Infeed from DR reduces substation breaker relay fault current detection

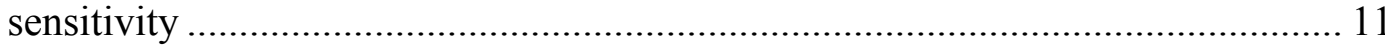

Figure 8. Nuisance fuse-blowing because of DR fault current.......................................... 13

Figure 9. Time-versus-fault-current curves for fuse and recloser ..................................... 15

Figure 10. Plot of maximum DR fault current versus recloser fault current ......................... 15

Figure 11. Faults within the DR zone are cleared with local protective devices ................... 17

Figure 12. Effects of infeed on system fault current ...................................................... 17

Figure 13. Selectivity coordination of EPS devices and DR zone devices ......................... 18

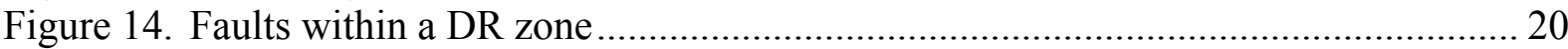

Figure 15. Selectivity coordination within the DR zone ................................................... 21

Figure 16. Coordination between devices is compromised when fault current exceeds

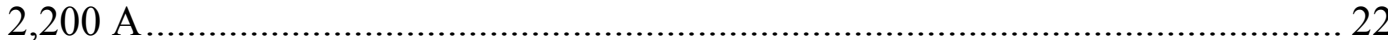

Figure 17. Equation for DR fault current limit................................................................ 23

Figure 18. Fuse-blowing for upstream fault ................................................................ 25

Figure 19. Tripping characteristics for 140-A recloser and 80k fuse showing fast and

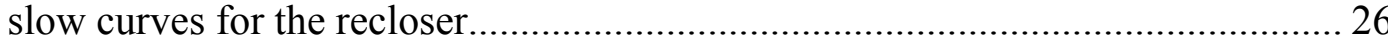

Figure 20. Trip-time-versus-current curves for fuse and recloser ..................................... 27

Figure 21. Plot of maximum added DR fault current versus recloser current....................... 27

Figure 22. Line-to-ground fault causes single-phase sectionalizing device to operate because of DR fault current conditions ......................................................... 28

Figure 23. General layout of the main trunk of the 13.2-kV Pioneer feeder......................... 33

Figure 24. Harmonic current injection at DG location on simplified representation of feeder incorporating capacitor bank for voltage regulation ................................ 36

Figure 25. Example of harmonic impedance characteristic for Pioneer feeder...................... 36

Figure 26. Reduced equivalent circuit depicting single-machine infinite bus system ........... 39

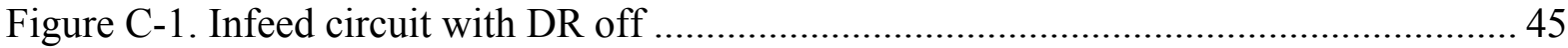

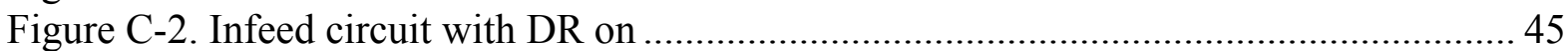

Figure C-3. The effects of infeeds............................................................................. 46

Figure C-4. The effect of DR size on system fault current .............................................. 48

Figure C-5. The effect of DR fault contribution on system fault current ............................ 49 


\section{Table of Tables}

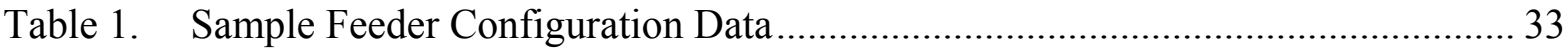

Table 2. Sample Listing of Data Requirements for Feeder Segments ................................... 33

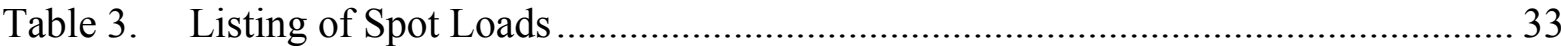

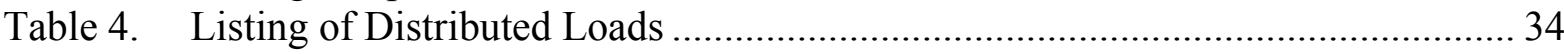

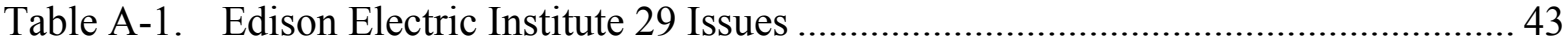

Table C-1. Source Current (Is) and DR Current (Idr) for Per-Unit Source and DR Impedances (Three-Phase Faults Only) ............................................................. 47

Table D-1. Faults Within the DR Zone …………....................................................... 50

Table D-2. Edison Electric Institute-National Electrical Manufacturers Association Type K Fuse Links .................................................................................... 50 


\section{Introduction}

This report is a supplement to the National Renewable Energy Laboratory subcontract report "Distributed and Electric Power System Aggregation Model and Field Configuration Equivalency Validation Testing" [1] (henceforth referred to as the "original report"). The original report presented methods for calculating penetration limits for distributed energy resources interconnected with distribution circuits (DCs) of utility-owned electric power systems (EPSs).

In the original report, Appendix J: List of Remaining Work for Future Study outlined the need for penetration limit software that included issues 1, 2, 8, 11, 15, 16, 21, 22, and 27. These issues were:

- Issue 1: Improper coordination

- Issue 2: Nuisance fuse-blowing

- Issue 8: Harmonics

- Issue 11: Voltage regulation malfunctions

- Issue 15: Faults within a DR zone

- Issue 16: Isolate DR for upstream fault

- Issue 21: Stability during faults

- Issue 22: Loss of exciters causes low voltage

- Issue 27: Upstream single-phase fault causes fuse-blowing.

This supplemental report describes the algorithms required to develop application software to calculate penetration limits. This software would use an equipment database and utility distribution line characteristics database to enable users to develop penetration limits by entering or selecting parameters such as fuse size, relay type, relay setting, system voltage, source impedance, distributed resource (DR) generator characteristics, line impedances, circuit topology, and voltage regulating equipment. The software is not part of this report, but the contractor used ASPEN One Liner and Excel to evaluate system protection issues and PSLF, MATLAB, and EMTP to evaluate voltage regulation and stability issues.

During the preparation of the original report, it became apparent that charts, models, databases, and processes could assist in determining penetration limits for several of the 29 Edison Electric Institute issues [2] (see Appendix A).

Some of the charts, models, and data included in this supplemental report were also presented in the original report. The charts in the original report were limited by the studies completed. For example, the protection penetration curves provide penetration limits for a single pair of protective devices. But there is a need to consider a variety of system conditions and equipment for an analysis of DR installation. 
It also became apparent that a computer software program could create charts and results for any specific set of equipment if the software followed the processes used to develop the original charts and models. It was determined such software would be a valuable tool for protection and planning engineers studying the effect of DR interconnections. To facilitate the creation of such software, the algorithms, models, and processes - including the selected licensed software stated earlier-were used to produce the charts and models in this supplemental report.

\subsection{Summary}

It is useful to develop methodologies to determine the maximum size of DR that can be added to DCs. This report addresses that for system protection and voltage and stability issues and describes the algorithms and graphical analyses used.

The maximum size of DR that can be added to a DC is dependent on many factors. These include system voltage, type of faults, available fault current, circuit configuration and line impedance, transformation type, system protection, generation type, DC voltage regulation equipment, generation voltage regulation, and the location of DRs on the circuit.

This report defines in detail the algorithms suitable for implementation in application software. This adaptation will expedite the process of interconnecting DRs with DCs, which can be a complex and onerous task. The algorithms are also valuable for instructing and training power system and system protection engineers to address the issues included in this report. Solutions to issues such as nuisance fuse-blowing, protective device coordination, harmonics, voltage regulation, and stability are key to ensuring a reliable, safe, and highpower-quality EPS when DCs are operated in unison with DRs.

\subsection{Scope}

This report provides algorithms for calculating penetration limits for the following Edison Electric Institute issues related to the interconnection of DRs:

Part 1: System Protection Issues

- Issue 1: Improper coordination - protective device operates for fault on adjacent circuit

- Issue 1: Improper coordination - reduced fault detection sensitivity

- Issue 2: Nuisance fuse-blowing

- Issue 15: Faults within the DR zone

- Issue 16: Isolate DR for upstream fault

- Issue 27: Upstream single-phase fault causes fuse-blowing 
Part 2: Voltage and Stability Issues

- Issue 8: Harmonics

- Issue 11: Voltage regulation malfunctions - not actively regulating system voltage

- Issue 11A: Voltage regulation malfunctions - actively regulating system voltage

- Issue 21: Transient stability

- Issue 22: Loss of exciters causes low voltage.

The software used to implement the algorithms described in this report is not within the scope of this project.

\subsection{Major Findings}

This report describes the algorithms and calculation methods for evaluating issues related to the interconnection of DRs with wye and delta system configurations and determining the maximum size of DRs that can be installed.

In some cases, known mathematical models and existing software were used as computational aids to solve complex power system problems. However, unique methods, models, and graphical analyses were developed to link existing software with an expedited solution process.

Some of the unique models and analyses include:

- Graphical analysis to determine the conditions for nuisance fuse-blowing thresholds

- Graphical analysis to define the threshold for improper protective device coordination and selectivity

- Penetration charts that are instructive in understanding parameters (e.g., system fault current) that govern the size of DRs that can be installed on the circuit.

Other unique aspects include:

- The use of harmonic current injections (for individual harmonic frequencies) at DC nodes to determine the resonant impedance (peak) and define the maximum voltage harmonic that does not exceed IEEE Standard 519 (which results in the largest DR inverter size for a specific set of circuit parameters, with and without capacitors)

- The use of fault current calculation to determine the approximate Thevenin source impedance and limits for voltage regulation malfunctions

- The use of a method similar to the above to determine the reactive requirement for loss of excitation. 
To achieve the maximum benefit from the methodologies and algorithms in this report, it is recommended that a compatible suite of software be developed using a database structure that allows users to enter system and machine parameters and access readily available equipment or system network databases. 


\section{Part 1: System Protection}

For Edison Electric Institute system protection issues 1, 2, 15, 16, and 27-except for the reduced fault sensitivity portion of Issue 1 -software will require only data from a selectable single pair of protective devices. The DR sizes, DR short-circuit impedances, line impedances, and system short-circuit impedances are not required.

Software for these issues should:

- Contain an expandable database of the time-current characteristics (TCCs) of all protective devices normally used by the user performing the study (An initial database would minimally contain the TCCs for the devices in Appendix B.)

- Provide the user with an input facility to select the TCCs for the related pair of protective devices

- Provide a graphic plot of the DR current penetration limit on the Y axis versus the system or other related current on the $\mathrm{X}$ axis and provide a table containing the data points specific to that graphic plot

- Provide the specific value of the DR current for an enterable value of system current or other related current, such as line breaker current.

\subsection{Issue 1: Improper Coordination - Protective Device Operates for Fault on Adjacent Circuit (Selectivity)}

As shown in Figure 1, faults on DC 1 may cause protective devices to operate on DC 2. Typically, this is undesirable because it interrupts service to customers that would have otherwise remained in service.

\subsubsection{Scenario}

- A fault occurs on DC 1.

- Fault current contributions are from the substation transformer $\left(\mathrm{I}_{\mathrm{fs}}\right)$ and the $\operatorname{DR}\left(\mathrm{I}_{\mathrm{fDR}}\right)$.

- The circuit breakers (CBs) $\mathrm{CB}-1$ and $\mathrm{CB}-2$, the recloser, and the fuse sense the fault current.

- If CB-1 does not trip soon enough, the fuse, the recloser, or both may trip.

\subsubsection{Question}

What is the limit of DR size for any specific combination of protective devices? 


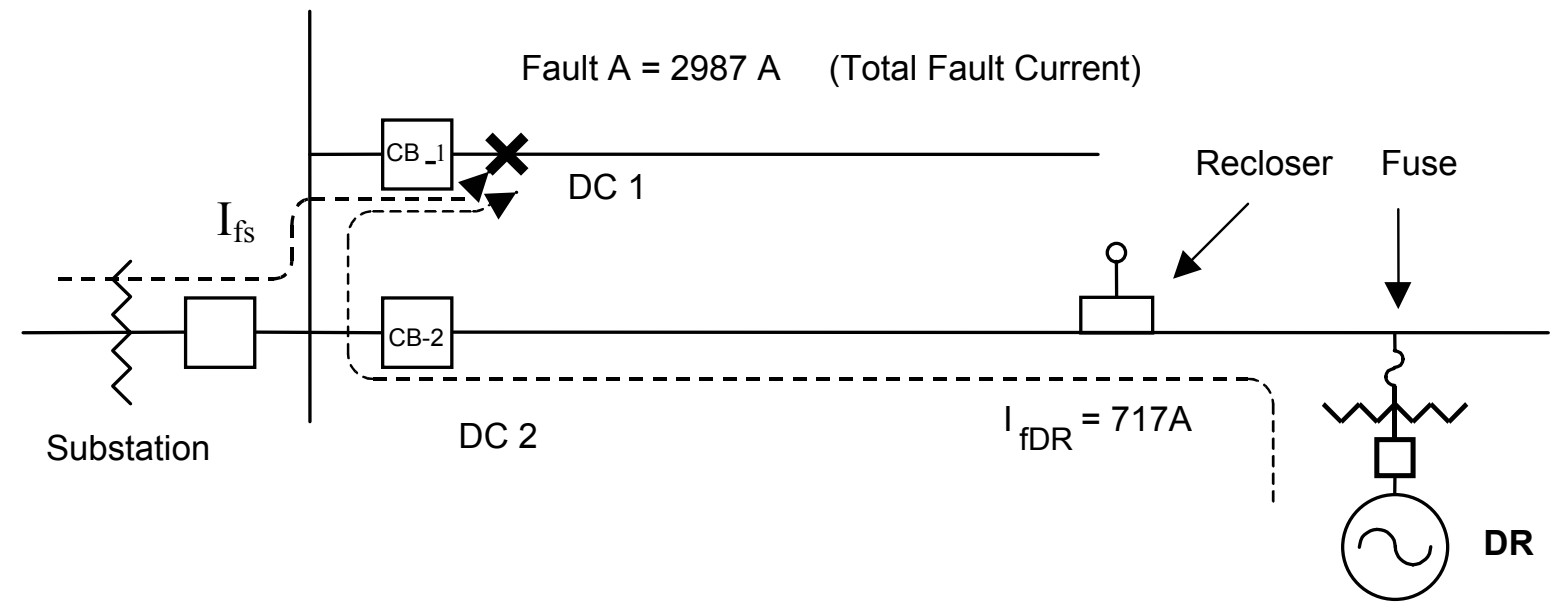

Figure 1. 13.2-kV radial distribution system improper device coordination fault current paths

For this issue, the DR penetration limit curve will indicate the maximum permissible DR current that will not cause the recloser to operate before the breaker on CB-1 operates.

\subsubsection{User Interface Description}

The user interactively selects the TCCs for the generator fuse, recloser, and CB-2 and compares these with the TCC of CB-1. This process is repeated for each pair of protective devices (e.g., fuse and CB-1, recloser and CB-1, and CB-2 and CB-1). The user also selects any current transformer ratios associated with the respective protective relays.

The user runs the software, which produces a graphic plot of the DR current penetration limit on the $\mathrm{Y}$ axis and the system or breaker current on the $\mathrm{X}$ axis. The software also provides a table containing the data points specific to the graphic plot.

In addition, if the user enters a single specific value of system or breaker current, the software calculates and displays or prints the corresponding limit of DR current.

\subsubsection{Associated Algorithm}

To determine the maximum DR fault current for a specified recloser and substation relay setting, the following process is used (refer to Figure 2):

1. For a specific value of recloser fault current (Y1), determine the trip time (T1) from the time-versus-current curve for the recloser in the database.

2. Determine the corresponding CB-1 fault current (X1) necessary to trip the breaker in the same trip time (T1) from the time-versus-current curve for the $\mathrm{CB}-1$ breaker in the database.

3. On a separate plot of current on both axes, plot the DR fault current (Y1) or the recloser fault current on the Y axis opposite the breaker fault current (X1) on the X axis (refer to Figure 3). 
4. Develop a curve of maximum DR fault current and breaker fault current by plotting a range of recloser and breaker fault currents - similar to Figure 3-as (X1, Y1), (X2, Y2), (X3, Y3) ... (Xn, Yn).

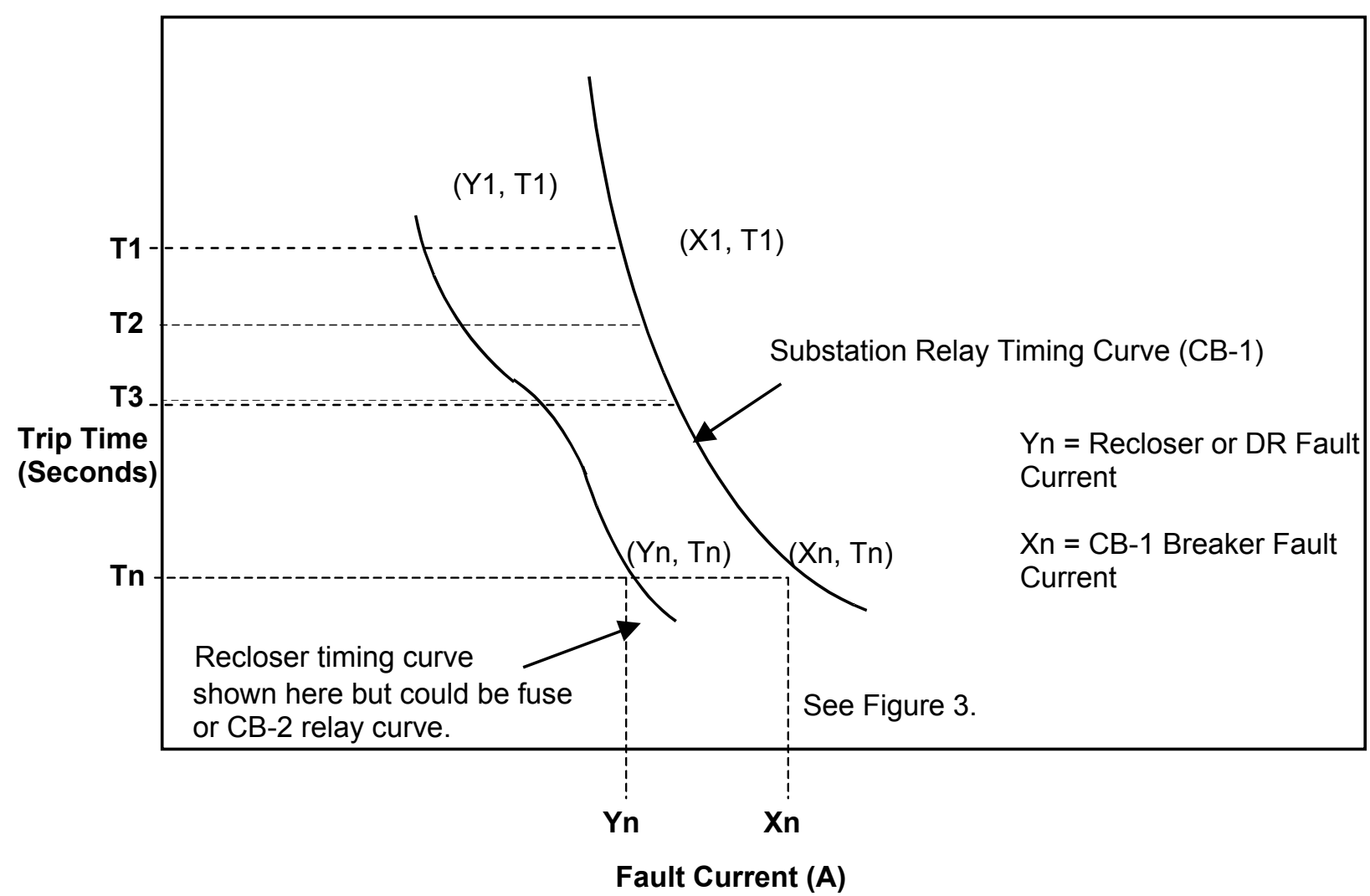

Figure 2. Time-versus-current curves 


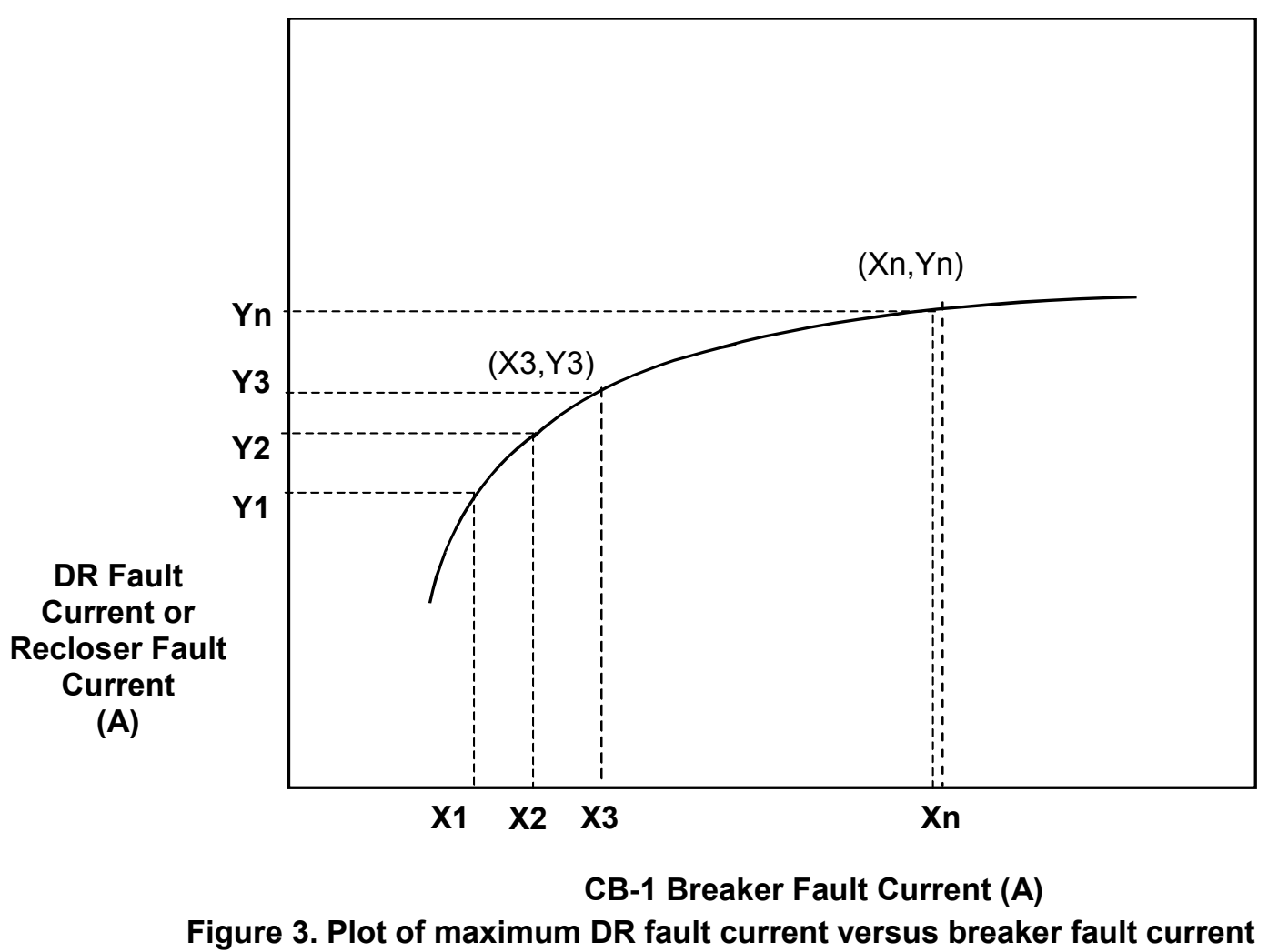

In a similar manner, create a plot showing DR fault current versus system fault current, which is breaker fault current CB-1 minus recloser current. Refer to figures 4 and 5.

1. For a specific value of recloser current (Y1), determine the trip time (T1) from the timeversus-current curve for the recloser in the database (see Figure 4).

2. Determine the corresponding breaker fault current (X1) necessary to trip the breaker in the same trip time (T1) from the time-versus-current curve for CB-1 in the database (see Figure 4).

3. On a separate plot of current on both axes, plot the DR fault current (Yn) (recloser current) on the $\mathrm{Y}$ axis opposite the system fault current (Xn - Yn) on the $\mathrm{X}$ axis (refer to Figure 5). 


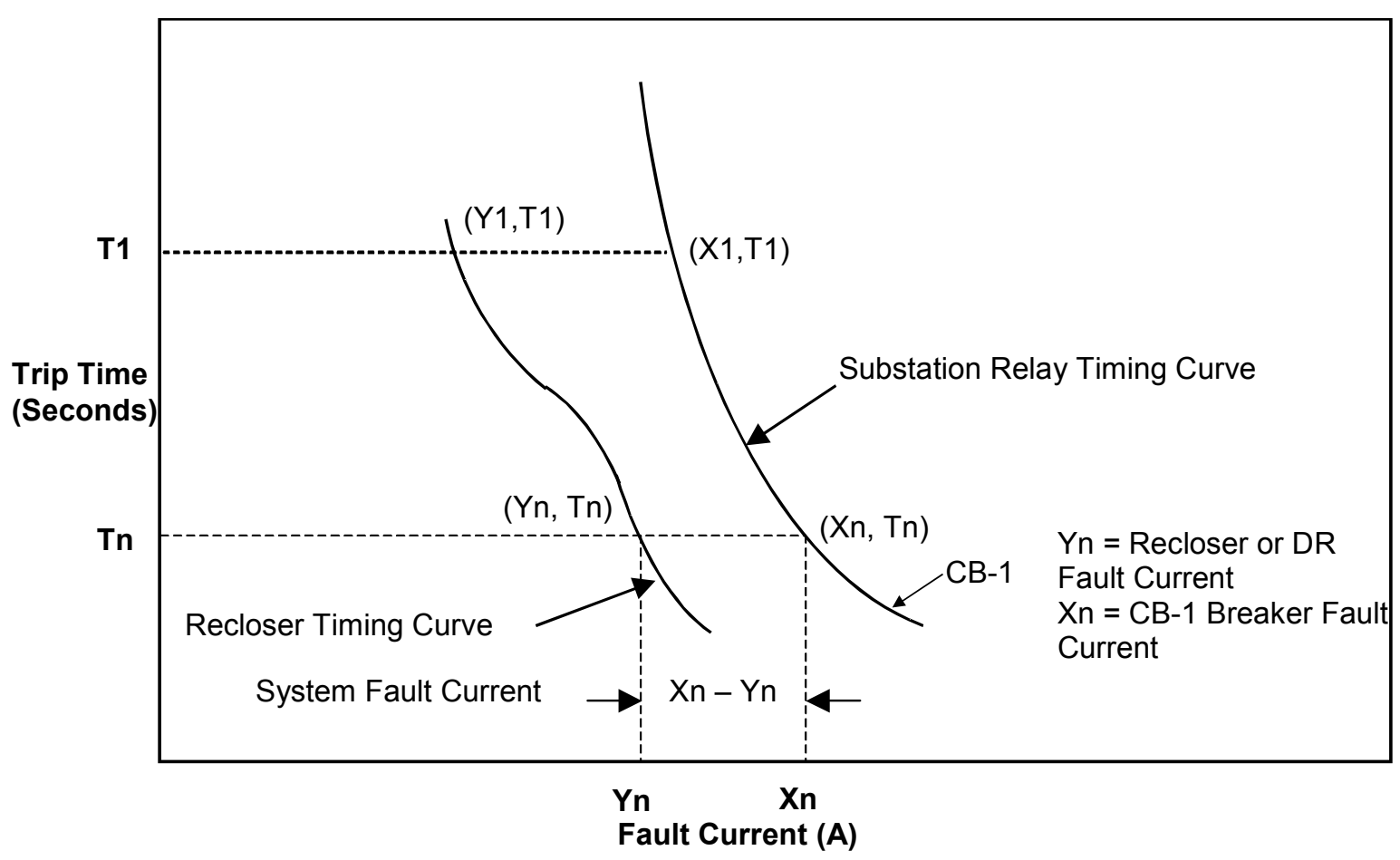

Note: Breaker fault current CB-1 equals system fault current plus recloser fault current, or DR fault current; therefore, system fault current equals $\mathrm{Xn}-\mathrm{Yn}$.

Figure 4. Plot showing system current as the difference between breaker current and recloser current

From Figure 5, the plot of DR fault current versus system fault current, the user can determine the maximum DR fault current that will cause the recloser to not operate (open) for the fault on the adjacent circuit, which results in correct selective operation. A margin of safety may be included to account for slight differences in the actual TCCs for each protective device. A suggested margin is a $25 \%$ difference in time, but the user can apply other margins to ensure correct selective operation. 


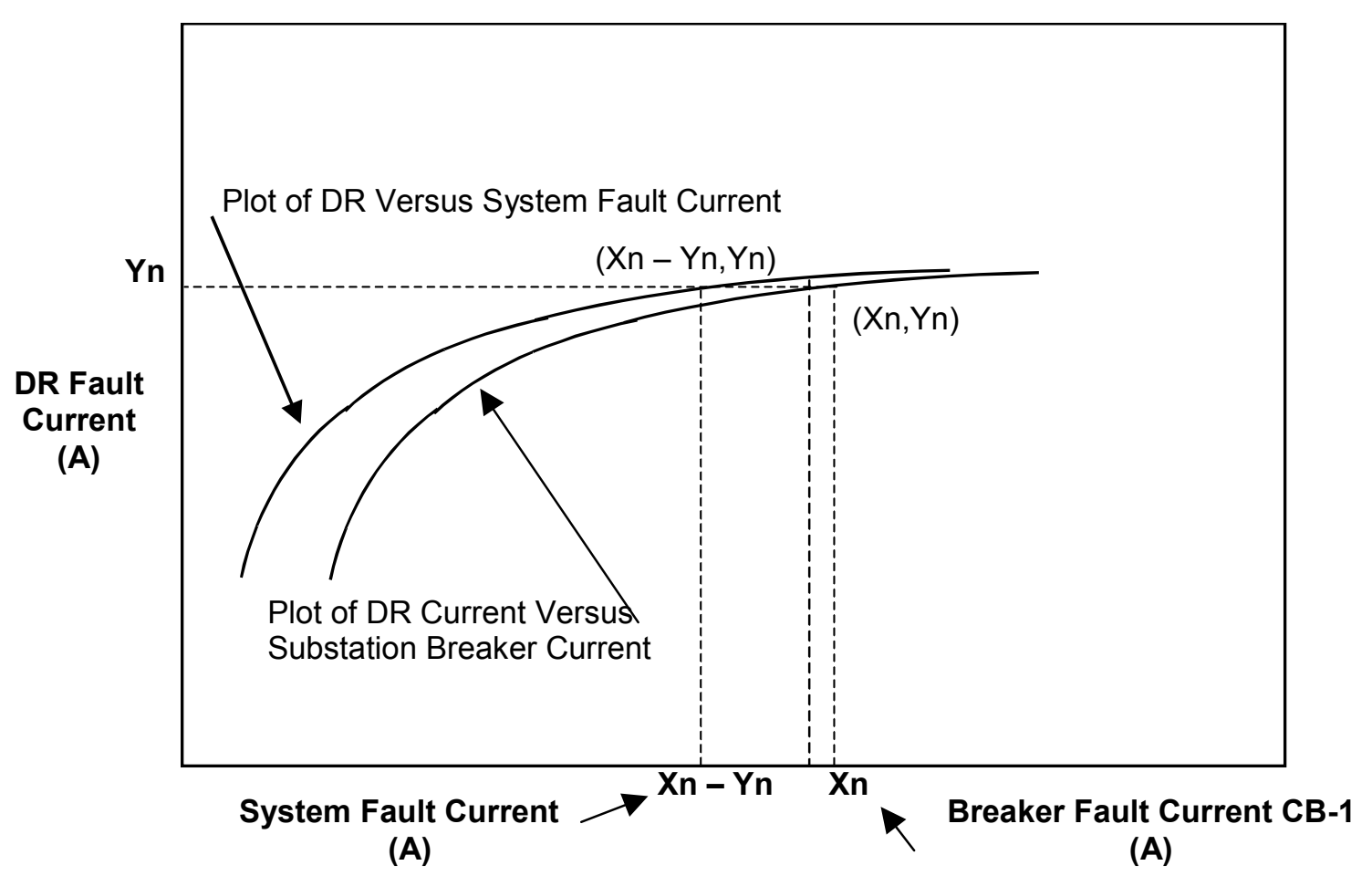

Note: $\mathrm{Yn}$ is equal to the maximum DR fault current.

(DR current versus breaker current CB-1 shown for reference)

Figure 5. DR fault current versus system fault current

\subsection{Issue 1: Improper Coordination - Reduced Fault Detection (Sensitivity)}

The addition of DRs to the DC will reduce the fault detection sensitivity of the substation protective relays.

\subsubsection{Scenario}

- Refer to Figure 6. The relay protection of the CB-1 breaker must sense the lowest fault current of the three shown fault locations (A, B, and C). Reclosers sense faults beyond the zone (i.e., D).

- The DR is located near the substation breaker because this represents the worst-case infeed condition (see infeed effects in Appendix C).

- There is a fault at A, as shown in Figure 7.

- The fault is near the line protection device that has the least available system fault current (A). The substation breaker will typically not be required to sense faults beyond this line protective device.

- The fault current contribution from the DR reduces fault circuit contribution from the substation (system fault current). 
- The protective device at the substation takes longer to trip because the system fault current through CB-1 is lower because of the infeed fault current from the DR or does not trip until the DR trips (i.e., the DR fault current contribution goes to zero), at which time the system fault current increases.

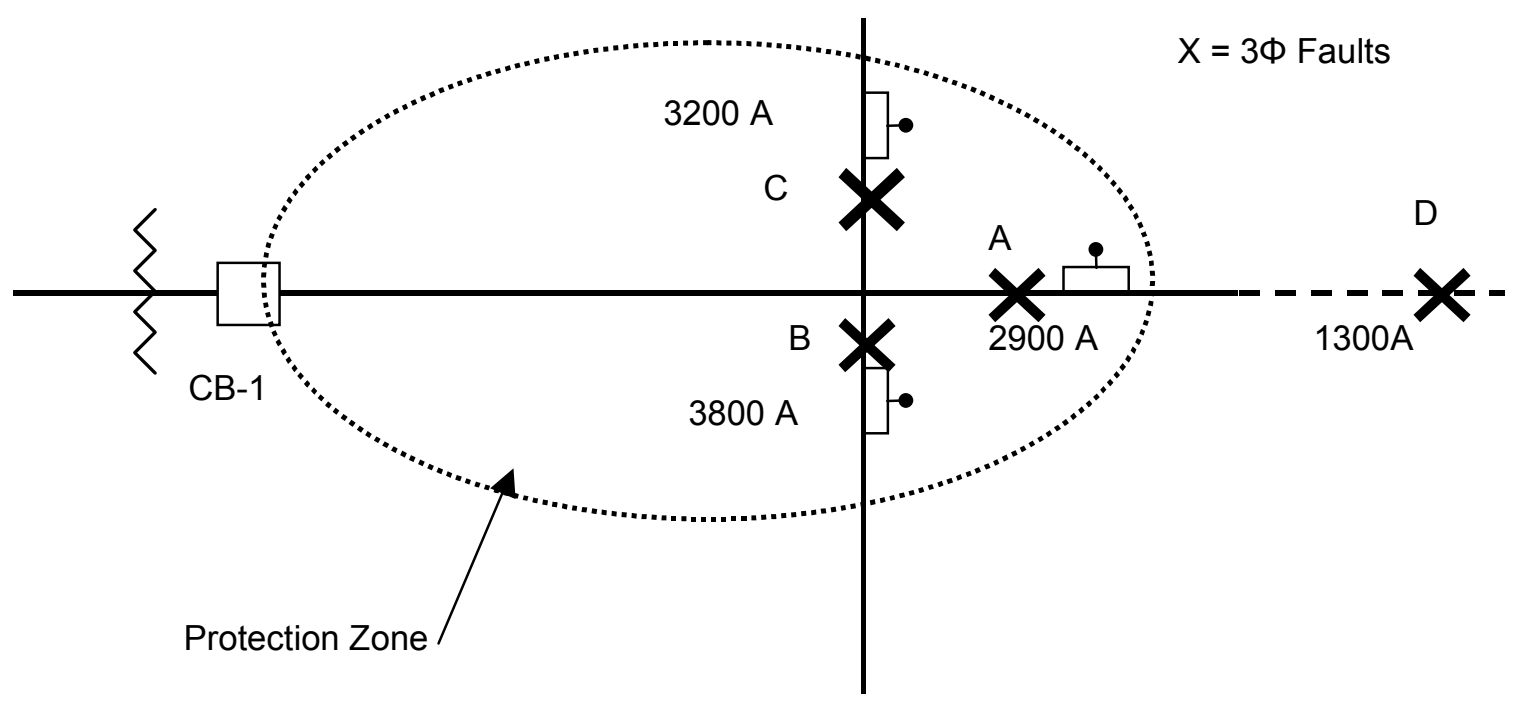

Figure 6. Breaker system protection zone

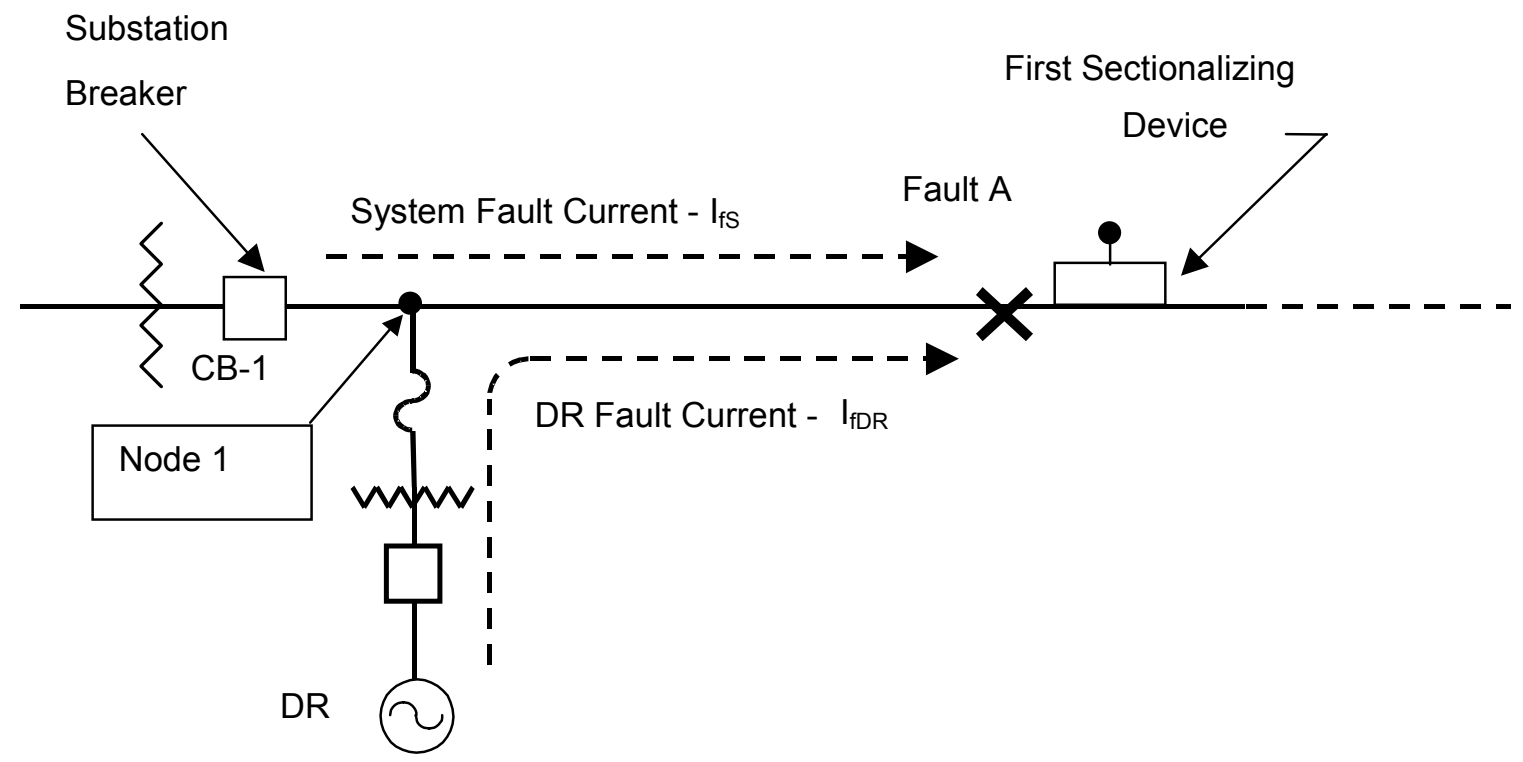

Figure 7. Infeed from DR reduces substation breaker relay fault current detection sensitivity 


\subsubsection{Question}

For the existing protective settings on the two circuits studied (i.e., Argo DC 326 and Pioneer DC 9795), what is the maximum DR generation that can be added without violating existing sensitivity guidelines?

\subsubsection{User Interface Description}

The user selects or enters the following parameters:

- DR positive sequence impedance, typically Xd' (three-phase fault or line-to-line fault)

- DR zero sequence impedance (line-to-ground faults)

- Positive, negative, and zero sequence system impedances Zs 1, Zs 2, Zs 0 to Node 1

- Positive, negative, and zero sequence line impedances ZL 1, ZL 2, ZL 0 from Node 1 to fault at A

- $\mathrm{TCC}$ for the recloser and TCC for the relay at CB-1 as well as any appropriate current transformer ratios.

The user runs the software, which produces a graphic plot of the decreasing system current as a function of the increasing DR fault current contribution (see Figure C-5). The software also provides a table containing the data points specific to the graphic plot. The user must decide the minimum system fault current such that the CB-1 breaker will operate for the maximumsize DR.

If the user enters a single specific value of system fault or breaker fault current, the software calculates and displays or prints the corresponding limit of DR fault current.

\subsubsection{Associated Algorithm}

Refer to Appendix C for details of plot development.

\subsection{Issue 2: Nuisance Fuse-Blowing Because of DR Fault Current}

As shown in Figure 8, faults on a lateral may cause the sectionalizing fuse to operate without being saved by the "fast" curve of the recloser. Typically, this is undesirable because many temporary faults can be cleared by momentarily de-energizing the system with the recloser before the fuse blows and then immediately reclosing the line. 


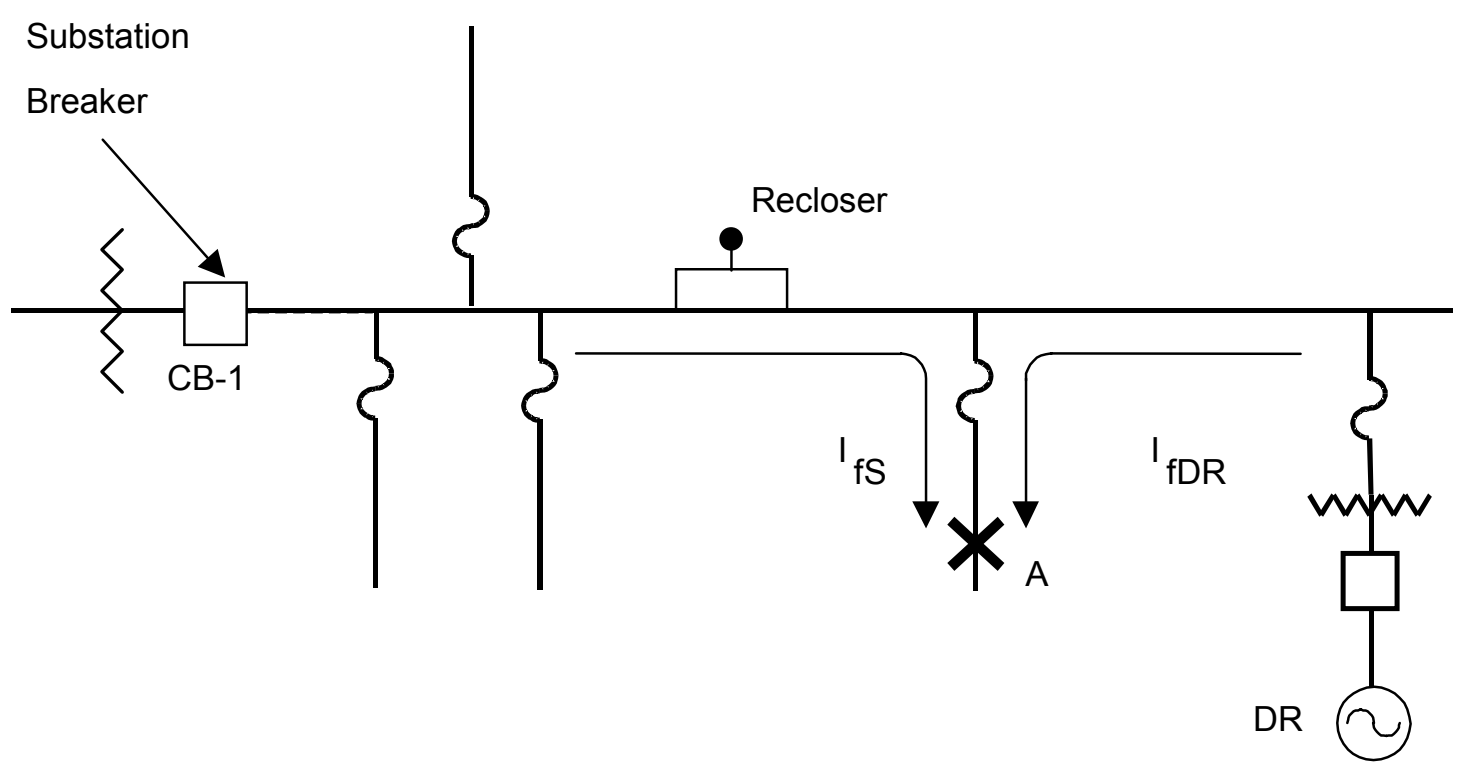

Figure 8. Nuisance fuse-blowing because of DR fault current

\subsubsection{Scenario}

- Fault occurs on the lateral at A.

- Current flows from the substation transformer $\left(\mathrm{I}_{\mathrm{fs}}\right)$ and the $\mathrm{DR}\left(\mathrm{I}_{\mathrm{fDR}}\right)$ to $\mathrm{A}$.

- The fuse senses the fault current through the recloser plus the fault current from the DR.

- Under normal operating conditions (without the DR), when a temporary fault occurs at A, the recloser will open for about 100 cycles to allow the temporary fault to clear. The recloser and fuse operating times are normally coordinated such that the recloser will open first to prevent the fuse from blowing and avoid unnecessary loss of load downstream from the fuse.

- The added current from the DR may cause the fuse to blow. If the DR were not present, the current through the fuse would be supplied only through the recloser.

- If the recloser does not trip soon enough because of the temporary fault, then the fuse will blow and cause loss of load beyond the fuse.

\subsubsection{Question}

What is the limit of DR size for a specific combination of fuse and recloser sizes?

\subsubsection{User Interface Description}

The user selects or enters the TCC for the recloser and the TCC for the fuse on the branch.

The user runs the software, which produces a graphic plot of the DR current penetration limit on the $\mathrm{Y}$ axis versus the system current on the $\mathrm{X}$ axis. The software also provides a table containing the data points specific to the graphic plot. 
If the user enters a specific value of system fault current, the software calculates and displays or prints the corresponding limit of DR fault current.

\subsubsection{Associated Algorithm}

For this issue, the DR penetration limit curve indicates the maximum permissible DR fault current that will not cause the fuse to operate before the recloser opens on the fast curve ("a" curve for Cooper V4L reclosers purchased by Detroit Edison).

To determine the maximum DR current for a specified recloser and fuse, the following process is used (refer to figures 8, 9, and 10):

- For a specific value of recloser fault current (Y1), determine the trip time (T1) from the fast "a" time-versus-current curve for the recloser in the database. See Figure 9.

- Determine the corresponding fuse fault current (X1, minimum melt) necessary to operate at the same time as the recloser trip time (T1) from the time-versus-current curves for these devices in the database.

- The maximum permissible DR fault current is the added current from the DR $\left(\mathrm{I}_{\mathrm{fDr}}\right.$ in Figure 8) that will not cause the fuse to blow before the recloser operates on the fast curve for T1. This current is determined as the difference between the respective operating currents for the fuse and the recloser $(\mathrm{X} 1-\mathrm{Y} 1)$. Refer to Figure 9.

- On a separate plot of current on both axes, plot the DR fault current (X1 - Y1) on the $\mathrm{Y}$ axis, opposite the recloser fault current (X1) on the X axis. Refer to Figure 10.

- Develop a curve of maximum DR fault current and breaker fault current by plotting a range of recloser and breaker currents $[(\mathrm{X} 1, \mathrm{X} 1-\mathrm{Y} 1),(\mathrm{X} 2, \mathrm{X} 2-\mathrm{Y} 2),(\mathrm{X} 3, \mathrm{X} 3-\mathrm{Y} 3)$ ... (Xn, Xn - Yn).

- Based on the data plotted in Figure 10, the maximum DR penetration limit can now be determined. It should be noted that the DR penetration limit is defined in terms of megavolt-amperes based on the rated current, not fault current. Once the fault current is determined, one can determine the corresponding rated current. 


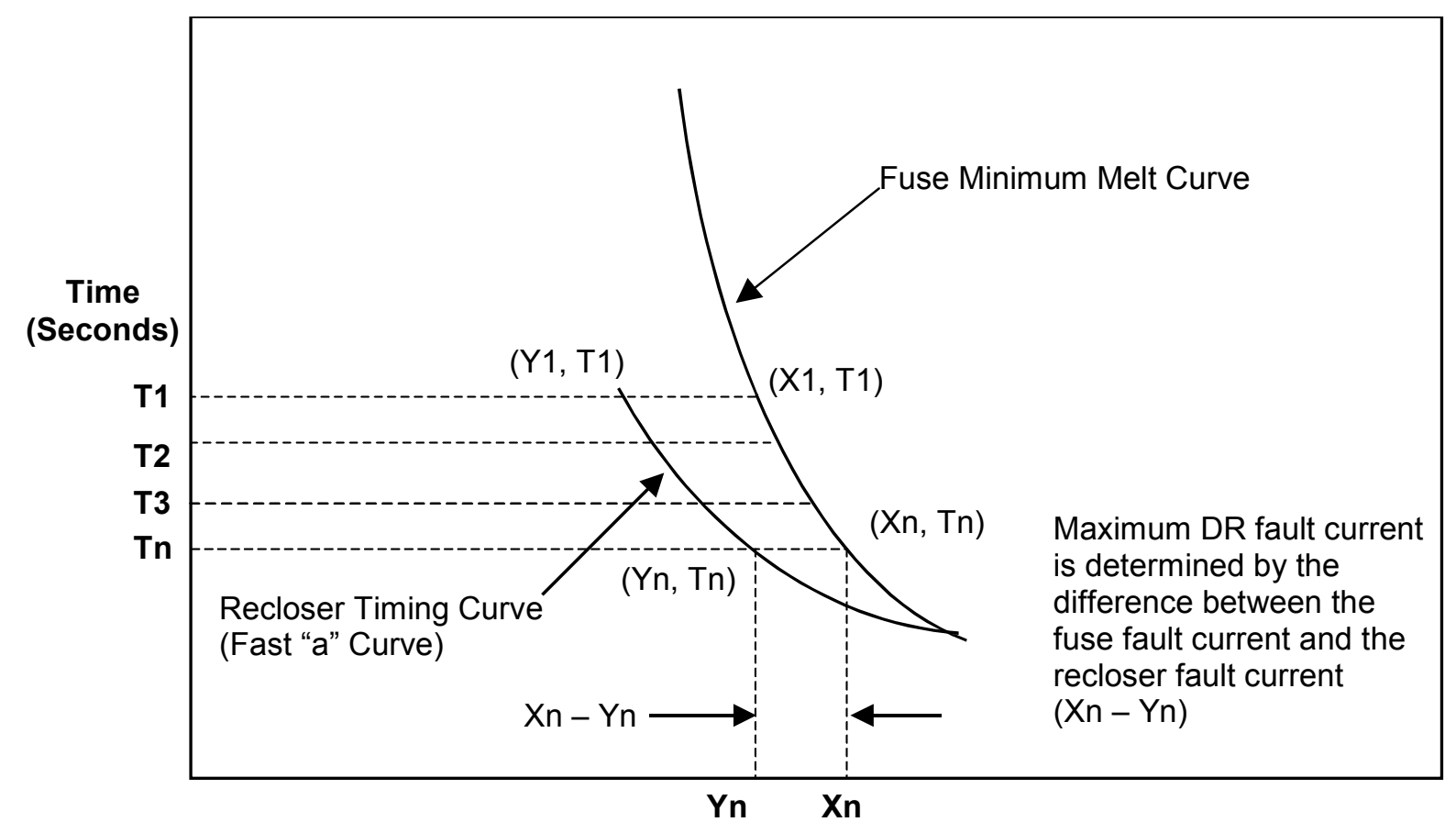

Fault Current (A)

Figure 9. Time-versus-fault-current curves for fuse and recloser

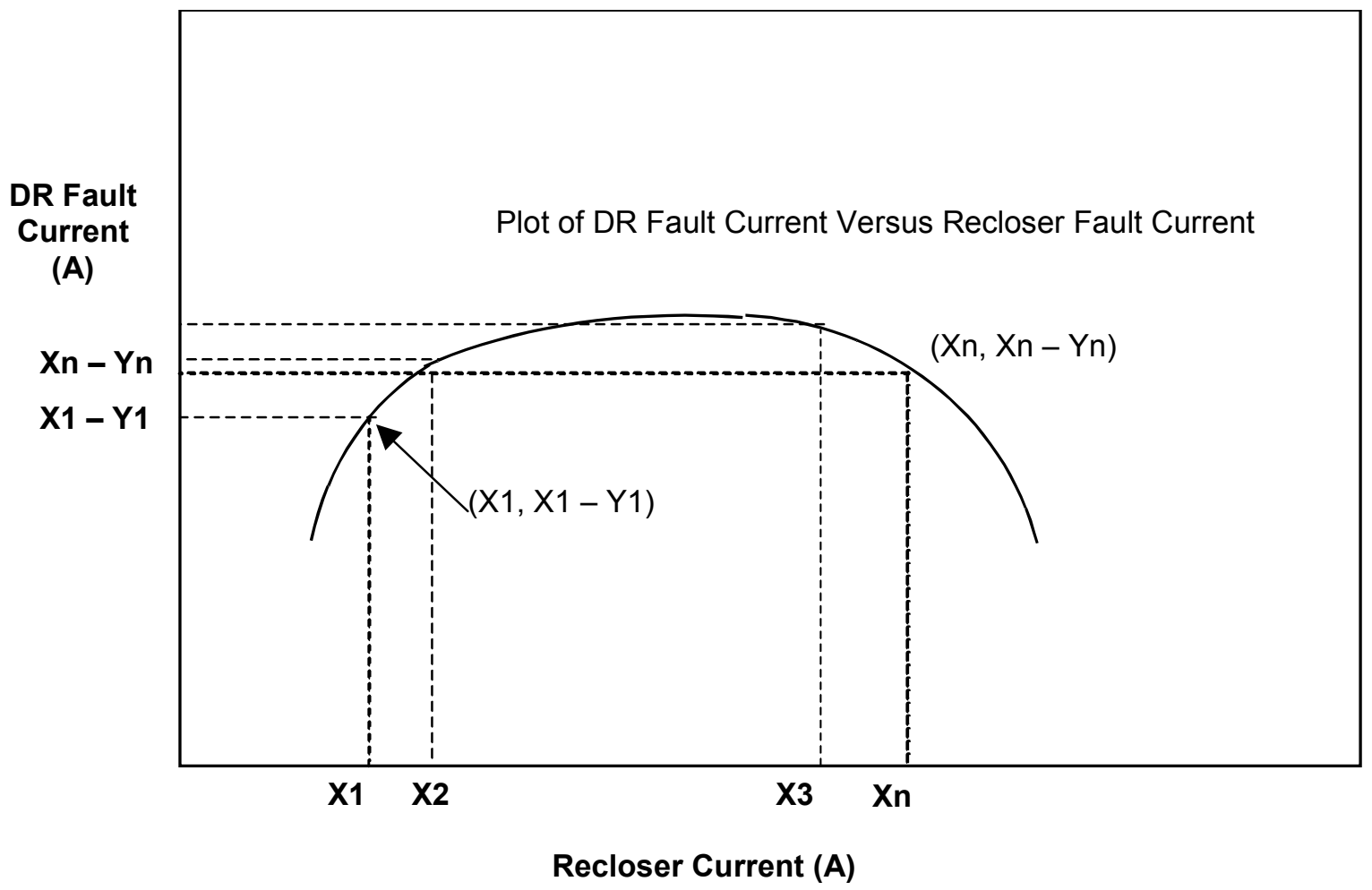

Figure 10. Plot of maximum DR fault current versus recloser fault current 


\subsection{Issue 15: Faults Within the Distributed Resource Zone}

The primary concern of the utility is faults within the DR zone (the local EPS containing the DR) that cause disruption of service to other loads on the circuit. This and related concerns are addressed in this section.

\subsubsection{Scenario 1}

- Faults within the DR zone should be cleared by local protective devices, as shown in Figure 11.

- The fault on the 480-V bus should be cleared by the secondary of the transformer CB2 and the generator CB-3 without any other protective device operating on the EPS.

- Coordination studies are conducted without the DR, and selectivity is maintained for all protective devices from the substation line breaker to the fault.

- With the DR operating, selectivity needs to be maintained between these same devices such that the protective devices nearest the fault clear first.

- Assuming the transformer turns ratio is included, fault current flowing through CB-1 will always equal fault current flowing through CB-2 for the configuration shown in Figure 12. For example:

5,011 A @ $\mathrm{CB}-2=182 \mathrm{Ax}\left(\frac{13.2}{0.48}\right) @ \mathrm{CB}-2$ when the generator is off.

The current flowing through CB-1 will be equal to the current flowing through CB-2 even though the magnitude will be reduced when the generator is on. Figure 13 shows the difference in clearing times (vertical separation) between the two CB-1 and CB-2 breakers when the generator is on. The TCC is larger when the fault current is lower or $3,160 \mathrm{~A}$. Because the generator reduces the system fault current contribution through CB-1 and CB-2, selectivity will normally be improved for this pair of breakers when the generator is on compared with when the generator is off. 


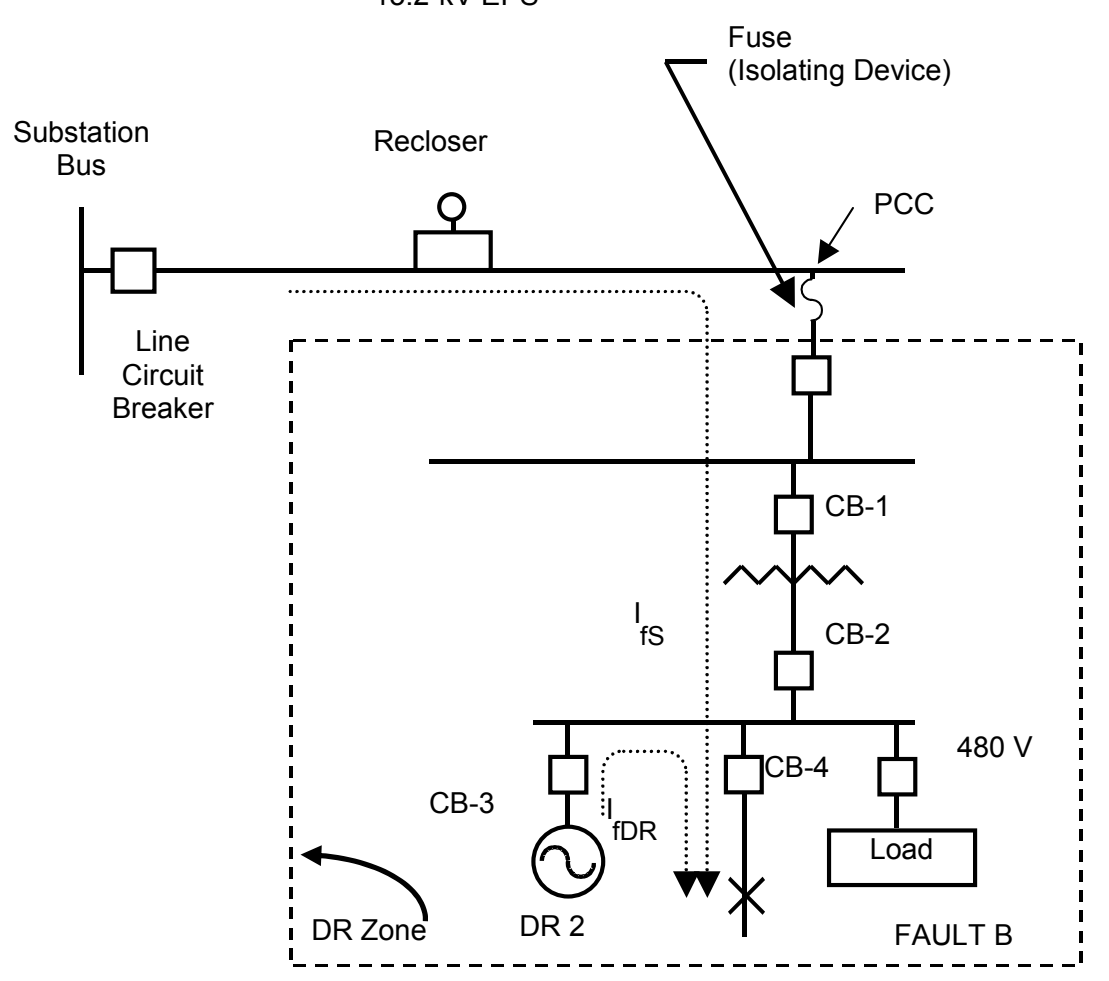

Figure 11. Faults within the DR zone are cleared with local protective devices

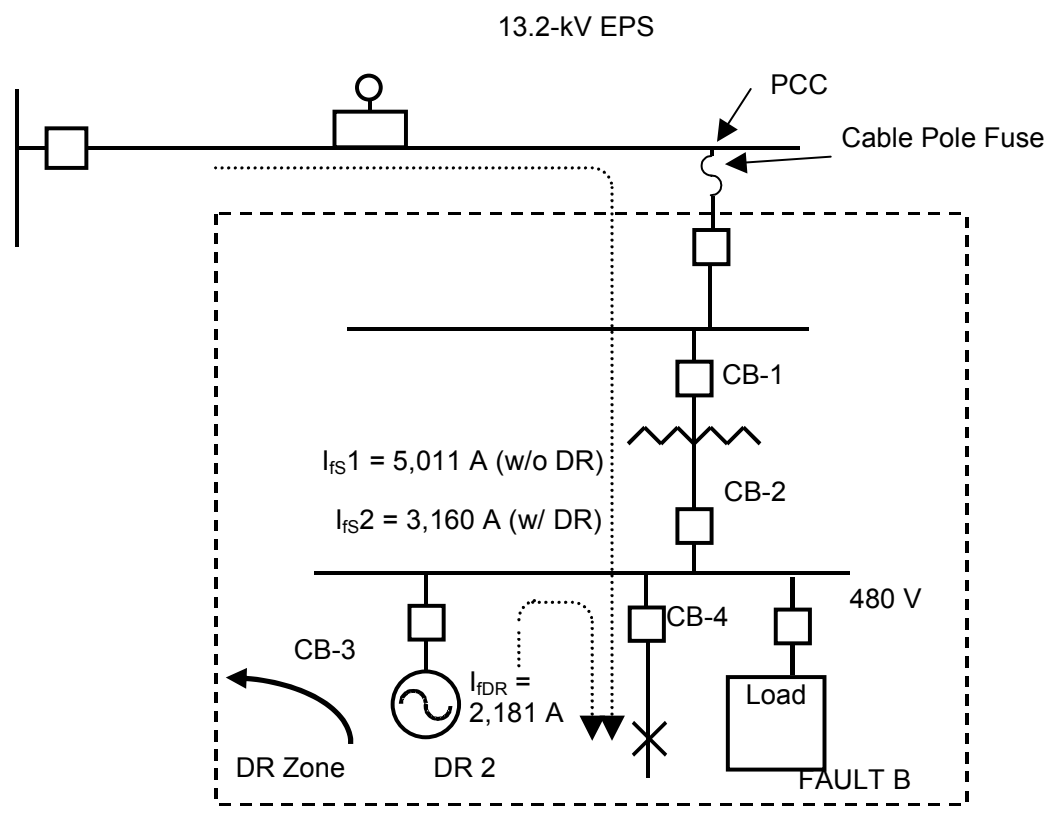

Figure 12. Effects of infeed on system fault current 


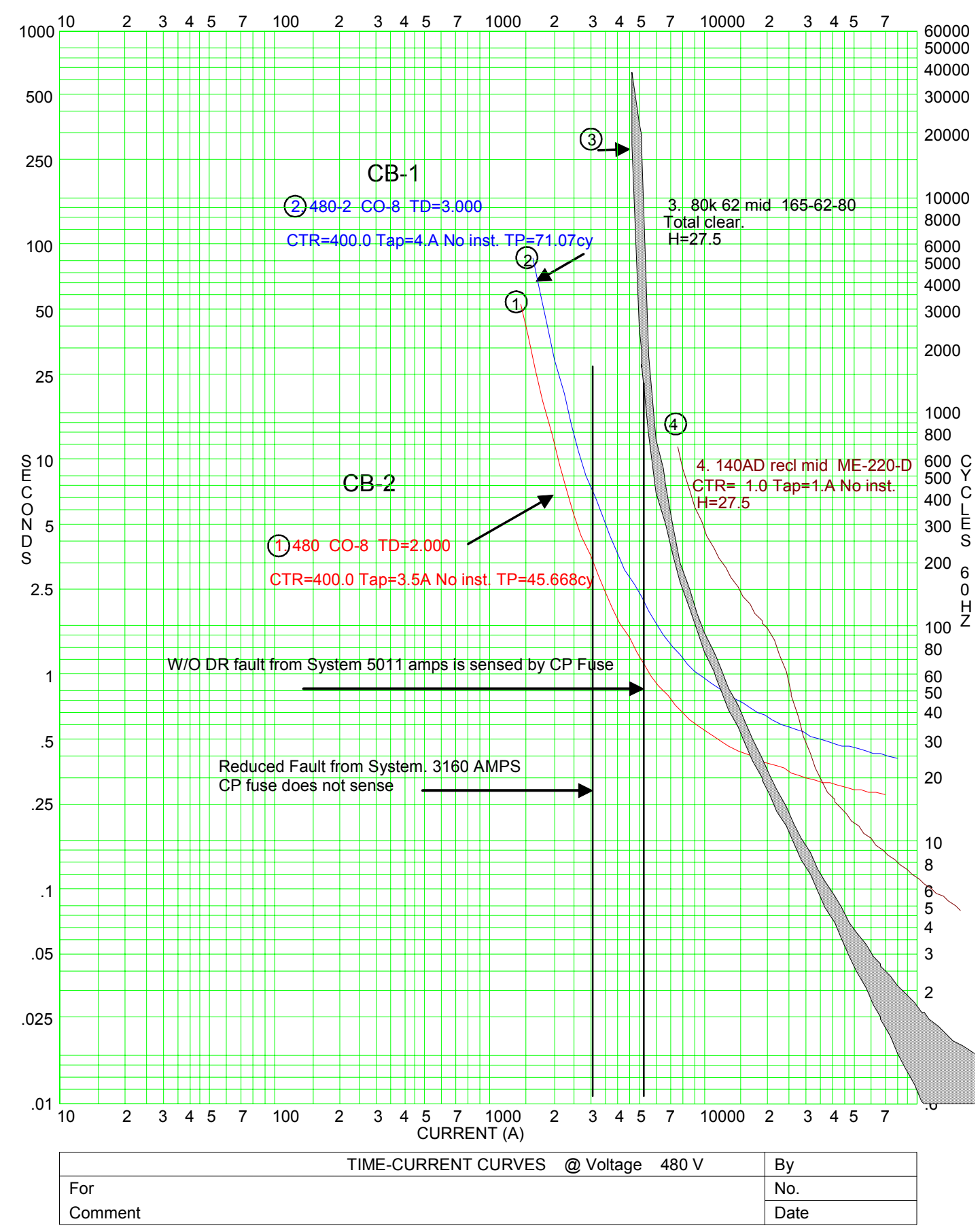

Figure 13. Selectivity coordination of EPS devices and DR zone devices

\subsubsection{Question 1}

Will selectivity be maintained between system protection devices after the DR is added? 


\subsubsection{Study Results 1}

In Figure 12, the system fault current without the DR is given. The system fault with the DR added is also shown in Figure 12. Figure 13 shows the TCCs of the cable pole fuse, the 140-A recloser, and the protective relays for CB-2. Note that these curves are plotted at $480 \mathrm{~V}$. The $80 \mathrm{k}$ cable pole fuse and the 140-A recloser curves have been shifted to show the operating (blowing) time for the fuse and recloser with respect to the operating time for the CB-2 breaker.

Notice the system fault current is lower when the DR is connected. This is because the voltage at the fault is higher because of the DR current flowing through the fault impedance. See Appendix D for an example of infeed effects and the reason system fault current will be lower when a DR is connected.

\subsubsection{Infeed Effect}

The desensitizing effects of infeed within the DR zone will normally be small for faults in which DR and Area EPS current flow only through local lines or buses. Because typical lines within the DR zone are short, infeed effects will be small for lines and buses that do not have a transformer fed from the Area EPS and the DR. In cases in which the infeed effect is appreciable - such as a transformer secondary fault whose primary source is the Area EPS, and the DR is on the transformer secondary - the fault current from the EPS may be reduced appreciably, and fault current sensitivity can be an issue. Selectivity with other devices on the Area EPS will not be compromised.

In Figure 14, DR 1 will typically have little effect on the fault current flowing from the 13.2$\mathrm{kV}$ EPS $\left(\mathrm{I}_{\mathrm{fS}}\right.$ ) to Fault A. However, DR 2 can have a significant effect on the fault current flowing from the EPS to Fault B. The increased effect of DR 2 is caused primarily by the impedance of the $13.2-\mathrm{kV}-$ to $-480-\mathrm{V}$ transformer, which is in series with the EPS source.

As an example, an ASPEN (a fault analysis software program) study was made on DC 9795. DR 2, a 2-MVA generator, reduced $\mathrm{I}_{\mathrm{fS} 2}$ fault current from $181 \mathrm{~A}$ to $115 \mathrm{~A}$ when changed from offline to online operation. For similar conditions, DR 1, also a 2-MVA generator, reduced the fault current from 181 A to only 164 A when changed from offline to online operation. A fault impedance of $0.05 \mathrm{ohm}$ was used for these studies.

Note that although selectivity on the utility system is not affected by infeed, fault detection sensitivity is. For cases in which infeed effects are appreciable, the current flowing from the Area EPS will be smaller. This will typically cause any protective devices on the EPS to operate more slowly or not at all. For most bus arrangements in which infeed effect is appreciable, a separate protective device will be installed (e.g., a transformer primary fuse). See Figure 15, F-2. For this situation, the Area EPS protective device (cable pole fuse F-1) would operate as a back-up protective device. If back-up protection is critical, fault studies should be conducted to model infeed effects to determine if adequate protection is provided. 


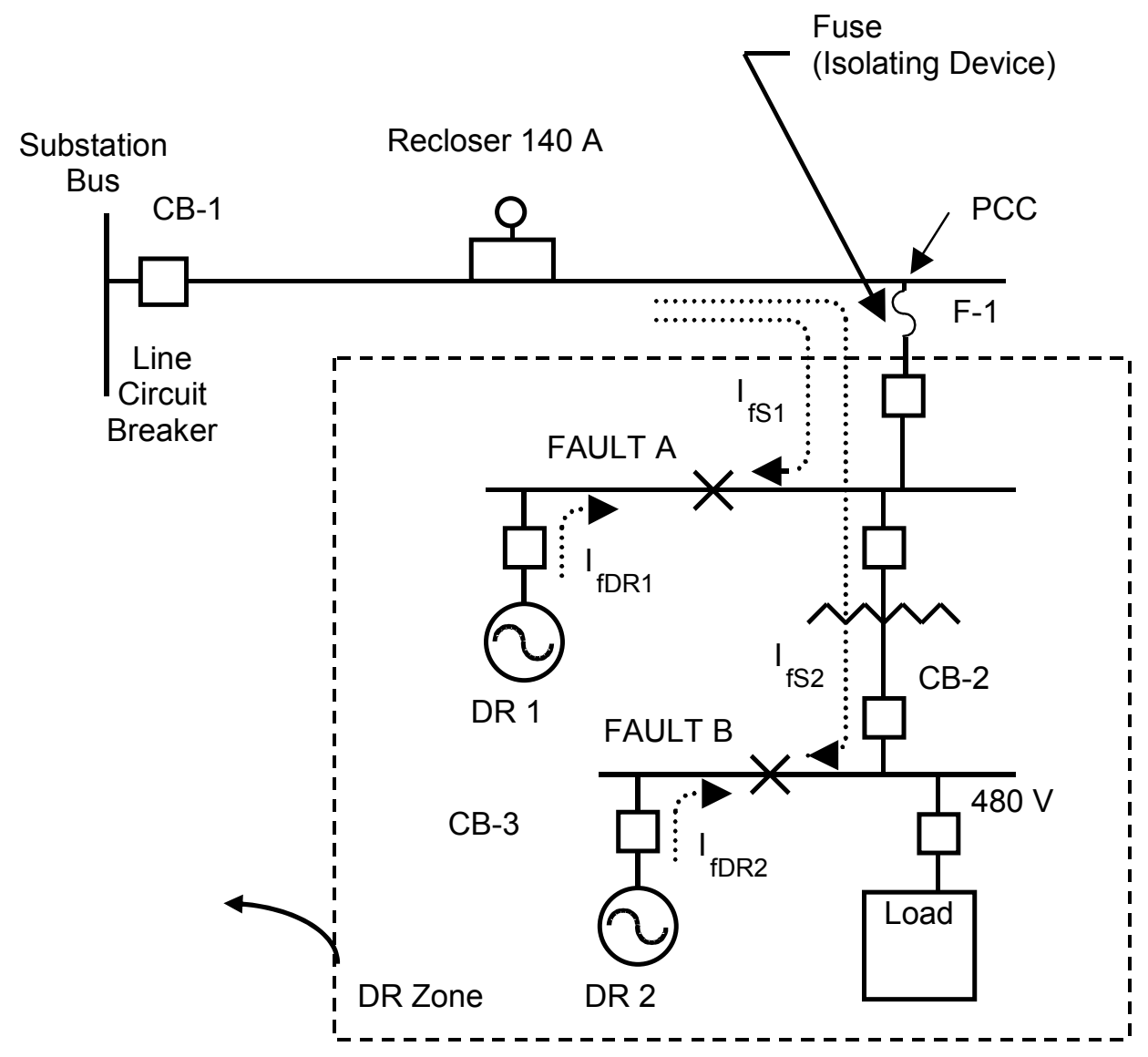

Figure 14. Faults within a DR zone

\subsubsection{Scenario 2}

- The fault current has increased at the point of fault such that the devices within the DR zone do not coordinate. See Figure 15.

- Faults within the DR zone should be cleared selectively by devices nearest the fault.

- With the addition of DR 1 in Figure 15, the fault current at "A" increases through the $65 \mathrm{k}, \mathrm{F}-1$ and $25 \mathrm{k}, \mathrm{F}-2$ fuses. Although $\mathrm{I}_{\mathrm{fS}}$ decreases, the total fault current at "A" increases. The point of this scenario is not to demonstrate the selectivity of devices on the EPS (this was covered in Scenario 1) but to demonstrate the selectivity of the devices within the DR zone.

- As the fault current increases through F-1 and F-2, the selectivity margin among the protective devices decreases within the DR zone.

\subsubsection{Question 2}

Will the addition of a DR increase the fault levels to a point at which the selectivity of devices between the DR and the fault is affected? 


\subsubsection{Study Results 2}

\subsubsection{Effects of Increased Fault Current on Selectivity}

For fuse coordination, increased fault current can cause fuses to become inselective. An additional local DR or changes to the EPS can increase fault current. The replacement of a substation transformer with a unit of larger size and load transfer of a DR site to a new substation with a larger transformer are also reasons for increases in fault current.

For an explanation of the effect fault current has on DR zone device coordination, refer to the fuse coordination table in Appendix D and Figure 16. Notice in Table D-2 that fault currents larger than 2,200 A will cause the $65 \mathrm{k}$ and $25 \mathrm{k}$ fuses to blow at the same time and thus do not coordinate. An added DR that supplies 200 A of fault current, as shown in Figure 15, increases the total fault current to 2,300 A. This further decreases the selectivity margin to a point at which the $65 \mathrm{k}$ and $25 \mathrm{k}$ fuses will blow for the fault shown. Refer to Figure 16, which shows the inselectivity of devices when fault current is 2,200 A or more.

This problem can be addressed several ways. For example, the $65 \mathrm{k}$ fuse can be replaced with a larger $80 \mathrm{k}$ fuse if other constraints of selectivity and sensitivity are not violated. If extensive system changes are needed, budget constraints may not allow the problem to be solved. At a minimum, operators should be alerted to the problem so they can react accordingly should both fuses blow during a fault.

13.2-kV EPS

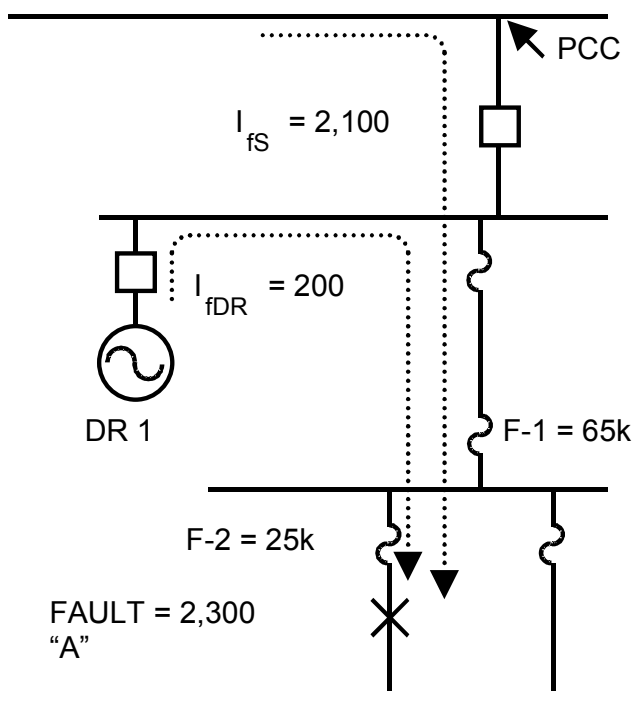

Figure 15. Selectivity coordination within the DR zone 


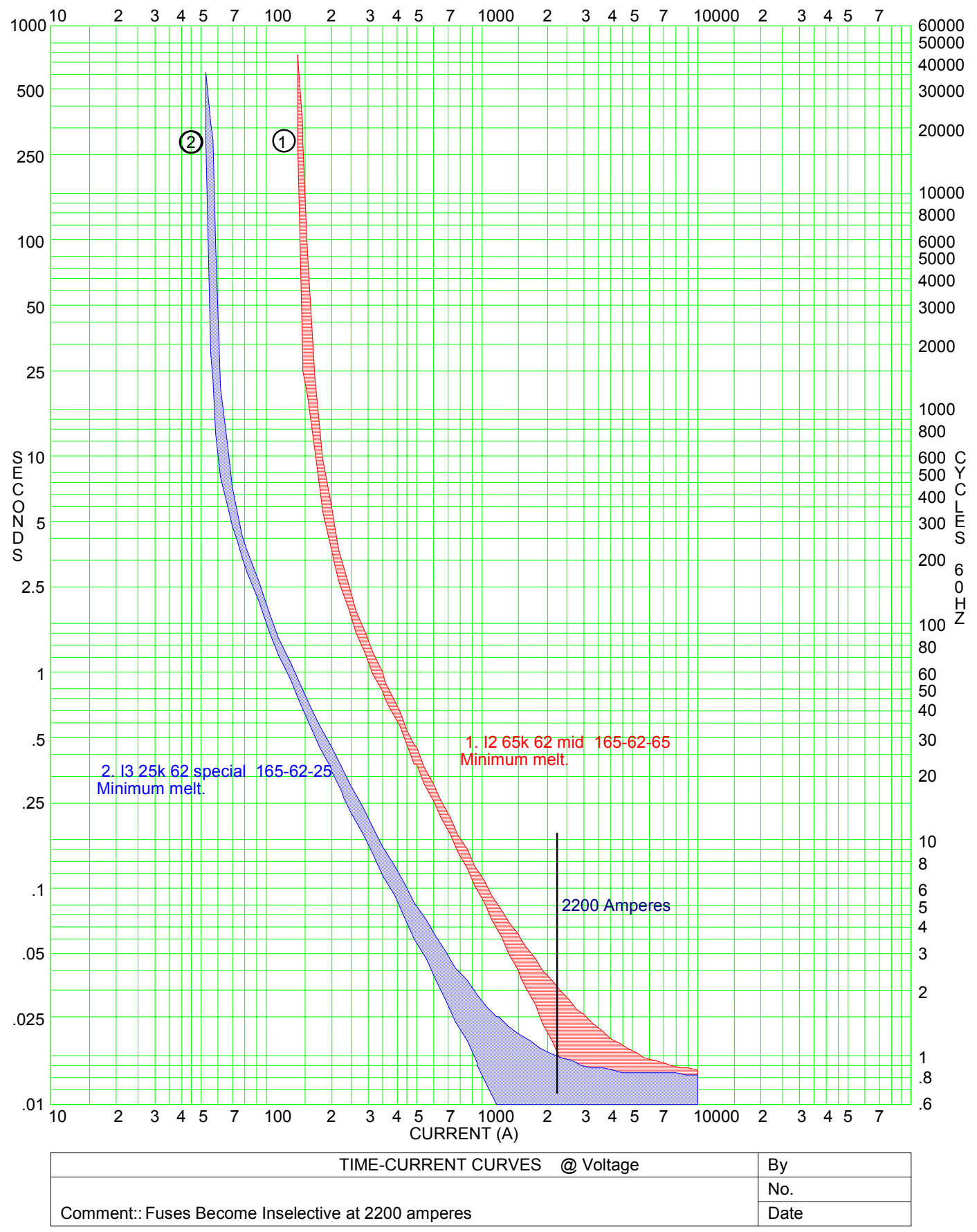

Figure 16. Coordination between devices is compromised when fault current exceeds 2,200 A 


\subsubsection{User Interface Description}

The user selects or enters the TCC for F-1 and the TCC for F-2.

The user runs the software, which produces a graphic plot of the DR current penetration limit on the $\mathrm{Y}$-axis versus the system or breaker current on the $\mathrm{X}$-axis. The limit indicates the maximum DR fault current that can flow through F-2 for a respective value of system fault current. It also provides a table of the data points specific to the graphic plot.

If the user enters a specific value of system fault current, the software calculates and displays or prints the corresponding limit of DR fault current.

\subsubsection{Associated Algorithm}

The software will determine the minimum fault current that will cause the two fuses to operate at the same time. For a $65 \mathrm{k}$ fuse at F1 and a $25 \mathrm{k}$ fuse at F2, this value is about 2,200 A. The plot is a line such that the sum of the DR fault current (Y) and the system fault current (X) equals this minimum value $(2,200 \mathrm{~A})$, or $\mathrm{X}+\mathrm{Y}=2,200$. For the $65 \mathrm{k}$ and $25 \mathrm{k}$ fuses, the plot will be similar to Figure 17.

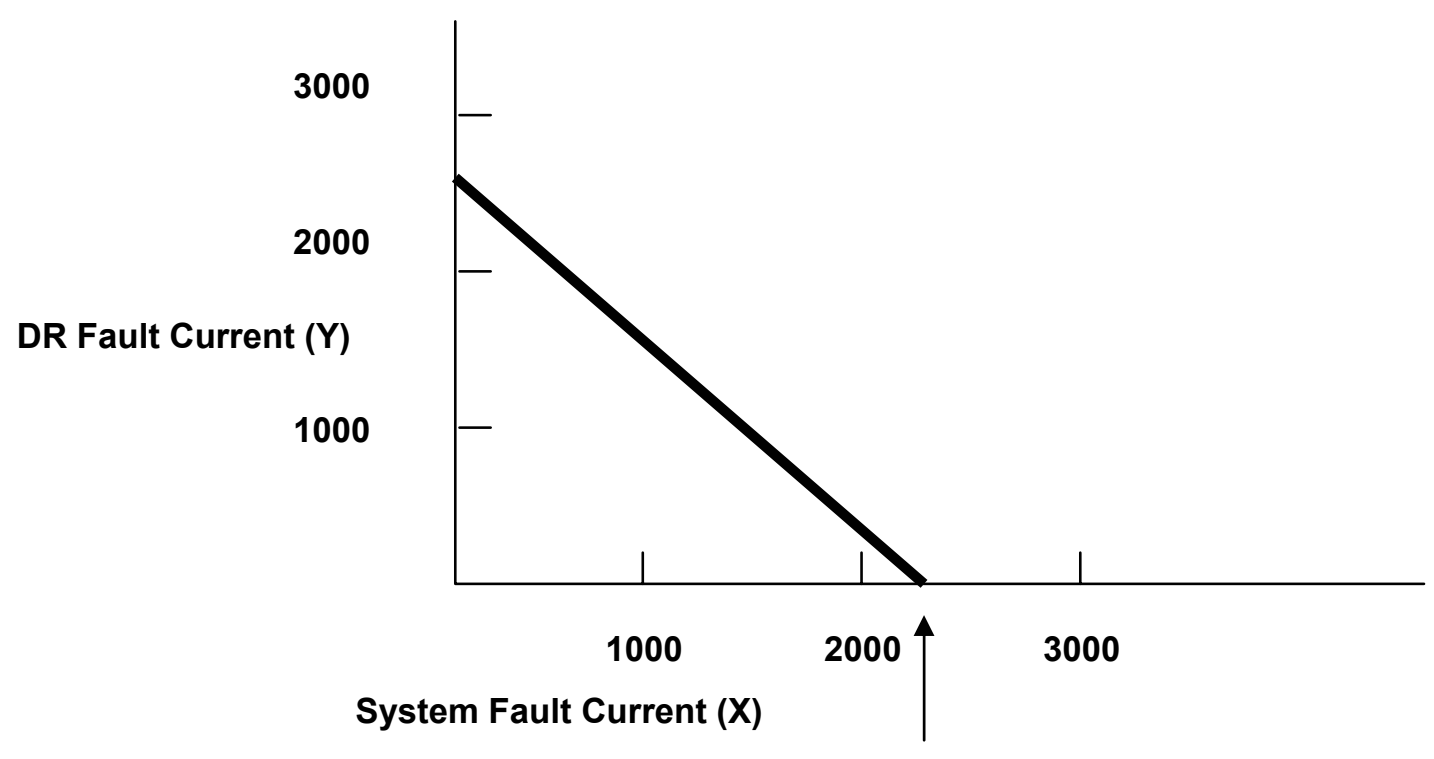

(2200)

Figure 17. Equation for DR fault current limit and system fault current to maintain selectivity

In Figure 17, the maximum DR fault current permissible while maintaining selectivity between F-1 and F-2 or other selected protective devices can be determined. 


\subsection{Issue 16: Isolate Distributed Resource for Upstream Fault}

Figure 18 shows a case in which faults upstream of a recloser may cause the recloser to operate because of current from a group of DRs downstream of the recloser. Even though the protection on each DR may be selective with the recloser, the added fault current from other DRs on the circuit may cause the recloser to operate.

If a fault causes system protection equipment to isolate load from the utility source, the remaining DRs may not be able to serve the load if their capacity is not large enough and there is no voltage regulation and frequency control.

This study considers the operation of a fuse at the point of common coupling of an existing DR. If the operation of the fuse at the point of common coupling is ignored, the total DR current required to operate the recloser of the sectionalizing device can be simply calculated as any value above the tripping point of the sectionalizing device. Operation of the fuse at the existing point of common coupling will stop the flow of fault current from the existing DR. Then only the additional DRs will supply fault current.

If the additional DRs are identical to the existing DR in fault current capability and fuse size, the fuse at each will blow simultaneously. This study will determine the fault current from the added DRs necessary to cause the recloser to operate on the slow curve.

Operation of the recloser on the fast curve is not considered in this study. TCCs for the recloser and fuse are shown in Figure 19. Although undesirable, operation on the fast curve will not cause the recloser to lock out. Therefore, priority was given to the study of tripping on the slow curve. Locking out a recloser will typically require a minimum of two operations on the slow curve.

See the introduction of Issue 27 (Section 2.6) for additional details. Paragraphs three through eight provide details that are essentially the same for single-phase and three-phase faults.

\subsubsection{Scenario}

- A fault occurs on the circuit at " $\mathrm{A}$ " in Figure 18, between the substation and recloser.

- Current flows from the substation transformer and the DR to the fault.

- The current from DR 1 is sensed by a local device (fuse) and the recloser.

- The current from the additional DRs on the circuit may cause the recloser to operate.

\subsubsection{Question}

Assume the protective devices at an existing DR will isolate the DR from the system prior to the recloser operating. How much current from additional DRs is necessary to cause the recloser to operate before the protective devices operate at the existing DR?

Determining the level of additional DR fault current that will cause protective device inselectivity will help planning and protective relay engineers quickly estimate if an added DR will cause a problem. 


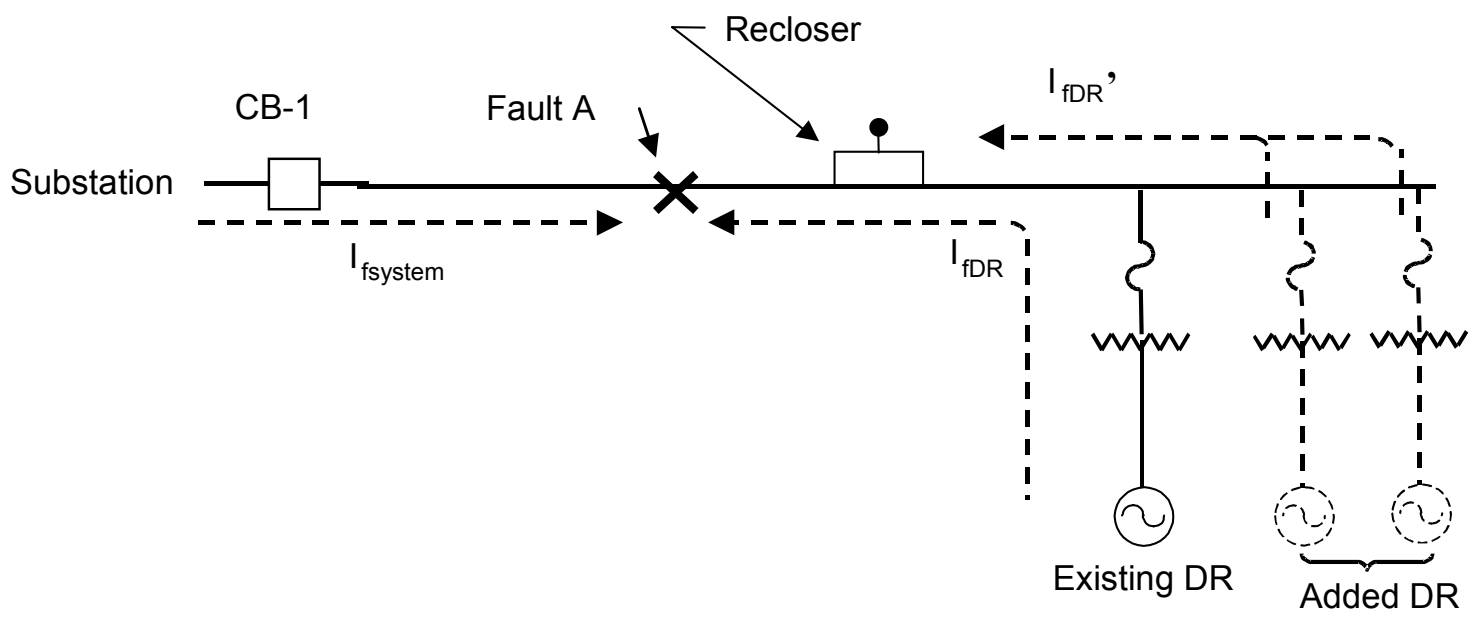

Figure 18. Fuse-blowing for upstream fault

\subsubsection{User Interface Description}

The user selects or enters the TCC for the recloser and the TCC for the fuse at the DR cable pole(s) or interface point(s).

The user runs the software, which produces a graphic plot of the DR fault current penetration limit on the $\mathrm{Y}$ axis versus the recloser fault current on the $\mathrm{X}$ axis. It also provides a table of the data points specific to the graphic plot.

If the user enters a specific value of recloser fault current, the software calculates and displays or prints the corresponding limit of DR fault current.

\subsubsection{Associated Algorithm}

To determine the maximum DR fault current for a specified recloser and fuse size:

- For a specific value of recloser current (X1), determine the trip time (T1) from the (slow "d" curve) time-versus-current curve for the recloser device in the database as shown in Figure 20.

- Determine the corresponding fuse current (Y1, total clearing) to operate in the same recloser trip time (T1) from the time-versus-current curve for the fuse in the database.

- The maximum permissible DR fault current is the added current from the added DRs ( $\mathrm{I}_{\text {fdr }}$ ' in Figure 18) that will cause the recloser to operate at the same time the fuse on the existing DR blows. This current is the difference between the operating currents for the fuse and the recloser $(\mathrm{X} 1-\mathrm{Y} 1)$.

- On a separate plot of current on both axes, plot the DR current (X1 - Y1) on the Y axis opposite the recloser current (X1) on the $\mathrm{X}$ axis. (Refer to Figure 21.) 
- Develop a curve of maximum DR fault current and recloser fault current by plotting a range of recloser and added DR fault current $[(\mathrm{X} 1, \mathrm{X} 1-\mathrm{Y} 1),(\mathrm{X} 2, \mathrm{X} 2-\mathrm{Y} 2),(\mathrm{X} 3, \mathrm{X} 3$ $-\mathrm{Y} 3), \ldots(\mathrm{Xn}, \mathrm{Xn}-\mathrm{Yn})]$.

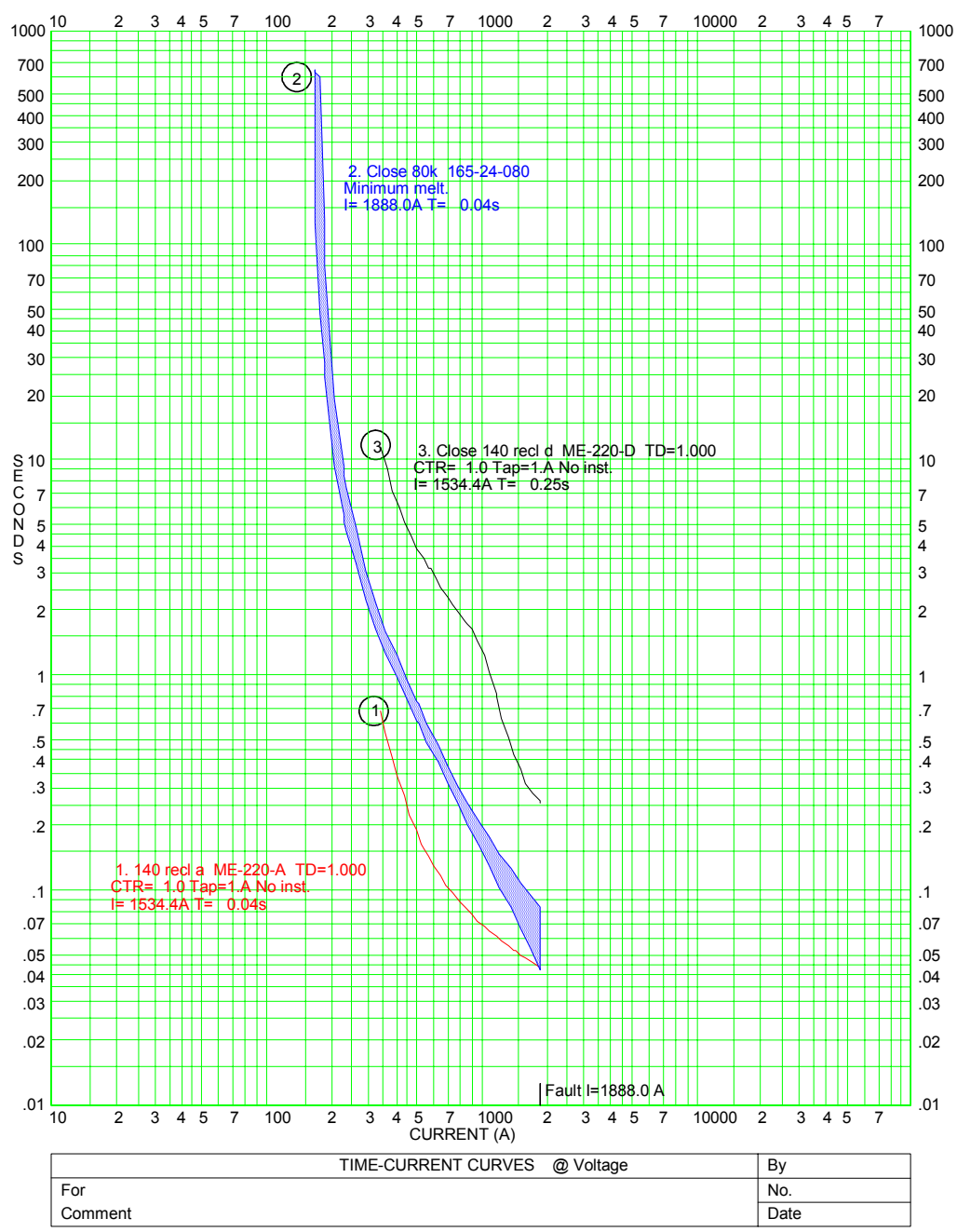

Figure 19. Tripping characteristics for $140-\mathrm{A}$ recloser and $80 \mathrm{k}$ fuse showing fast and slow curves for the recloser 


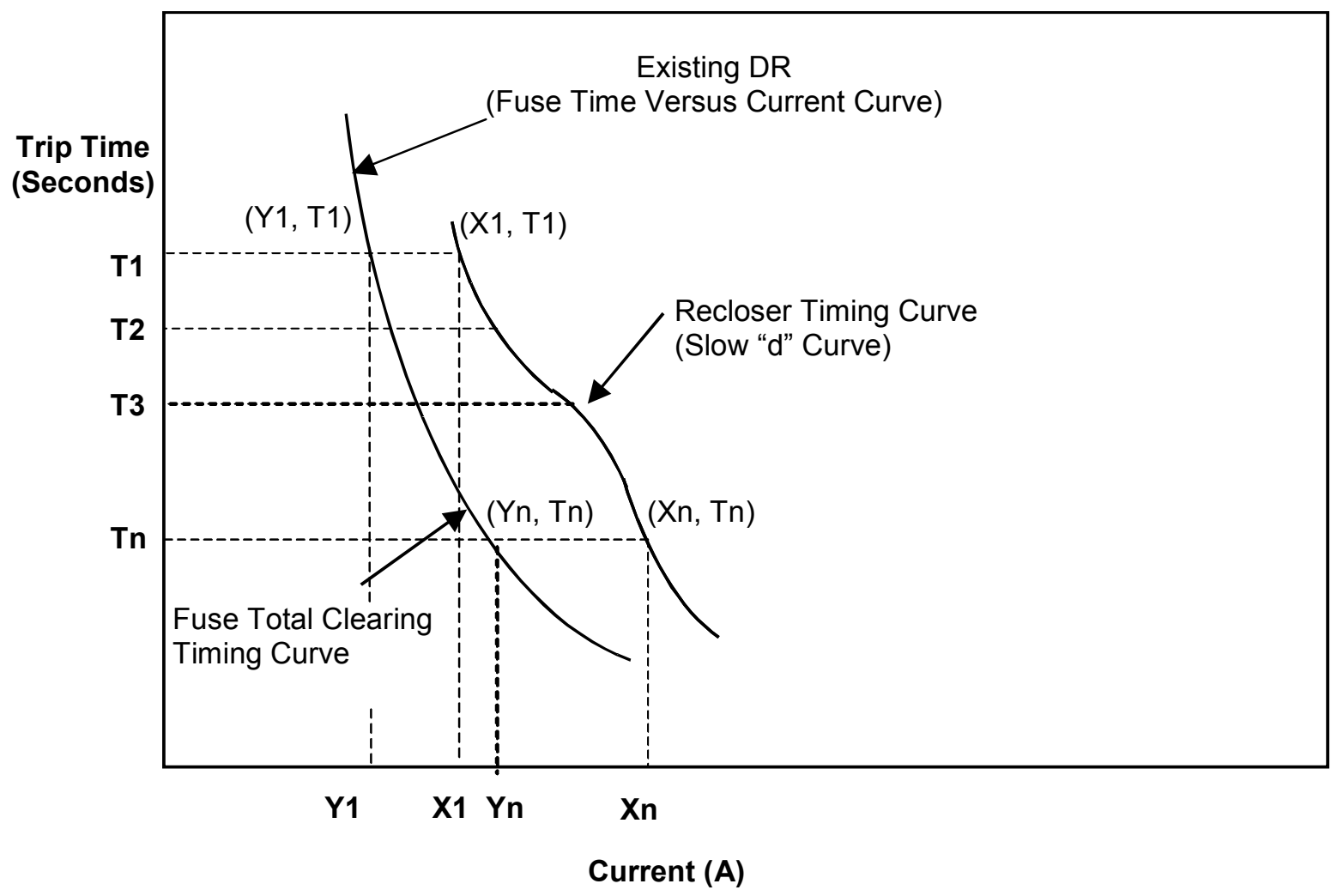

Figure 20. Trip-time-versus-current curves for fuse and recloser

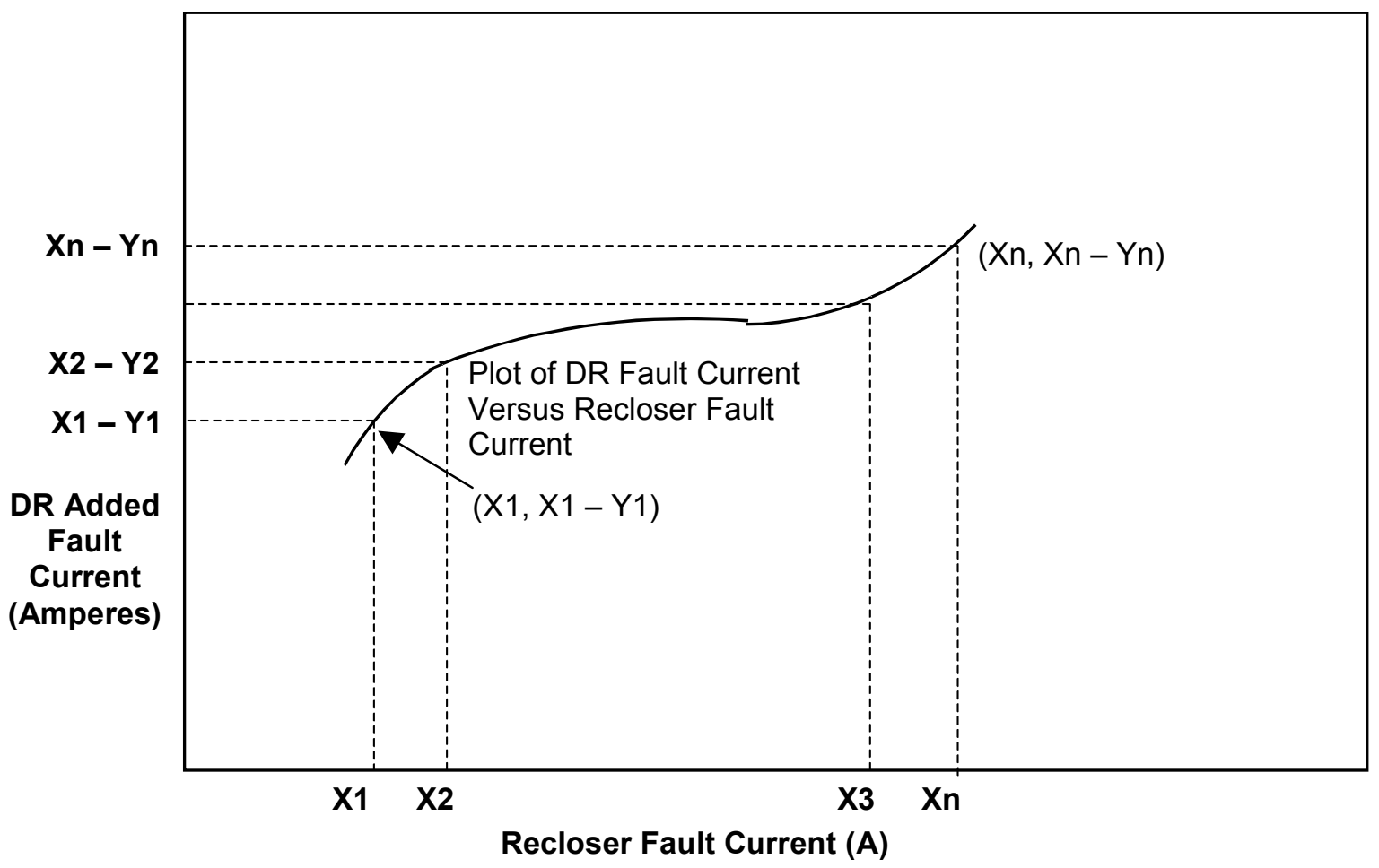

Figure 21. Plot of maximum added DR fault current versus recloser current 
Notice from the curve plotted in Figure 21 that the maximum DR added fault current can be determined from the total recloser fault current.

\subsection{Issue 27: Upstream Single-Phase Fault Causes Fuse-Blowing}

The method for developing penetration curves for Issue 27 is identical to that used for Issue 16. Refer to the penetration curve development for Issue 16.

Figure 22 shows a line-to-ground fault upstream from a recloser or sectionalizing fuse (sectionalizing device) may cause the sectionalizing device to operate because of current from a group of DRs downstream from the device.

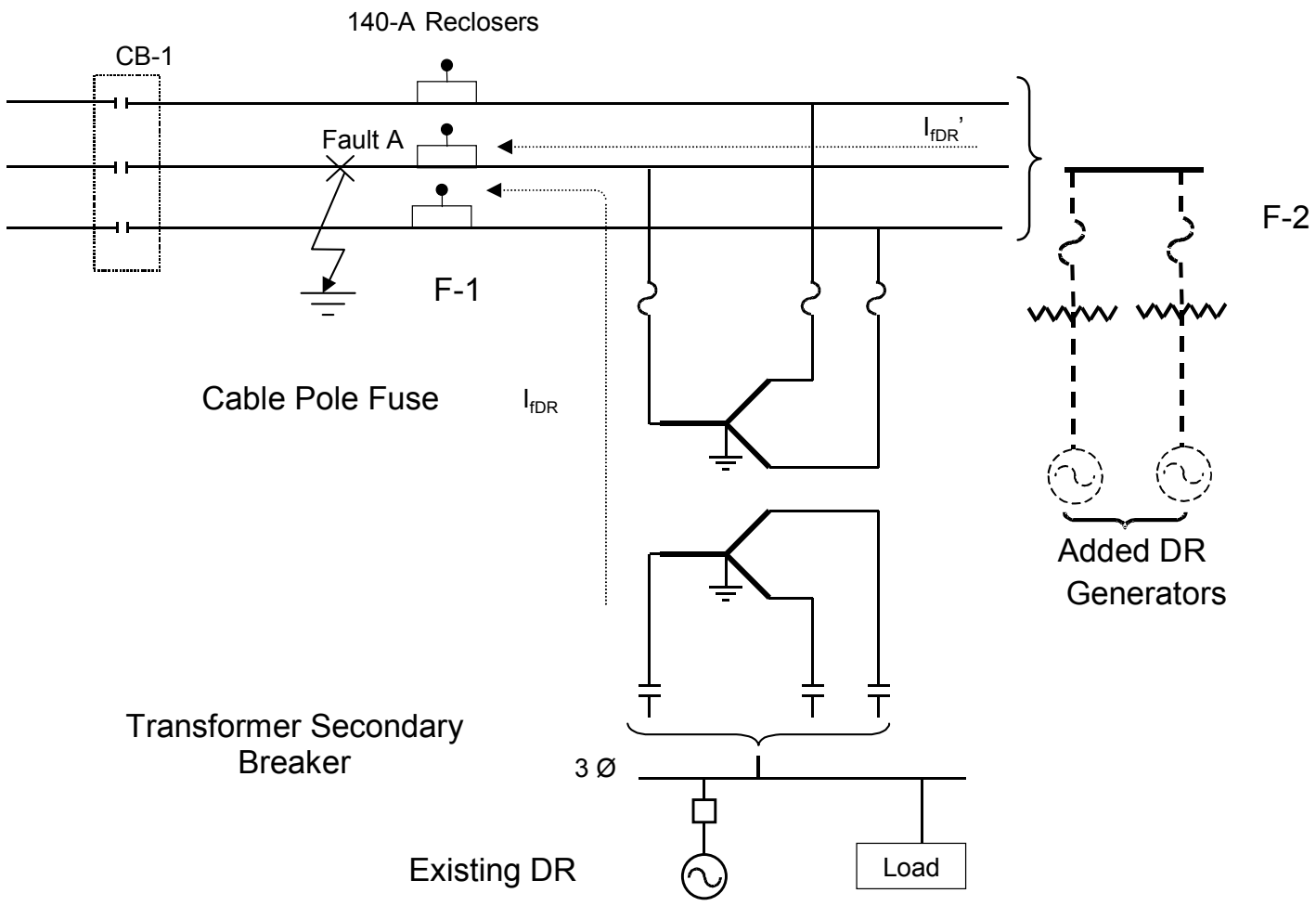

Figure 22. Line-to-ground fault causes single-phase sectionalizing device to operate because of DR fault current conditions

This condition is nearly identical to the condition presented in Issue16. Although the effects of these faults are similar to those discussed in Issue16, single-phase faults that cause singlepole operation of the reclosers in Figure 22, or an open phase, will result in unbalanced load currents and, consequently, negative-sequence generator currents.

Without the existing DR connected to the circuit, the normal fault-clearing process involves opening the CB-1 line breaker to eliminate the source of the $\mathrm{I}_{\mathrm{fS}}$ fault current to the fault "A." Because there is no DR connected with the system in this case, no fault current will flow through the single-phase recloser to the fault. 
When the first DR (shown as "Existing DR") is added to the circuit, the typical system protection scheme includes an overcurrent relay that operates the CB-1 breaker, sectionalizing devices (recloser or fuses), a cable pole fuse for the DR, a transformer secondary breaker, and a DR breaker.

For a fault at the generator terminals, there is fault current from the area EPS, and the protective devices are coordinated to operate because of overcurrent in the following order:

1. DR breaker

2. Secondary transformer breaker

3. Cable pole fuse F-1

4. Recloser or line fuses

5. CB-1 line breaker.

Proper coordination will result in only the DR breaker operating for a fault at its terminals. The remaining devices will operate only if one or more fail to operate correctly.

For a fault at "A," $\mathrm{I}_{\mathrm{fDR}}$ fault current will flow from the DR to the fault at "A," and $\mathrm{I}_{\mathrm{fS}}$ will flow from the substation to the fault at "A." In this case, $\mathrm{I}_{\mathrm{fDR}}$ current is the same through each protective device from the DR to the fault. It is not important whether the DR breaker or CB-1 breaker operates first, as long as the DR breaker or the CB-1 breaker isolates the fault. However, it is important that the DR breaker open before the transformer secondary breaker, cable pole fuse, and sectionalizing devices open.

If it is desired that the DR continue to serve its load, then directional overcurrent relays should be installed on the transformer secondary breaker to open it and permit the DR breaker to remain closed and serve local load.

When additional DRs are connected with this circuit, the total fault current $\left(\mathrm{I}_{\mathrm{fDR}}+\mathrm{I}_{\mathrm{f}^{\prime} \mathrm{DR}}\right)$ through the sectionalizing devices (reclosers or fuses) is the sum of the existing DR and additional DR fault contributions. This additional current may cause the sectionalizing device to open before the DR breaker on any DRs open. This condition could result in the DRs serving an islanded load, which may or may not be desirable. If the condition is undesirable, then the DR breaker must be opened, and the load is temporarily lost because of the recloser being open but not locked out (after three to four openings). Now, the fault condition is removed before the recloser is automatically reclosed. The CB-1 breaker will reclose automatically (because of the reclosing relay operation), which restores service to the circuit load. Note that the DRs have remained off line to permit this desirable operation to occur. The DRs can now return to normal operation through re-synchronizing operation with the system. 
For a permanent single-phase fault such that the fault current from the DRs causes only one single-phase recloser to lock out (assuming CB-1 is open), the DRs may remain online and serve the single-phase loads on the unfaulted phases between the reclosers (closed contacts) and CB-1 breaker and serve three-phase load downstream from the reclosers. This situation may cause severe load imbalance for the DRs and could result in enough negative-sequence current to overheat the DR generators. Normally, DR generators are equipped with negativesequence protection to trip the DR units.

Where three single-phase fuses are used in lieu of three single-phase reclosers, the fault current from the DRs causes the fuse on the faulted phase to blow, which results in the loss of loads on the faulted phase from the substation to the fuse. The DRs could continue to serve the unfaulted phase single-phase loads upstream and all load (three-phase and single-phase) downstream of the open fuse. If the DRs cannot serve the load and the fault at " $\mathrm{A}$ " is cleared, CB-1 could automatically reclose and serve all load upstream of the previously faulted phase and downstream from the open fuse because of the primary windings of the distribution transformer being connected phase to phase. However, the voltage on the phase with the open fuse may be low. This condition could go undetected - especially if DRs are operating downstream - until there is notification from customers served by the previously faulted phase.

The most desirable case is when the DR breakers open, the fuses are not blown, the fault is temporary, the CB-1 opens and recloses after the fault is cleared, all load (circuit and DR) is restored, and the DRs are re-synchronized.

\subsubsection{Scenario}

- A fault occurs on the circuit at "A," between the substation line CB and the sectionalizing device (single-phase reclosers or fuses).

- Current flows from the substation transformer $\left(\mathrm{I}_{\mathrm{fs}}\right)$ and the $\mathrm{DR}\left(\mathrm{I}_{\mathrm{fDR}}\right)$ to the fault.

- Current from the existing DR is sensed by a local device (F-1) and the sectionalizing devices (single-phase reclosers or fuses).

- Current from the additional DRs on the circuit may cause the sectionalizing devices to open before the F-1 and F-2 fuses operate.

\subsubsection{Question}

Assume the protective devices at an existing DR will isolate the DR from the system prior to the recloser opening (without additional DRs). How much additional DR capacity can be added to cause the recloser to open sooner than when the protective device (F-1) on the existing DR operates?

\subsubsection{User Interface Description}

See User Interface Definition for Issue 16 (Section 2.5.3).

\subsubsection{Associated Algorithm}

See Associated Algorithm for Issue 16 (Section 2.5.4). 


\section{$3 \quad$ Part 2: Methodology for Assessing Voltage and Stability Effects of Distributed Generation}

Part 2 of this report describes the methodology used to conduct the studies of Edison Electric Institute issues $8,11,21$, and 22; presents the models and equivalent circuits used; and outlines the applicable solution algorithms.

\subsection{Introduction}

A previous project that involved case studies of two feeders in suburban Michigan assessed the following issues identified by the Edison Electric Institute as related to the penetration of distributed generation (DG) on distribution feeders:

- Issue 8: Harmonics

- Issue 11: Voltage regulation malfunctions

- Issue 21: Dynamic stability during fault conditions

- Issue 22: Loss of exciters causes low voltage.

The scope covered DG technologies based on directly connected rotating synchronous machines as well as units that use a power converter interface (e.g., photovoltaics, microturbines, fuel cells, and some forms of wind turbines). The objective was to identify the aggregate DG capacity that could be installed on a feeder without unduly affecting operations.

\subsection{Modeling Techniques}

Distribution feeders are radial in nature. They are supplied from a common bus, which, in turn, is supplied from a high-voltage grid network through step-down transformers. They incorporate a feeder, or backbone, that serves some loads directly and others from lateral branches. To assess the effect of DG on such feeders, a detailed model was needed of the distributed backbone, the laterals, the major loads, and intervening regulating equipment (e.g., capacitors and voltage regulators).

\subsubsection{Distribution Bus}

Primary feeders originate at distribution substations and are supplied from a distribution bus with known three-phase and line-to-ground fault current levels $\left(\mathrm{I}_{\mathrm{f} 3 \phi}\right.$ and $\mathrm{I}_{\mathrm{fSLG}}$, respectively) or three-phase short circuit capacity $\left(\mathrm{I}_{\mathrm{sc} 3 \phi}\right)$ as measured in megavolt-amperes. These allow the power system upstream of the substation bus to be modeled by a Thevenin network, defined as a constant voltage source behind a fixed impedance (series R, L). The three-phase short circuit capacity yields positive-sequence series reactance (in consistent units):

$$
X_{1}=\frac{V_{L-G}}{I_{f s 3 \phi}}=\frac{V_{L-L}^{2}}{I_{s c 3 \phi}}
$$

and zero-sequence reactance: 


$$
X_{0}=\frac{3 V_{L-G}}{I_{f S L G}}-2 X_{1} \quad \text { [Equation 2]. }
$$

The resistance may be obtained from an assumed $\mathrm{X} / \mathrm{R}$ ratio (typically $5-10$ for positive sequence and 5-15 for zero sequence), though it may be neglected here without materially affecting findings.

\subsubsection{Feeder Backbone}

The physical layout of a typical distribution feeder is depicted in Figure 23. Nodes on the feeder correspond to locations where the physical conductor configuration is altered for a tap to supply a load, a lateral to serve a group of loads, or equipment such as fuses, reclosers, capacitors, or transformers. This level of feeder segmentation is generally needed for the types of studies contemplated here.

Each discrete section is modeled by a balanced pi section consisting of a longitudinal impedance branch (series R, L) between the terminals and an identical shunt admittance (capacitance) branch at each terminal. The model for the complete feeder is therefore a cascaded pi network —often comprising 50-100 nodes - with loads supplied from the nodes.

Branch parameters are determined from per-unit length parameters for the particular conductor configuration and are scaled by the length of the feeder section. Most feeders use no more than a handful of conductor configurations, and normalized parameters for these configurations are generally available from planning studies. If not, they can be determined analytically from the physical geometry as described in Appendix E.

Finally, in preparation for modeling, it is useful to assemble feeder data as follows:

- Prepare a list of the various conductor configurations (overhead and underground) and include the corresponding per-unit length positive- and zero-sequence longitudinal impedance $\mathrm{Z}(\mathrm{R}$ and $\mathrm{L}$ ) and shunt admittance $\mathrm{Y}(\mathrm{C})$. (See Table 1.)

- Compile a list of individual feeder segments in terms of terminal node identifications, conductor configurations, and individual segment lengths. (See Table 2.)

- Organize load data into two lists. The first list includes large - mostly industrial and commercial — spot loads that can be considered concentrated at particular locations on the feeder. (See Table 3.) The second list includes aggregated loads that are distributed over a feeder segment. (See Table 4.) For modeling purposes, the latter are split equally between the terminal nodes. 


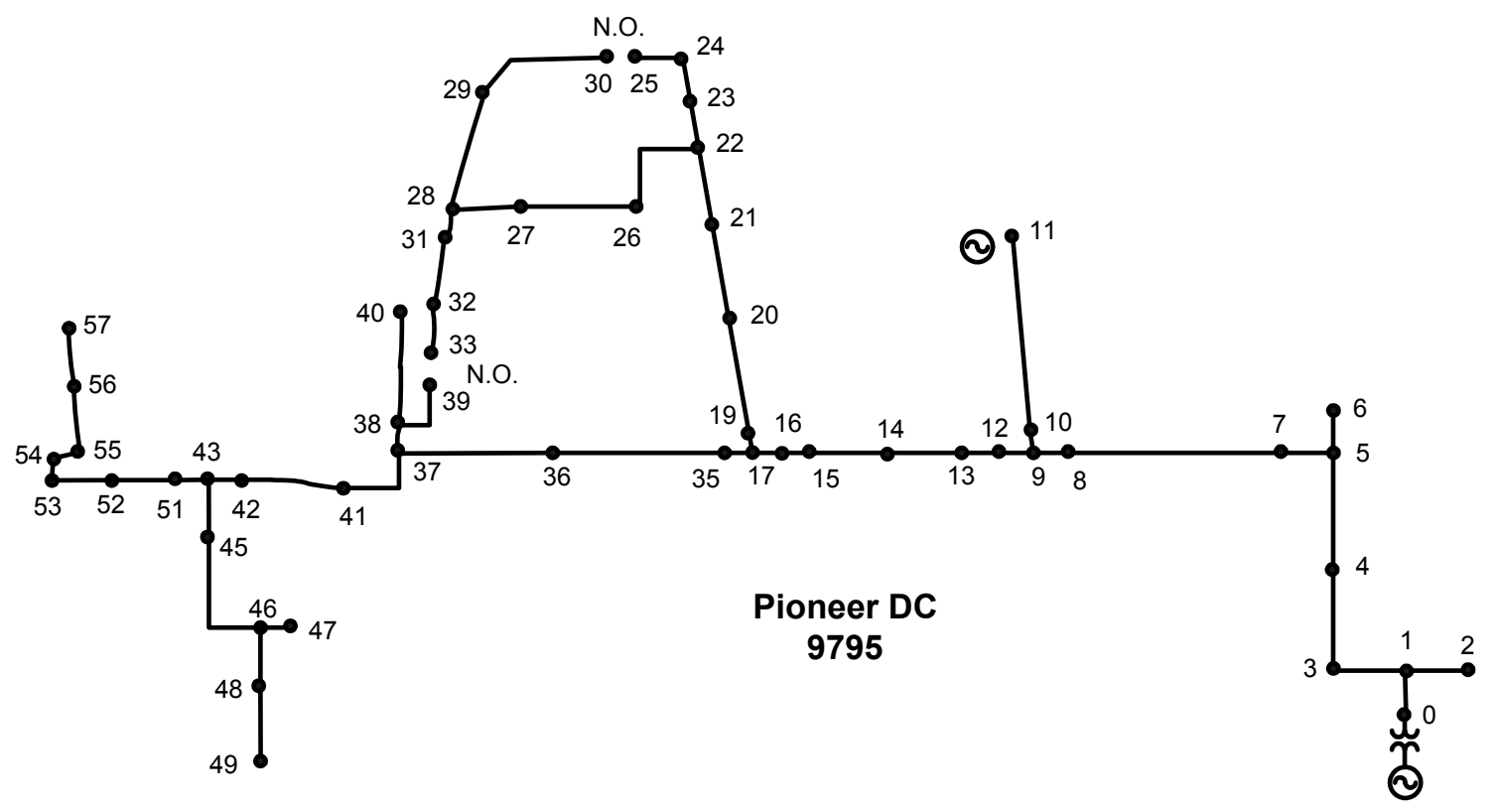

Figure 23. General layout of the main trunk of the 13.2-kV Pioneer feeder

Table 1. Sample Feeder Configuration Data

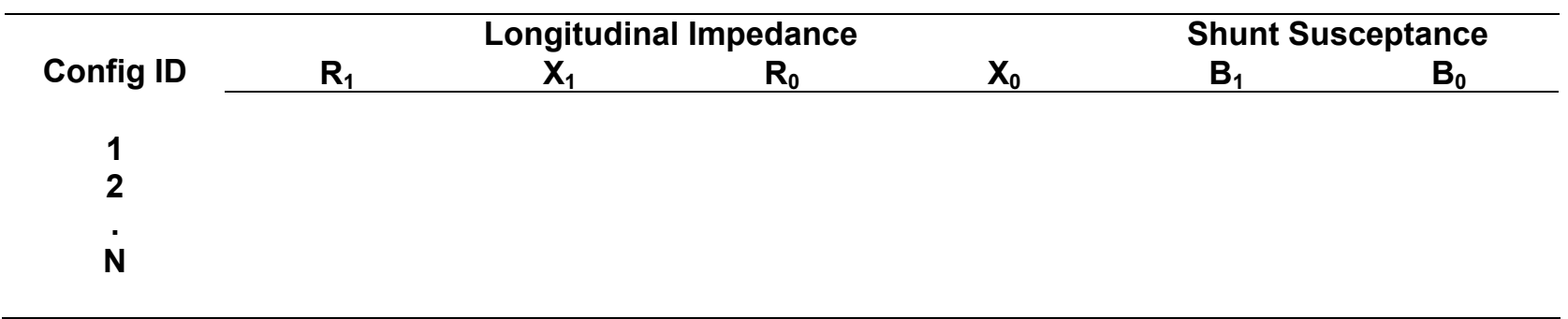

Table 2. Sample Listing of Data Requirements for Feeder Segments

$\begin{array}{llll}\text { From Node } & \text { To Node } & \text { Config. ID } & \text { Section Length }\end{array}$

Table 3. Listing of Spot Loads

$\begin{array}{lll}\text { Node } & P_{\mathrm{S}}(\mathrm{kW}) & \mathbf{Q}_{\mathrm{S}}(\mathrm{kVAr})\end{array}$


Table 4. Listing of Distributed Loads

\begin{tabular}{llll} 
Node1 & Node2 & $P_{\mathrm{S}}(\mathrm{kW})$ & $Q_{\mathrm{S}}(\mathrm{kVAr})$ \\
\cline { 2 - 3 }
\end{tabular}

It should be noted that distribution feeders are generally not transposed. Therefore, the selfand mutual impedances among phases are not alike. Mathematically, this means the impedance and admittance matrices are unbalanced (though still symmetric), which, in turn, implies there are no pure positive, negative, or zero sequence representations for this feeder configuration. A simplifying assumption normally made in distribution analysis to circumvent this problem treats the phase conductors as if they were continuously transposed. In this event, the sequence representations are rigorously defined.

\subsubsection{Loads}

In principle, loads can be characterized as constant impedance, constant current, or constant power. This distinction can matter in load-flow studies under stressed system conditions whereby the load voltage deviates sufficiently from normal values. However, for the types of generic impact studies contemplated here, this distinction was neglected to simplify analysis. Accordingly, all loads were modeled as constant impedance, lumped series R-L branches, determined as:

$$
\begin{array}{lll}
R=\frac{V^{2} \cdot P F}{s_{3 \phi}}, \quad(\mathrm{k} \Omega) & \text { [Equation 3] } \\
X=\omega L=\frac{V^{2} \cdot \sqrt{1-P F^{2}}}{s_{3 \phi}}, & (\mathrm{k} \Omega) & \text { [Equation 4], }
\end{array}
$$

with $\mathrm{S}_{3 \phi}$ denoting the specified three-phase load (kilovolt-amperes), PF denoting load power factor, and $\mathrm{V}$ representing the three-phase root mean square (rms) system line-to-line voltage (kilovolts) at rated frequency radians per second.

\subsubsection{Capacitor Banks and Cables}

Capacitor banks and cable laterals are modeled as lumped capacitive loads. For capacitor banks, branch susceptance is determined as:

$$
B=\omega C=\frac{Q_{3 \phi}}{V^{2}}, \quad(\text { mhos }) \quad \text { [Equation 5], }
$$

with $\mathrm{Q}_{3 \phi}$ (megavolt-amperes reactive) and $\mathrm{V}$ (in kilovolts) denoting the three-phase bank rating. 
Significant lengths of cables, either in the backbone or for laterals serving loads, can materially influence the harmonic response of feeders. As such, these should be included as lumped capacitors at the respective nodes based on published values.

\subsubsection{Voltage Regulators}

Tap-changing regulators were not modeled because the focus of this project is momentary voltage sags and swells such as those caused by temporary faults (or even loss of excitation on rotating DG units). Conventional tap-changing regulators are too slow to respond to such disturbances.

\subsection{Analysis}

The fundamental feeder model, as outlined above, is largely suitable for assessing the identified issues. The following describes the required analytic approach.

\subsubsection{Issue 8: Harmonics}

Power converter-based DG could produce current waveforms that contain significant harmonics relative to the output of traditional (rotating) generators. These harmonics give rise to voltage distortion, the severity of which depends on the impedance exhibited by the feeder at the point of current injection. Therefore, it is necessary to characterize the harmonic impedance characteristic of the feeder, as seen from the DG location, to assess its effect on harmonic voltage distortion. This can be done as follows:

1. Assemble the nodal admittance matrix (Y) for the feeder as shown in Appendix F. Large generators existing on the feeder should be modeled by their nameplate subtransient inductance from $60-\mathrm{Hz}$ reactance.

2. Compute the mesh impedance matrix $(\mathrm{Z})=(\mathrm{Y})^{-1}$.

3. Inject $1 \mathrm{~A}$ current at the DG location and compute the resulting voltage profile at all nodes on the feeder (for the specified frequency) as follows. (See Figure 24.) In the column current vector (I), set all entries at zero except for the row corresponding to the DG location. Compute the nodal voltage vector $(V)=(Z)(I)$.

4. Repeat the above steps for frequency corresponding to the individual harmonics over a range extending from power frequency to the 200th harmonic (given the high frequency of modern power converters).

Note that the computed voltages represent driving point and transfer impedances for a singlephase harmonic source. The critical resonant modes for the feeder are those corresponding to a local impedance maxima on the computed impedance-versus-frequency characteristic (as, for example, illustrated in Figure 25). The peak impedance values represent the harmonic voltage produced at the respective node because of injecting one ampere of harmonic current. 


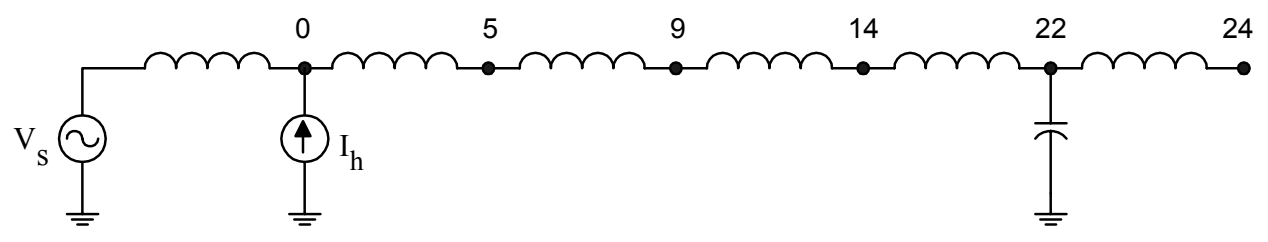

Figure 24. Harmonic current injection at DG location on simplified representation of feeder incorporating capacitor bank for voltage regulation

(distributed feeder capacitance not shown)

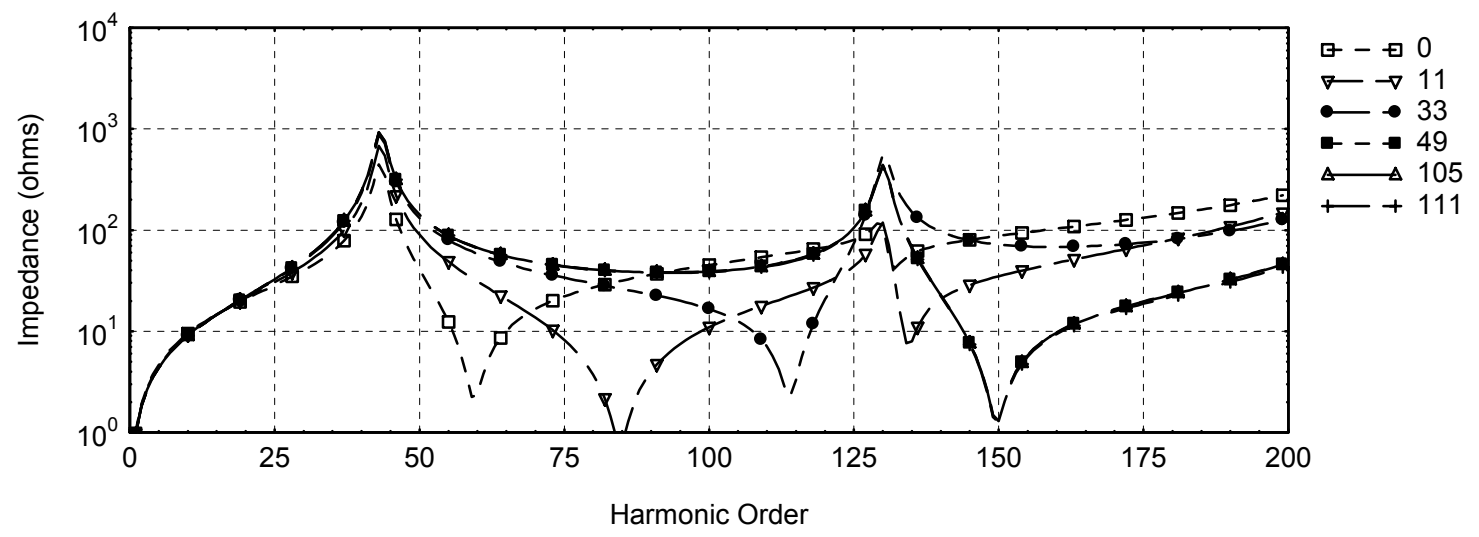

Figure 25. Example of harmonic impedance characteristic for Pioneer feeder

But what is the maximum size of inverters that can be connected at a particular point on the circuit, given that maximum permissible voltage distortion at any single frequency is $3 \%$ and that the inverters must meet industry harmonic emission limits?

The answer depends on the type of DG converter being considered. For those using older, line-commutated switching technology, the frequencies of interest extend to about the 15th harmonic, and the permissible injection limit is $4 \%$ of rated current. In comparison, modern converters that use pulse-width mode-switching inject harmonics principally at frequencies beyond about the 35th harmonic. The associated injection limit is $0.3 \%$ of rated current.

Therefore:

1. Scan the computed impedance spectra and identify the local impedance maxima (denoted here as $Z_{\mathrm{m} 15}$ and $Z_{\mathrm{m} 35}$, respectively) over the frequency ranges.

2. Note that the permissible magnitude of voltage distortion is $3 \%$ of system voltage (i.e., 0.03 times the line-to-ground or line-to-line voltage, depending on whether the resonance corresponds to line mode or ground mode). Therefore, the associated limits on the magnitude of harmonic current injected over the respective frequency ranges is determined as follows, with $V_{\mathrm{S}}$ denoting the line-to-ground or line-to-line voltage in volts: 


$$
\left|I_{h 15}\right|=\frac{0.03 V_{S}}{Z_{h 15}} \quad,(\mathrm{~A})
$$

[Equation 6]

and $\quad\left|I_{h 35}\right|=\frac{0.03 V_{S}}{Z_{h 35}}$, (A)

[Equation 7]

for resonant frequencies up to the 15th and beyond the 35 th harmonic. The $\mathrm{I}_{\mathrm{h}}$ is the current at the $\mathrm{h}$ harmonic, and $\mathrm{Z}_{\mathrm{h}}$ is the impedance at the $\mathrm{h}$ harmonic.

3. The corresponding maximum permissible current ratings $\left(\mathrm{I}_{\mathrm{r}}\right)$ for converters meeting harmonic current emission requirements ( $4 \%$ below the 15 th harmonic and $0.3 \%$ beyond the 35th harmonic) are determined as:

$$
\left|I_{r}^{h 15}\right|=\frac{I_{h 15}}{0.04}=\frac{3 V_{S}}{4 Z_{h 15}},
$$

[Equation 8]

and $\left|I_{r}^{h 35}\right|=\frac{I_{h 35}}{0.003}=\frac{10 V_{S}}{Z_{h 35}}$,

[Equation 9].

4. Accordingly, the maximum permissible converter power ratings $\left(\mathrm{S}_{\mathrm{DGmax}}\right)$, as dictated by each of the harmonic resonance peaks over the respective frequency ranges (determined as $\sqrt{3} I^{\mathrm{R}} \mathrm{V}_{\mathrm{S}}$ in consistent units), is given by:

$$
\begin{array}{rlrlrl}
S_{D G \max } & =\frac{3 \sqrt{3} V_{S}^{2}}{4 Z_{h 15}}, \mathrm{kVA} & & \text { [Equation 10] } \\
\text { and } & S_{D G \max } & =\frac{10 \sqrt{3} V_{S}^{2}}{Z_{h 35}}, \mathrm{kVA} & & \text { [Equation 11]. }
\end{array}
$$

For a general assessment study, DG locations should be chosen to include the backbone as well as remote ends of laterals. In principle, one should also inject negative $1 \mathrm{~A}$ on a second phase while applying $1 \mathrm{~A}$ on Phase A to excite phase-to-phase modes. This requires modeling each feeder as a three-phase network and is best carried out using more advanced simulation software such as the EMTP.

\subsubsection{Issue 11: Voltage Regulation Malfunctions}

All issues related to voltage regulation malfunction require a load flow solution, as described in Appendix F, for the specified loading conditions. This section addresses the question, What are the maximum real power $(\mathrm{P})$ and reactive power $(\mathrm{Q})$ injections from a $\mathrm{DR}$ that will not cause voltage limit violations at particular points on the feeder? 
The question can be answered by carrying out a load flow solution with different DG output values until the limiting value at which voltage deviates beyond permissible limits is found. Alternatively, the following approach, based on determining the approximate Thevenin source impedance as viewed from the DG location, can be used:

1. Simulate a three-phase fault at the DG location by connecting a suitably large admittance at the DG node. In practice, this amounts to connecting a very large (preferably reactive) load at the DG node, such that the corresponding diagonal entry in the admittance matrix $(\mathrm{Y})$ is perhaps 10-100 times larger than all the other diagonal entries. The resulting load flow solution should confirm that this causes the voltage at the node to approach ground potential. The ratio of the resulting voltage at the distribution bus and the feeder current defines the impedance $Z_{\mathrm{FDR}}$ between the fault location and the distribution bus:

$$
Z_{F D R}=R_{F D R}+j X_{F D R}=\frac{V_{D S}}{I_{F D R}}=\frac{V_{D S}}{I_{N}-Y_{N} V_{D S}} \quad \text { [Equation 12], }
$$

where $\mathrm{I}_{\mathrm{N}}$ is the Norton current source of the DR.

2. $Z_{\mathrm{FDR}}$ is augmented by the Thevenin source impedance $\left(\mathrm{R}_{1}+j \mathrm{X}_{1}\right)$ at the distribution bus to yield the source impedance from the DG:

$$
Z_{S}=R_{S}+j X_{S}=\left(R_{1}+R_{F D R}\right)+j\left(X_{1}+X_{F D R}\right) \quad \text { [Equation 13]. }
$$

3. Then, for typical feeders operating at a relatively small power factor angle, the scalar voltage difference between the distribution bus and the DG terminal can be approximated as:

$$
\Delta V=I R_{S} \cos \theta+I X_{S} \sin \theta=R_{S} \frac{P_{D G}}{V_{D G}}+X_{S} \frac{Q_{D G}}{V_{D G}} \quad \text { [Equation 14], }
$$

which corresponds approximately to the voltage change caused at the DG terminal by the change in real or reactive power flow on the feeder (in consistent units-i.e., normalized or absolute quantities). Therefore, Equation 14 answers the question given above.

\subsubsection{Issue 21: Dynamic Stability During Fault Conditions}

Transient stability is the ability of synchronous generators to remain in synchronism with the grid when subjected to a severe momentary disturbance such as a fault on a nearby DC or subtransmission line. In the context of DG, the question is, What is the critical fault-clearing time such that synchronous generators can remain stable when faults occur either close to or remote from the DG? 
Some utilities prefer that DGs be isolated immediately upon evidence of certain disturbances on the grid, including nearby faults. However, because faults are often cleared by protective apparatus, in some instances, it may be prudent not to trip a DG immediately. This reduces the likelihood of DGs tripping unnecessarily and enhances grid reliability by improving the availability of generating resources under stressed grid conditions. In this event, the question becomes, How quickly must faults be cleared before a DG is inherently forced off line because of loss of synchronism?

The fundamental concepts and principles of transient stability can be analyzed with very simple models - particularly in the context of DG facilities, which are modestly rated compared with conventional bulk power generation and are therefore likely to be equipped with basic excitation systems. Advanced excitation system features, such as a power system stabilizer, tend to enhance transient stability. In this sense, simplified models yield more conservative conclusions.

The generator is represented by the classical machine model, with a voltage E' behind the transient machine reactance Xd' (see Figure 26). Speed governor effects are neglected. The rotor angle $\delta$ represents the angle by which E' leads the voltage at the reference bus $E_{R}$, taken here as the main distribution bus supplying the feeder. When the system is disturbed, the magnitude of E' remains constant at its pre-disturbance value (because field excitation is assumed to remain constant), and $\delta$ changes as the generator rotor speed deviates from the synchronous speed.

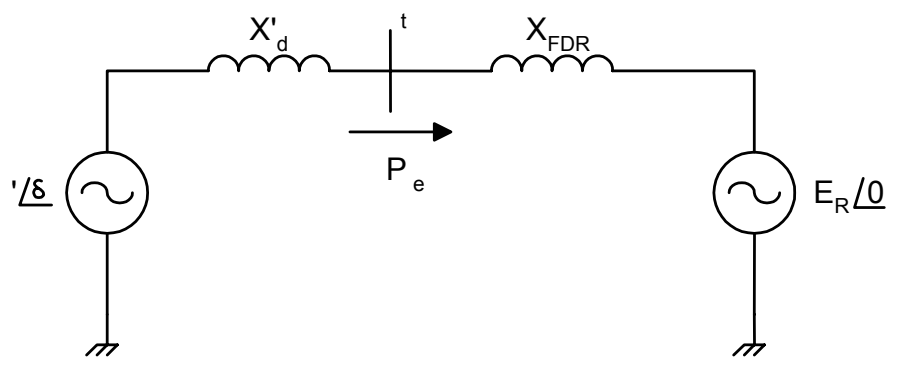

Figure 26. Reduced equivalent circuit depicting single-machine infinite bus system

The calculation, based on applying the classical equal area criterion for analysis of singlemachine infinite bus systems, is:

1. Reduce the system model to the form shown in Figure 26. Here, $E_{t}$ is the voltage at the machine terminals (all quantities in pu of machine rating) as obtained from a load flow solution, and $\mathrm{X}_{\mathrm{T}}$ is the sum of $\mathrm{X}_{\mathrm{d}}{ }_{\mathrm{d}}$ and the reactance of the feeder from the machine terminal to the distribution bus. Given the DG real power output $P_{e}$, the internal voltage $\mathrm{E}^{\prime}$ is determined as:

$$
E^{\prime}=E_{t}+j X_{d}^{\prime} I_{t}=E_{t}+j X_{d}^{\prime} \frac{P_{e}}{E_{t}}, \quad(\mathrm{pu}) \quad \text { [Equation 15] }
$$


and the rotor angle as:

$\delta=\sin ^{-1}\left(\frac{X_{T} P_{e}}{E^{\prime} E_{R}}\right), \quad$ (radians) $\quad$ [Equation 16].

2. Solve for the positive-sequence voltage at machine terminals during the disturbance. Three-phase faults are the easiest to analyze and result in worst-case conditions for instability. The voltage at the machine terminals drops to nearly ground potential for nearby (three-phase) faults. For more distant faults, see Section 3.3.2.

3. Determine the change in machine loading $\left(\mathrm{dP}=\Delta \mathrm{V}_{1}, \cos \theta\right)$, expressed per unit of machine rating, by multiplying the per-unit drop in positive sequence voltage during the fault by the machine power factor. The greater $\mathrm{dP}$ becomes the smaller critical clearing time.

4. Determine the maximum permissible clearing time $t$ as:

$$
t=\sqrt{\frac{H\left(\frac{\pi}{2}-\delta\right)}{5400 d P}}, \quad \text { (s) [Equation 17] }
$$

with $\mathrm{H}$ denoting the combined generator and turbine inertia constant $(\mathrm{kW} \bullet \mathrm{s} / \mathrm{kVA})$ and representing the time taken by the machine to accelerate from standstill to $0.5 \mathrm{pu}$ rated speed with rated applied mechanical torque. This assumes the fault is isolated such that the feeder remains substantially intact or, more rigorously, that the postdisturbance value for $\mathrm{X}_{\mathrm{T}}$ is substantially the same as its pre-disturbance value. The worst-case condition is when the generator is operating at full load.

A more detailed modeling approach may be warranted in cases involving multi-machine systems or those equipped with more sophisticated excitation controllers.

\subsubsection{Issue 22: Loss of Excitation Causes Low Voltage}

A sudden loss of excitation to a synchronous generator will cause it to operate temporarily as a motor, with the grid supplying the excitation. Thus, loss of DG excitation is associated with an increase in reactive demand on the feeder, which causes a regulation voltage drop along the feeder. This can be a concern from a power-quality perspective because nearby customers may be subjected to undesirable voltage sags. Thus, the question is, What is the maximum DG size that can be installed at certain nodes without exceeding the $10 \%$ voltage dip created by loss of excitation? Or alternatively, how much voltage sag will result from a loss-ofexcitation event on a particular DG? 
A loss-of-excitation event contributes to voltage sag by curtailing DG output, which is addressed in Issue 11, and placing an added reactive burden on the feeder. The latter can be analyzed in the same manner as Issue 11 by connecting a load equal to generator synchronous reactance (typically $1-2$ pu on rating or a reactive loading of $0.5-1$ pu of machine rating) at the respective feeder node. Xd equals $1-2$ pu.

Alternatively, one can carry out a detailed load flow calculation, initially with the DG operating at a prescribed output and then with the DG replaced by a reactive load that corresponds to the generator synchronous reactance. 


\section{References}

[1] Davis, M.W.; Costyk, D.H.; Narang, A. Distributed and Electric Power System Aggregation Model and Field Configuration Equivalency Validation Testing. NREL/SR560-33909. Golden, CO: National Renewable Energy Laboratory, July 2003.

[2] Davis, M.W. Edison Electric Institute Planning, Operations, and Interconnection Distributed Resources Task Force 29 Issues. September 1999.

[3] Kundur, P. Power System Stability and Control. New York: McGraw Hill, 1993. 


\section{Appendix A: Edison Electric Institute 29 Issues}

Table A-1. Edison Electric Institute 29 Issues

\begin{tabular}{cll}
\hline & Issue & Description \\
\cline { 2 - 3 } Detroit Edison & 1 & Improper Coordination \\
Detroit Edison & 2 & Nuisance Fuse-Blowing \\
$*$ & 3 & Reclosing Out of Synchronism \\
$*$ & 4 & Transfer Trip \\
$*$ & 5 & Islanding \\
$*$ & 6 & Equipment Overvoltage \\
$*$ & 7 & Resonant Overvoltage \\
Kinectrics & 8 & Harmonics \\
$*$ & 9 & Sectionalizer Miscount \\
$*$ & 10 & Reverse Power Relay Malfunctions \\
Kinectrics & 11 & Voltage Regulation Malfunctions \\
$*$ & 12 & Line Drop Compensator Fooled by DRs \\
$*$ & 13 & LTC Regulation Affected by DRs \\
$*$ & $14 a$ & Substation Load-Monitoring Errors \\
$*$ & $14 b$ & Cold Load Pickup With and Without DRs \\
Detroit Edison & 15 & Faults Within a DR Zone \\
Detroit Edison & 16 & Isolate DR for Upstream Fault \\
$*$ & 17 & Close-In Fault Causes Voltage Dip - Trips DR \\
$*$ & 18 & Switchgear Ratings \\
$*$ & 19 & Self-Excited Induction Generator \\
$*$ & 20 & Long Feeder Steady-State Stability \\
$*$ & 21 & Stability During Faults \\
$*$ & 22 & Loss of Exciters Causes Low Voltage \\
$*$ & 23 & Inrush of Induction Machines Can Cause Voltage Dips \\
$*$ & 24 & Voltage Cancelled by Forced Commutated Inverters \\
$*$ & 25 & Capacitor Switching Causes Inverter Trips \\
Kinectrics & 26 & Flicker From Windmill Blades \\
Kinectrics & 27 & Upstream Single-Phase Fault Causes Fuse-Blowing \\
* & 29 & Underfrequency Relaying \\
Detroit Edison & & \\
\hline & & \\
\hline & 27 isibution Automation Studies \\
\hline & & \\
$*$ & &
\end{tabular}

* These issues are not included in the scope of this report. 


\section{Appendix B: Time-Versus-Current Characteristics Database}

The ultimate database will include time-versus-current characteristics (TCCs) for commonly used protective relays, reclosers, and fuses.

An initial database would include:

- S\&C k-type universal link fuses (TCC 165), 6-200 A

- SMD 20 14.4-kV fuses TCC 153 and 165, 6-200 A

- $\quad$ ABB CO-8 relay curves TD 0.5-10

- IAC 53 relay curves TD $0.5-10$

- Basler 851 relay curves for ground faults: V2R

- Cooper recloser curves for 70 A, 100 A, 140 A, 200 A, 280 A type; V4L reclosers "a," "b," and "d" curves

- Cooper recloser and curves for Form 3A control curves for ground faults: 4 (fast), 6 (slow); phase: R (fast), C (slow)

- Cooper recloser curves for Form 5 control curves for ground faults: Kyle_106 (fast), Kyle_136 (slow); phase faults: Kyle_105 (fast), Kyle_133 (slow).

The time-versus-current curves can be a series of data points or an equation that provides tripping time as a function of current.

Some of the algorithms in this report require one to determine the current as a function of the tripping time. Therefore, inversion of the equation may be required to produce an equation that provides current as a function of tripping time. 


\section{Appendix C: Infeed Effects}

The effects of infeed are shown in the simple circuit below. Two sources are connected to a single node through separate impedances. The node is then connected to ground through a single impedance.

With the DR off, 1 A flows from the system source through the two 0.5-ohm impedances. The voltage at the node is $0.5 \mathrm{~V}$.

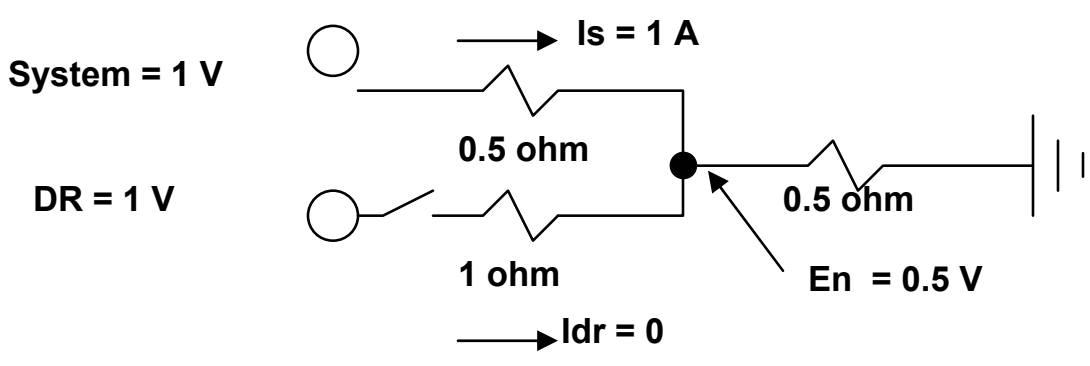

Figure C-1. Infeed circuit with DR off

With the DR on, the total current increases to $1.2 \mathrm{~A}$, with 0.8 A contributed by the system source and $0.4 \mathrm{~A}$ contributed by the DR source. The voltage at the node has increased to $0.6 \mathrm{~V}$ (or $1.2 \mathrm{~A} \times 0.5 \mathrm{ohms}$ ).

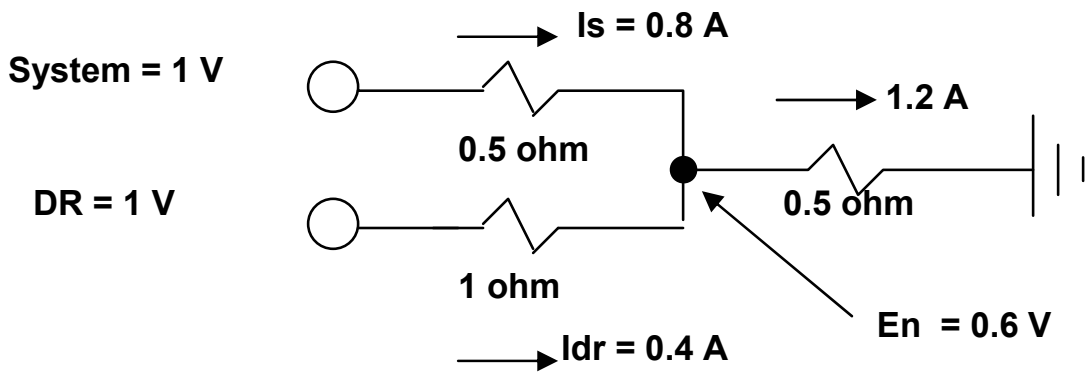

Figure C-2. Infeed circuit with DR on

Calculation notes:

- Because the source voltages are equal, the two sources can be treated as a single node.

- Then the source impedances can be treated as a parallel combination of impedances.

- The combined parallel impedance of $0.5 \mathrm{ohm}$ and $1 \mathrm{ohm}=1 / 3 \mathrm{ohm}$.

- $1 / 3 \mathrm{ohm}$ in series with $0.5 \mathrm{ohm}$ equals $5 / 6 \mathrm{ohm}$.

- Total current $=1 \mathrm{~V} /(5 / 6 \mathrm{ohm})=6 / 5 \mathrm{~A}=1.2 \mathrm{~A}$.

- System current $=(1 \mathrm{~V}-0.6 \mathrm{~V}) / 0.5 \mathrm{ohm}=0.8 \mathrm{~A}$. 
Note that additional current from the DR will raise the voltage at the node. This is due to additional current flowing through the grounded impedance. A higher voltage at the node will cause less current to flow from the system source. This is due to less of a voltage drop across the system source impedance.

Because the current contributed by the system source is less with the DR on, protective devices will become "less sensitive" to faults (represented by the ground on this system). The DR can, in this way, desensitize protective devices at other sources.

A more detailed description of infeed effects can be found in: Elmore, W.A. Protective Relaying Theory and Applications. Marcel Dekker, 1994.

\section{C.1 Penetration Curve Development}

The infeed curves can be developed directly from the infeed equations, as described above. Excel charts were created from the table that uses these equations. However, the spreadsheet uses only scalar quantities. The final version should be capable of accepting complex impedances in symmetrical component form.

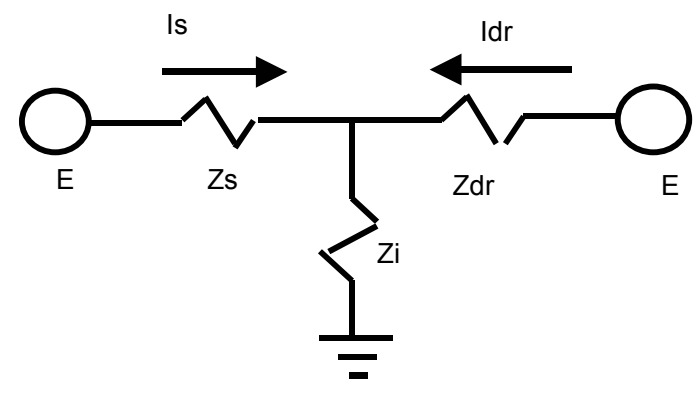

Figure C-3. The effects of infeeds 
Table C-1. Source Current (Is) and DR Current (Idr) for Per-Unit Source and DR Impedances (Three-Phase Faults Only)

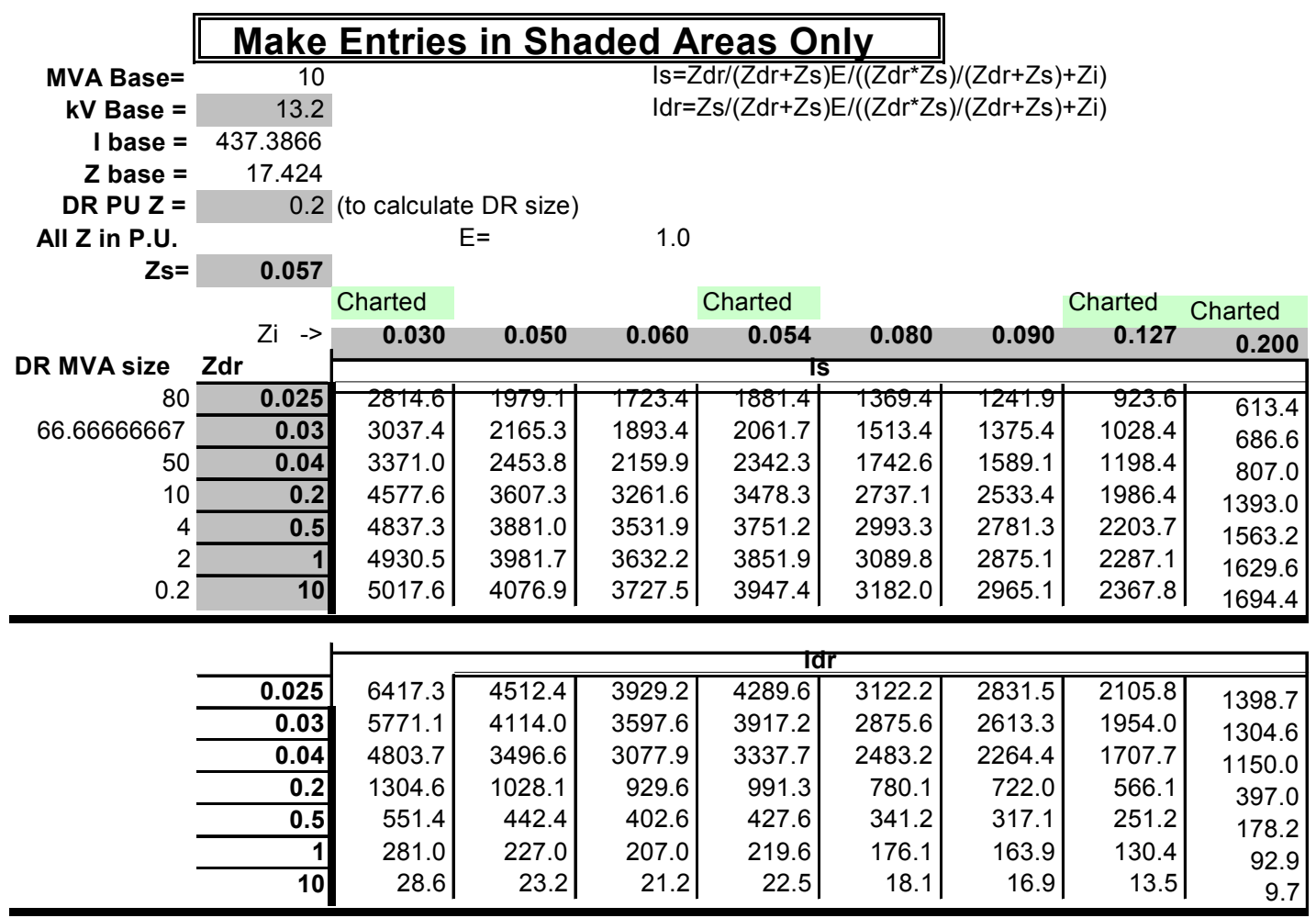

This table shows the effects of infeed for varouious lateral $(\mathrm{Zi})$ impedances and various DR impedances (Zdr) Currents are in amperes for a $13.2 \mathrm{kV}$ system The upper table shows the Source current. Each column represents a different line impedance $(\mathrm{Zi})$. Each row represents a different DR impedance (Zdr). The lower table shows the DR current (Idr) All calculations are for a fixed source impedance (Zs)

Spreadsheet to verify last equation

\begin{tabular}{|c|c|c|c|}
\hline & $\begin{array}{l}\text { Enter P.U. } \\
\text { E Zs Zi }\end{array}$ & $\begin{array}{l}\text { Enter } \\
\text { Desired } \\
\text { Is (amps) }\end{array}$ & \\
\hline Ils & 4.573 & 2000.000 & $I s=Z d r /(Z d r+Z s) E /\left(\left(Z d r^{\star} Z s\right) /(Z d r+Z s)+Z i\right)$ \\
\hline E & 1.000 & & $\mathrm{Idr}=Z \mathrm{~s} /(Z \mathrm{dr}+Z \mathrm{~s}) \mathrm{E} /\left(\left(Z \mathrm{dr} \mathrm{r}^{\star} \mathrm{Zs}\right) /(\mathrm{Zdr}+Z \mathrm{~s})+Z \mathrm{i}\right)$ \\
\hline Zs & 0.057 & & \\
\hline Zi & 0.127 & & \\
\hline$Z d r=$ & 0.209 & d DR Impedance & $\mathrm{Zdr}=\left(\mathrm{Zi}{ }^{\star} \mathrm{Zs}\right) /((\mathrm{E} / \mathrm{ls}-(\mathrm{Zs}+\mathrm{Zi}))$ \\
\hline
\end{tabular}




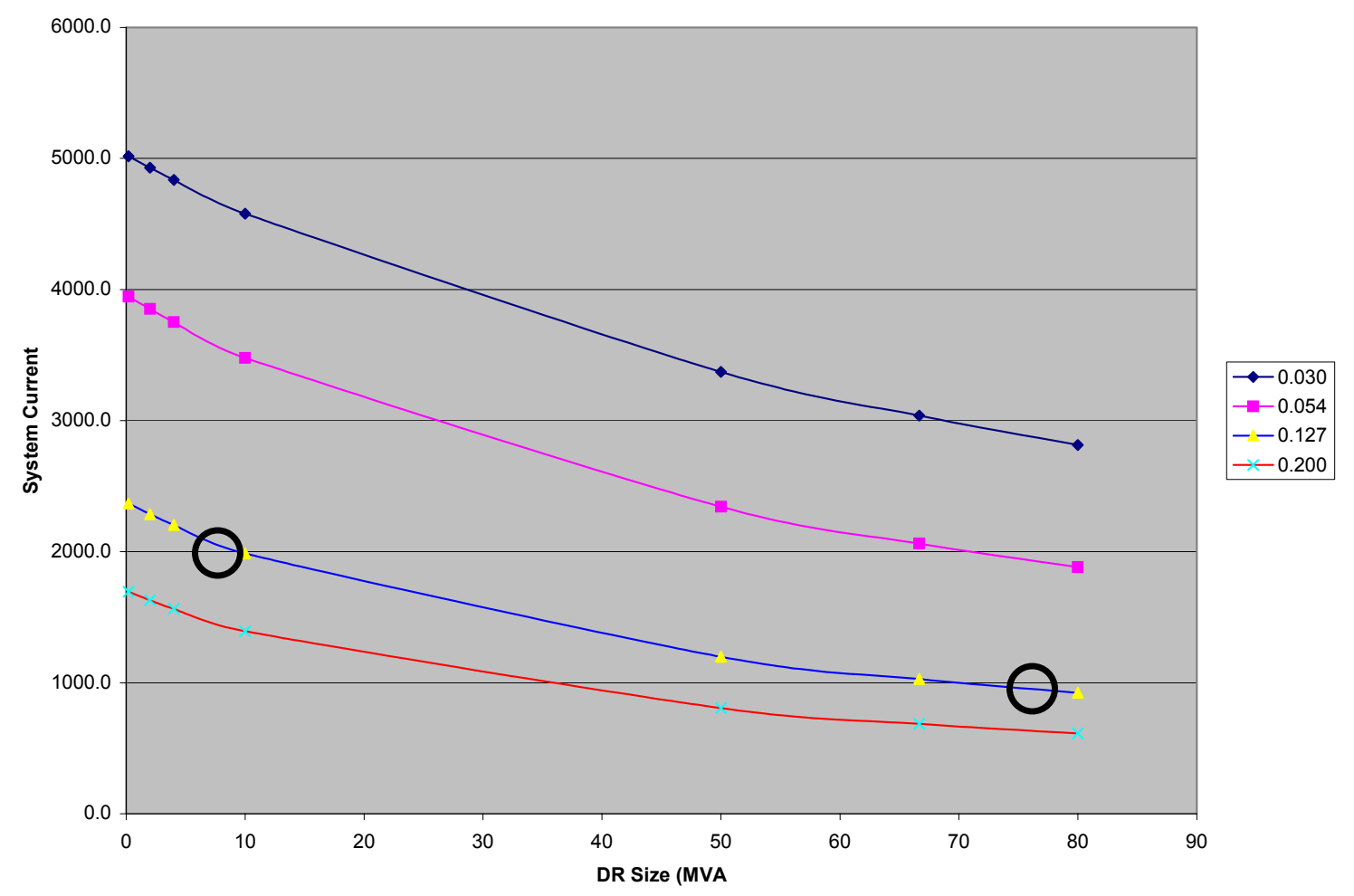

Figure C-4. The effect of DR size on system fault current

The above chart and table indicate the effect of adding DR generators to a circuit similar to DC 9795 Pioneer. Each line represents a different length from the substation. The second line from the top $(0.054 \mathrm{pu} \mathrm{Z})$ represents the length to Node 17 , the first sectionalizing point. The third line $(0.127 \mathrm{pu} Z)$ represents the length to Node 57.

As DR size increases, current through the substation breaker (system current) decreases. The chart is consistent with Aspen results that show an 80-MVA DR will reduce system current to 2,000 A for faults at Node 17. A 10-MVA DR will reduce system current to 2,000 A for faults at Node 57.

\section{C.2 Table Use and Restrictions}

The table uses a fixed source impedance and a fixed DR impedance. For different impedances, Zs and Zdr must be re-entered.

The spreadsheet and chart use only the magnitudes for voltage, current, and impedance. Therefore, they will not produce results identical to Aspen, which uses the magnitude and angle of all parameters. Circled areas represent the Aspen results of 10 and 80 MVA.

However, because the angles of the impedance of the DR, system, and lines are generally not more than $30^{\circ}$ apart, reasonable results can be obtained using only magnitude. This gets in the "ballpark." Results can be used for training and rough estimates. Final analysis for actual DR connections should be done with software that includes the angle of the impedances. 
Also note that the table and chart are meant to be used only for three-phase faults. Line-toground faults require that the zero sequence impedance be included. This was not done for this table or chart.

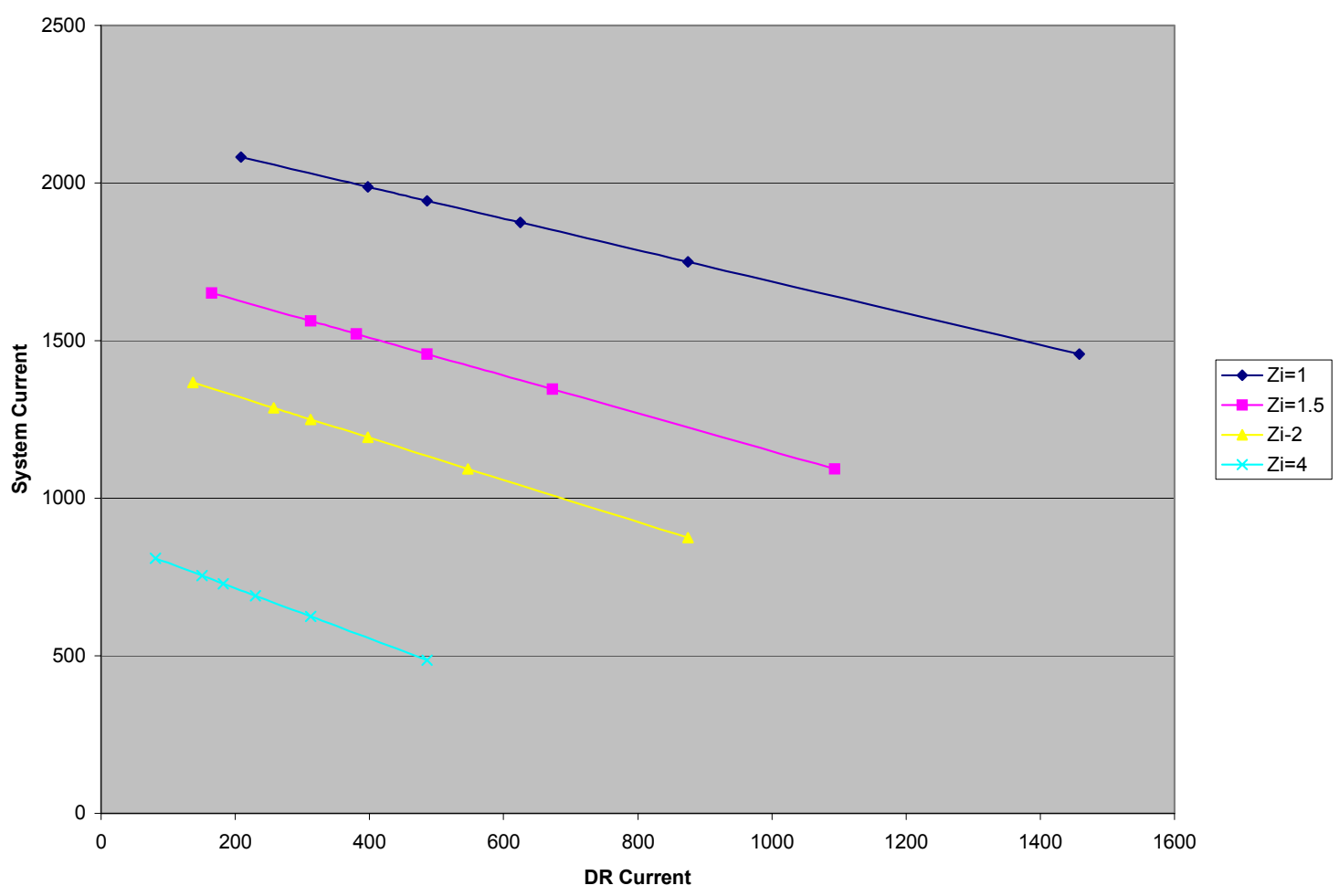

Figure C-5. The effect of DR fault contribution on system fault current 


\section{Appendix D: Issue 15: Faults Within the Distributed Resource Zone}

Table D-1. Faults Within the DR Zone

\begin{tabular}{lcrr}
\hline \multicolumn{1}{c}{ Condition } & $\begin{array}{c}\text { Total Fault } \\
\text { Current }\end{array}$ & $\begin{array}{c}\text { DR } \\
\text { Contribution }\end{array}$ & $\begin{array}{c}\text { System Fault } \\
\text { Contribution }\end{array}$ \\
\cline { 2 - 4 } No DR on & $5,011 \mathrm{~A} @ 480 \mathrm{~V}$ & 0 & $181 \mathrm{~A} @ 13.2 \mathrm{kV}$ \\
DR 1 on, DR 2 off & $5,033 \mathrm{~A} @ 480 \mathrm{~V}$ & $18 \mathrm{~A} @ 13.2 \mathrm{kV}$ & $164 \mathrm{~A} @ 13.2 \mathrm{kV}$ \\
DR 2 on, DR 1 off & $5,338 \mathrm{~A} @ 480 \mathrm{~V}$ & $2,181 \mathrm{~A} @ 480 \mathrm{~V}$ & $115 \mathrm{~A} @ 13.2 \mathrm{kV}$ \\
\hline
\end{tabular}

DR 1: size $=2$ MVA, $X^{\prime} d=0.2$ pu on own base

DR 2: size $=2$ MVA, $X^{\prime} d=0.2$ pu on own base 13.2-kV, 480-V transformer: size $=1 \mathrm{MVA}, 5.75 \% \mathrm{Z}$ on own base System positive sequence Thevenin impedance at DR 1 bus: $0.61172+\mathrm{j} 1.77788$ 100-MVA base

Fault impedance: $0.05 \mathrm{ohm}$ resistive, actual

Table D-2. Edison Electric Institute-National Electrical Manufacturers Association Type K Fuse Links

\begin{tabular}{|c|c|c|c|c|c|c|c|c|}
\hline \multirow{2}{*}{$\begin{array}{l}\text { Protecting } \\
\text { Fuse Link } \\
\text { Amperes }\end{array}$} & \multicolumn{8}{|c|}{ Protected Link Amperes } \\
\hline & $\begin{array}{l}\text { 30k } \\
\text { Maximum }\end{array}$ & $\begin{array}{l}40 k \\
\text { Fault-C }\end{array}$ & $\begin{array}{l}\text { 50k } \\
\text { rrent Prs }\end{array}$ & $\begin{array}{l}65 \mathrm{k} \\
\text { ection } \mathrm{P}\end{array}$ & $\begin{array}{l}80 k \\
\text { vided bj }\end{array}$ & $\begin{array}{l}100 \mathrm{k} \\
\text { Protecting }\end{array}$ & $\begin{array}{l}140 \mathrm{k} \\
\text { Link - }\end{array}$ & $\begin{array}{r}200 k \\
\text { iperes }\end{array}$ \\
\hline $20 \mathrm{k}$ & 500 & 1,100 & 1,700 & 2,200 & 2,800 & 3,900 & 5,800 & 9,200 \\
\hline $25 \mathrm{k}$ & & 660 & 1,350 & 2,200 & 2,800 & 3,900 & 5,800 & 9,200 \\
\hline $30 \mathrm{k}$ & & & 850 & 1,700 & 2,800 & 3,900 & 5,800 & 9,200 \\
\hline $40 \mathrm{k}$ & & & & 1,100 & 2,200 & 3,900 & 5,800 & 9,200 \\
\hline $50 \mathrm{k}$ & & & & & 1,450 & 3,500 & 5,800 & 9,200 \\
\hline $65 \mathrm{k}$ & & & & & & 2,400 & 5,800 & 9,200 \\
\hline $80 \mathrm{k}$ & & & & & & & 4,500 & 9,200 \\
\hline $100 \mathrm{k}$ & & & & & & & 2,400 & 9,100 \\
\hline $140 \mathrm{k}$ & & & & & & & & 4,000 \\
\hline
\end{tabular}

This table shows maximum values of fault currents at which Edison Electric InstituteNational Electrical Manufacturers Type K fuse links will coordinate with each other. The table is based on maximum clearing-time curves FL2B for protecting links and $75 \%$ of minimum melting-time curves FL1B for protected links. 


\section{Appendix E: Line Parameters From Geometry}

\section{E.1 Longitudinal Impedance}

The impedance matrix for a continuously transposed three-phase, four-wire line takes the form:

$$
Z=\left[\begin{array}{cccc}
Z p s & Z p m & Z p m & Z n m \\
Z p m & Z p s & Z p m & Z n m \\
Z p m & Z p m & Z p s & Z n m \\
Z n m & Z n m & Z n m & Z n s
\end{array}\right]
$$

with subscripts " $\mathrm{p}$ " and " $\mathrm{n}$ " denoting phase and neutral conductors, respectively, and "s" and " $m$ " denoting the self and mutual terms. Self-impedances Zps and Zns may be estimated as:

$Z s=R a c+0.059+j 0.0377 \ln \left[\frac{8440 \rho}{r_{o}^{2}}\right], \quad \Omega / \mathrm{km} \quad[$ Equation E-2]

where $\operatorname{Rac}(\Omega)$ is the AC resistance of the phase conductor and $r_{o}(m)$ is its geometric mean radius, both of which are normally available from published manufacturer literature. Earth resistivity $\rho$ may be taken as $100 \Omega$-m if not known specifically for the geographic area.

Similarly, mutual impedance among phase conductors, or between the phases and the neutral, is determined as:

$$
Z m=0.059+j 0.0377 \ln \left[\frac{8440 \rho}{d_{o}^{2}}\right], \quad(\Omega / \mathrm{km}) \quad \text { [Equation E-3]. }
$$

Because phase conductors are assumed to be uniformly transposed, $d_{0}$ is taken as the geometric mean spacing between the individual phases, or between the phases and the neutral conductor (denoted here as $d_{1}, d_{2}$, and $d_{3}$ ).

$$
d_{0}=\sqrt[3]{d_{1} d_{2} d_{3}} \quad, \quad(\mathrm{~m}) \quad \text { [Equation E-4] }
$$

Eliminating the grounded neutral conductor to yield a reduced three-by-three impedance matrix $\left(Z_{\text {red }}\right)$ :

$$
Z_{\text {red. }}=\left[\begin{array}{ccc}
Z_{p s}^{r e d} & Z_{p m}^{r e d} & Z_{p m}^{r e d} \\
Z_{p m}^{r e d} & Z_{p s}^{r e d} & Z_{p m}^{r e d} \\
Z_{p m}^{r e d} & Z_{p m}^{r e d} & Z_{p s}^{r e d}
\end{array}\right]
$$

[Equation E-5] 
with $\quad Z_{p s}^{r e d .}=Z_{p s}-\frac{Z_{n m}^{2}}{Z_{n n}}$

[Equation E-6]

and $\quad Z_{p m}^{r e d}=Z_{p m}-\frac{Z_{n m}^{2}}{Z_{n n}}$

[Equation E-7]

allows the sequence-domain impedances to be computed as:

$$
\begin{aligned}
& Z_{1}=Z_{2}=Z_{p s}^{r e d}-Z_{p m}^{r e d} \\
& Z_{0}=Z_{p s}^{r e d}+2 Z_{p m}^{r e d}
\end{aligned}
$$

[Equation E-9]

with subscripts 1,2 , and 0 denoting positive, negative, and zero sequence modes respectively.

\section{E.2 Shunt Admittance}

Shunt admittance because of capacitance to ground for overhead feeder sections is generally neglected in distribution planning studies because it is of little consequence in load flow or protective coordination studies. It is unlikely, therefore, that the required values would be available for immediate use. It is needed here for harmonic analysis, which requires identifying the dominant quarter-wave resonant modes for the subject feeder. The researchers propose a simplified calculation based on impedance values as determined above or as available from planning studies. Recall that with the feeder assumed to be continuously transposed, the shunt admittance can be characterized in the sequence domain by positive-sequence and zero-sequence values (note that the positivesequence and negative-sequence values are identical). The basis of the calculation is the fact that the propagation velocity for electromagnetic waves occurs nearly at the speed of light for line modes (i.e., for positive sequence) and somewhat more slowly for ground modes (i.e. zero sequence). Given the canonical form of propagation velocity $v$ in terms of the per-unit length inductive and capacitive feeder parameters (per meter):

$$
v=\frac{1}{\sqrt{L C}}=\frac{\omega}{\sqrt{X_{L} X_{C}}}, \quad(\mathrm{~m} / \mathrm{s}) \quad \text { [Equation E-10] }
$$

Then for line-mode propagation velocity at the speed of light $\left(c=3 \times 10^{8} \mathrm{~m} / \mathrm{s}\right)$, the positive sequence capacitance:

$$
C_{1}=\frac{1}{c^{2} L_{1}} \quad, \quad(\mathrm{~F} / \mathrm{m}) \quad \text { [Equation E-11] }
$$

and for ground-mode propagation velocity taken as about $70 \%$ of the speed of light, the zero-sequence capacitance: 


$$
C_{0}=\frac{1}{0.5 c^{2} L_{0}} \quad,(\mathrm{~F} / \mathrm{m})
$$

[Equation E-12]. 


\section{Appendix F: Rudimentary Network Solution Algorithm}

Modern introductory text books on power systems describe advanced load-flow solution algorithms that can efficiently and reliably solve the fundamental load flow problem for networks to tens of thousands of busses and for loads characterized as constant power, constant current, or constant impedance. Although such algorithms are elegant and desirable, they tend to be time-consuming to implement from scratch for small-scale studies. The researchers found it more convenient to adopt a more rudimentary approach and found that approach adequate for the relatively small networks (50-100 nodes) encountered here. Although this approach has certain limitations (e.g., all loads are modeled as constant impedance), it can be implemented readily using a commonly available library of mathematical functions (i.e., matrix inversion routines). In the present context, the approach was implemented using MATLAB, a Windows-based, high-level mathematical software that is available commercially.

\section{F.1 Base Case Load Flow Solution}

The process begins by building an admittance matrix formulation for the network to be solved. Vector I denotes the nodal current injections into the network, and V denotes the vector of nodal voltages:

$$
[\mathrm{I}]=[\mathrm{Y}][\mathrm{V}]
$$

[Equation F-1].

The admittance matrix, Y, can be assembled by inspection, as follows. The diagonal elements in the matrix, say for node "n," correspond to the algebraic sum of the values of all admittance branches connected at this node. Similarly, the off-diagonal element for nodes " $n$ " and " $m$ " is negative of the aggregate sum of all admittance branches connected between these nodes. Note that the distribution bus is modeled by its Norton equivalent, defined as a current source in shunt with parallel admittance $Y_{\mathrm{N}}=G_{\mathrm{N}}+j B_{\mathrm{N}}$ :

$$
G_{N}=\frac{R_{1}}{\left(R_{1}\right)^{2}+\left(X_{1}\right)^{2}} \text { and } \quad B_{N}=-\frac{X_{1}}{\left(R_{1}\right)^{2}+\left(X_{1}\right)^{2}} \quad \text { [Equation F-2] }
$$

where $R_{1}$ and $X_{1}$ are the respective positive sequence values determined earlier from the distribution bus short-circuit capacity. Thus, the Norton current source $I_{\mathrm{N}}$ is connected directly at the feeder head end, and the matrix order is $\mathrm{N} \mathrm{X} \mathrm{N}$, with $\mathrm{N}$ denoting the number of nodes identified on the feeder.

Inverting (K-1) obtains the corresponding impedance relation:

$$
[\mathrm{V}]=[\mathrm{Z}][\mathrm{I}] \text {, where }[\mathrm{Z}]=[\mathrm{Y}]^{-1}
$$

[Equation F-3]. 
Normally, algorithms that require explicit matrix inversions are not favored because more efficient algorithms are available to achieve the same objective. However, such algorithms tend to be more tedious to implement, and, for the purpose of this project, the present approach was considered both expeditious and practical given the processing power and speed of modern desktop computers. Having therefore computed [Z] by inversion, it is a relatively simple matter to determine the voltage profile along the feeder.

Note that all entries in the vector of current injections [I] are zero except for those that correspond to nodes at which a power source is connected. The latter includes the distribution bus and those nodes at which a DG is present. Applying the Norton current source at the feeder head end (Node 1) with all DGs omitted initially:

$$
\left[\begin{array}{c}
V_{1} \\
\cdot \\
V_{n-2} \\
V_{n-1} \\
V_{n}
\end{array}\right]=\left[\begin{array}{ccccc}
Z_{1,1} & Z_{1,2} & \cdot & Z_{1, n-1} & Z_{1, n} \\
\cdot & \cdot & \cdot & & \\
\cdot & \cdot & \cdot & & \\
\cdot & \cdot & \cdot & & \\
Z_{n, 1} & \cdot & \cdot & Z_{n, n-1} & Z_{n, n}
\end{array}\right]\left[\begin{array}{c}
I_{N} \\
0 \\
0 \\
0 \\
0
\end{array}\right]
$$

[Equation F-4]

shows that the resulting voltage profile on the feeder is given by the corresponding column of the $[\mathrm{Z}]$ matrix (here, Column 1) scaled by $I_{\mathrm{N}}$. Evidently then, choosing $I_{\mathrm{N}}$ to be equal in magnitude to $V_{0} / Z_{1,1}$ yields the desired base case load flow voltage solution, with $\mathrm{V}_{0}$ representing the desired operating voltage at the head end (i.e., at the distribution bus).

\section{F.2 Distributed Generation in Load Flow Solution}

DGs are accommodated in the above load flow solution by specifying a suitable current value at an appropriate position in the current injection vector in a manner analogous to the primary grid supply. An initial estimate of the injected current is obtained from the known nodal voltage $V_{\mathrm{n}}$ (e.g., as obtained from prior base case solution) and the specified DG output $\left(S_{\mathrm{DG}}=P_{\mathrm{DG}}+\mathrm{j} Q_{\mathrm{DG}}\right)$ :

$$
I_{D G}=\frac{S_{D G}^{*}}{V_{N}}=\frac{P_{D G}-j Q_{D G}}{V_{N}}
$$

[Equation F-5].

This is only an initial estimate. The presence of the DG itself will influence the terminal voltage $V_{\mathrm{n}}$, which, in turn, means the actual DG power output differs somewhat from the specified value. Thus, the solution is repeated a few times, each time with an improved estimate of $\mathrm{I}_{\mathrm{DG}}$, until the computed DG output is sufficiently close to the desired value.

Multiple DGs distributed on the feeder are accommodated by applying suitable current at the locations in the current injection vector. 
Appendix G: Fact Sheet 


\section{Background}

In the 20th century, the United States built an electric power system that became the envy of the world for its reliable, low-cost power. Today, that system consists primarily of large central-station power plants intertied via a high-voltage transmission system. The transmission system feeds lowervoltage, local distribution networks that provide oneway power flow to end-users.

Interest in distributed resources (DR), or local energy generation and storage, has increased substantially because of their potential to improve reliability and lower costs by providing power at or near the load. To realize these benefits on a larger scale, utilities and generating customers need quantitative data and analytical tools to assess interactions between DR and distribution lines.

\section{Aggregation Effects}

The effects of low concentrations of DR on the distribution system are generally known. However, the effects of larger generators and larger concentrations of generators are not well understood. A number of utility grid coordination issues-including the performance of utility fuses, reclosers, and protective relays as well as limits to uphold system quality and reliability standards-are involved.

\section{Goals}

DR can provide many benefits, but local electric distribution systems traditionally have not been designed to operate in parallel with interconnected distributed power systems. As a result, there are concerns about compatibility, reliability, power

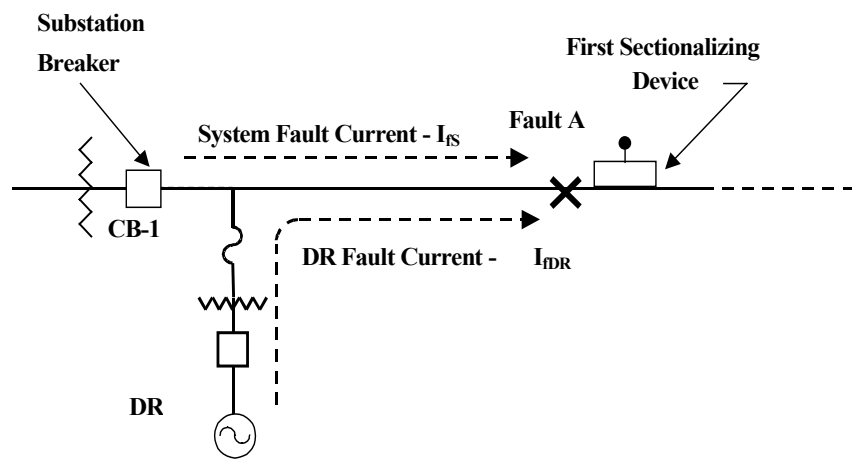

Current sensitivity example quality, system protection, voltage dynamics, and safety. The goals of this study are to address selected system integration issues and determine the DR system penetration limits imposed by the local grid because of utility coordination issues.

\section{System Protection Issues}

- Improper coordination - protective device operates for fault on adjacent circuit

- Improper coordination - reduced fault detection sensitivity

- Nuisance fuse blowing because of DR fault current

- Faults within the DR zone

- Isolating DR for upstream fault

- Fuse blowing because of upstream single-phase fault

\section{Voltage and Stability Issues}

- Harmonics

- Voltage regulation malfunctions

- Steady-state stability

- Dynamic stability during fault conditions

- Loss of exciters causes low voltage

\section{Overview}

This research is an example of ongoing efforts to develop the data and analytical tools necessary to assess the reliability and performance of the transmission and distribution system and foster the deployment of new technologies.

The study examined two typical distribution feeder circuits in the Ann Arbor, Michigan, area. One was a radial distribution line, and one was a ring configuration. DTE developed three-phase circuit models of the feeder lines, protective devices, and DR. It used comparisons with simplified analytical results and short test simulations to verify the accuracy of the models. Later, it used ASPEN, MATLAB, PTI PSS/E, and EMTP software to generate detailed simulations that represent how aggregated DR affect system characteristics such as voltage, harmonics, phase and ground overcurrent, 
fault conditions, islanding detection, loss of excitation, transient stability, and coordination between circuit breakers, fuses, and reclosers.

DTE determined the maximum size of aggregated DR possible at locations on the sample feeders without disrupting the line performance or the behavior of protective devices. In general, the study should help other engineers determine DR penetration limits by providing validated methods, algorithms, and device charts that can be adapted to specific cases.

\section{Findings}

This study provided detailed modeling, simulations, and validated analyses to ensure sound conclusions and recommendations concerning DR penetration limits and equipment requirements. It established generic methods and procedures to evaluate DR effects.

The conclusions include:

- The DR aggregation limits were typically on the order of 1-10 MVA.

- The system voltage has a significant effect on the maximum DR size (or aggregated size) that can be connected to a circuit. Doubling or tripling the system voltage would roughly double or triple the maximum aggregated size of DR.

- The type of fault influences the size of DR.

- Nuisance fuse blowing tends to limit DR sizes to less than 2 MVA for compact circuits fed from 15MVA substation transformers (high system fault current $=7,600 \mathrm{~A}$ at substation).

- Harmonic analysis may be required for inverters because of the wide range of acceptable DR sizes (820 kVA-9.2 MVA).

- The location of the DR's circuit is very important in determining the voltage limits for loss of excitation DR limits.

- If critical clearing time is 0.1 seconds or less, stability should be maintained. The larger the machine inertia, the more stable the unit. Multiple machines on a feeder may increase stability by tending to support local voltage during upstream disturbances.

Too much distributed generation in the wrong location can create or aggravate problems with voltage, harmonic content, system stability, or protective device coordination. However, DTE clearly presents how DR, far from being a detriment, can significantly benefit the grid-with proper evaluation of the local power grid and careful DR selection and placement.
Issue 1 Maximum DG Current With No Recloser / Fuse Operation

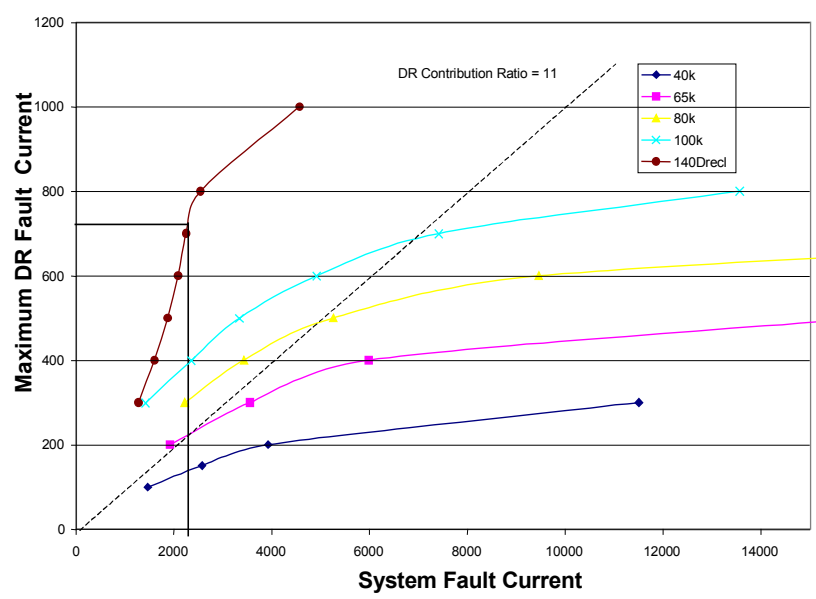

Maximum DR fault current versus system fault current

\section{Publications}

Davis, M.; Costyk, D.; Narang, A. "Distributed and Electric Power System Aggregation Model and Field Configuration Equivalency Validation Testing." NREL/SR-560-33909. July 2003.

Publications are available on the NREL publications database at http://www.nrel.gov/publications/.

\section{Contacts}

NREL Technical Monitor

Tom Basso - (303) 275-3753

National Renewable Energy Laboratory

1617 Cole Blvd.

Golden, CO 80401

\section{NREL DEER Technology Manager}

Richard DeBlasio - (303) 275-4333

National Renewable Energy Laboratory

1617 Cole Blvd.

Golden, CO 80401

DOE Program Manager

Eric Lightner - (202) 586-8130

U.S. Department of Energy

EE-2D/Forrestal Building

1000 Independence Ave. SW

Washington, DC 20585

Additional Distributed Power Information http://www.electricity.doe.gov/

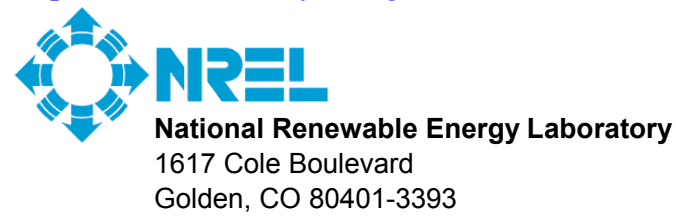

NREL is a U.S. Department of Energy National Laboratory Operated by Midwest Research Institute • Battelle • Bechtel

NREL/FS-560-35039 October 2003

Printed on paper containing at least $50 \%$ wastepaper, including $20 \%$ postconsumer waste. 


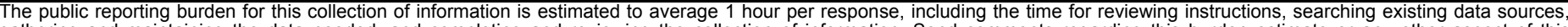

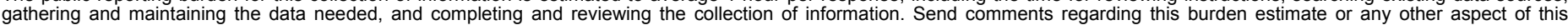

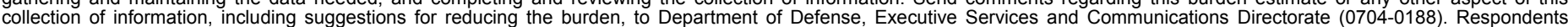

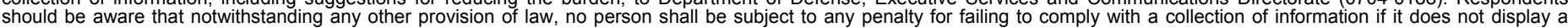

should be aware that notwithstanding

PLEASE DO NOT RETURN YOUR FORM TO THE ABOVE ORGANIZATION.

\section{REPORT DATE (DD-MM-YYYY) March 2005}

4. TITLE AND SUBTITLE

Distributed and Electric Power System Aggregation Model and Field Configuration Equivalency Validation Testing: Supplemental Report on Penetration Software Algorithms
3. DATES COVERED (From - To)

5a. CONTRACT NUMBER

DE-AC36-99-G010337

5b. GRANT NUMBER
6. AUTHOR(S)

M. Davis, D. Costyk, A. Narang 5d. PROJECT NUMBER

NREL/SR-560-37572

5e. TASK NUMBER

DP05.1001

5f. WORK UNIT NUMBER
7. PERFORMING ORGANIZATION NAME(S) AND ADDRESS(ES)

DTE Energy Technologies

37849 Interchange Dr.

Farmington Hills, MI 48335

9. SPONSORING/MONITORING AGENCY NAME(S) AND ADDRESS(ES)

National Renewable Energy Laboratory

1617 Cole Blvd.

Golden, CO 80401-3393
8. PERFORMING ORGANIZATION REPORT NUMBER

\section{DISTRIBUTION AVAILABILITY STATEMENT}

National Technical Information Service

U.S. Department of Commerce

5285 Port Royal Road

Springfield, VA 22161

\section{SUPPLEMENTARY NOTES}

NREL Technical Monitor: Thomas S. Basso

14. ABSTRACT (Maximum 200 Words)

This report supplements the July 2003 report "Distributed and Electric Power System Aggregation Model and Field Configuration Equivalency Validation Testing" (NREL/SR-560-33909). The original report presented methods for calculating penetration limits for distributed energy resources interconnected with distribution circuits of utility-owned electric power systems. This report describes the algorithms required to develop application software to calculate penetration limits. The original report can be found at http://www.nrel.gov/docs/fy03osti/33909.pdf.

\section{SUBJECT TERMS}

distributed power; distributed resources; distributed generation; interconnection; aggregation; electric power system; penetration; algorithms; DTE; Kinectrics; National Renewable Energy Laboratory; NREL

\begin{tabular}{|c|c|c|c|c|}
\hline \multicolumn{3}{|c|}{ 16. SECURITY CLASSIFICATION OF: } & \multirow{2}{*}{$\begin{array}{l}\text { 17. LIMITATION } \\
\text { OF ABSTRACT } \\
\text { UL }\end{array}$} & \multirow{2}{*}{$\begin{array}{l}\text { 18. NUMBER } \\
\text { OF PAGES }\end{array}$} \\
\hline $\begin{array}{l}\text { a. REPORT } \\
\text { Unclassified }\end{array}$ & $\begin{array}{l}\text { b. ABSTRACT } \\
\text { Unclassified }\end{array}$ & $\begin{array}{l}\text { c. THIS PAGE } \\
\text { Unclassified }\end{array}$ & & \\
\hline
\end{tabular}

19a. NAME OF RESPONSIBLE PERSON
19b. TELEPONE NUMBER (Include area code)

